\title{
Analysis and Development of a Tunable Fiber Bragg Grating Filter Based on Axial Tension/Compression
}

\author{
A Thesis Submitted to the \\ College of Graduate Studies and Research \\ In Partial Fulfillment of the Requirements \\ For the Degree of Master of Science \\ In the Department of Mechanical Engineering \\ University of Saskatchewan \\ Saskatoon, Canada
}

By

Najeeb Mohammad

CCopyright Najeeb Mohammad, September 2005. All rights reserved. 


\section{PERMISSION TO USE}

In presenting this thesis in partial fulfillment of the requirements for a Postgraduate degree from the University of Saskatchewan, I agree that the Libraries of this University may make it freely available for inspection. I further agree that permission for copying of this thesis in any manner, in whole or in part, for scholarly purposes may be granted by the professor or professors who supervised my thesis work or, in their absence, by the Head of the Department or the Dean of the College in which my thesis work was done. It is understood that any copying or publication or use of this thesis or parts thereof for financial gain shall not be allowed without my written permission. It is also understood that due recognition shall be given to me and to the University of Saskatchewan in any scholarly use which may be made of any material in my thesis.

Requests for permission to copy or to make other use of material in this thesis in whole or part should be addressed to:

Head of the Department of Mechanical Engineering University of Saskatchewan Saskatoon, Saskatchewan CANADA S7N 5A9 


\begin{abstract}
Fiber Bragg gratings (FBGs) are key elements in modern telecommunication and sensing applications. In optical communication, with the advancement of the Erbium doped fiber amplifier (EDFA), there is a great demand for devices with wavelength tunability over the Erbium gain bandwidth (in particular, for wavelength division multiplexing (WDM) networks). The center wavelength of a FBG can be shifted by means of change of temperature, pressure or mechanical axial strain. The axial strain approach is the best method among all other techniques because it allows relatively large wavelength shifts with high speed. Axial strain of up to $4 \%$ will be required to cover the whole EDFA region (more than $40 \mathrm{~nm}$ of central wavelength shift). The formation of Bragg grating results in significant reduction in mechanical strength of optical fibers especially in tension. As a result, axial strain of only about $1 \%$ can be achieved by mechanical stretching of FBGs. In order to achieve the remaining 3\% strain compression of FBGs has to be applied.
\end{abstract}

In this thesis, the design and analysis of a novel device for achieving central wavelength shift are presented. In particular, the device has achieved, for a fiber with $12 \mathrm{~mm} \mathrm{FBG}$, a shifting of $46 \mathrm{~nm}$ in compression and $10.5 \mathrm{~nm}$ in tension with a reflection power loss of less than $0.25 \mathrm{~dB}$ and a FWHM bandwidth variation of approximately $0.1 \mathrm{~nm}$. Both variations are well below the Bellcore standards requirement of $0.5 \mathrm{~dB}$ for peak reflectivity variation and $0.1 \mathrm{~nm}$ for bandwidth variation. The device consists of two fixed and one guiding ferrules. The difficulties associated with compressing the FBG were handled by carefully selecting tolerances and adjustment procedures. The device allows both tension and compression of FBGs, and the use of different FBG lengths and actuators. The effects of glue deformation and bending of the FBG during compression were analyzed in detail. Further, using the piezoelectric transducer (PZT) actuator as a driver, tuning speed of around $1.5 \mathrm{~nm} / \mathrm{ms}$ was achieved. 


\section{ACKNOWLEDGMENTS}

Upon the completion of this thesis, I would like to express my sincere gratitude and appreciation to my supervisors Professor Chris W. J. Zhang and Professor Walerian Szyszkowski for their invaluable guidance, constructive discussion, encouragement, and inspiration, without which this work would not have been possible.

I would like to thank the research team at MPB Communications Inc. Space Photonics Group (Dr. Wes Jamroz, Dr. Roman Kruzelecky, Dr. Emile Haddad and Jing Zou) for their invaluable support, guidance, suggestion and wisdom throughout my M.Sc. study. My appreciation is extended to the members of the Advisory Committee: Professor D. Torvi and Professor I. Oguocha for their scholarly suggestions, pieces of advice and examination in the whole process

I would like to thank Mr. Roy Josephs for his help in manufacturing the device described in Chapter 3.

My research was made possible by the generous support of the Natural Sciences and Engineering Research Council (NSERC) and MPB Communications Inc. 


\title{
DEDICATED TO
}

\author{
My parents \\ M. A. Mannan and S. Z. Saghir
}

For their continuous love and unwavering support!!! 


\section{TABLE OF CONTENTS}

PERMISSION TO USE...........................................................i

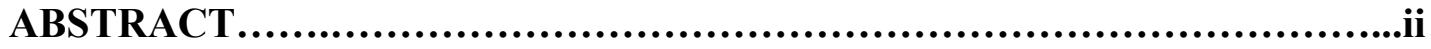

ACKNOWLEDGMENTS...........................................................iii

DEDICATION....................................................................iv

TABLE OF CONTENTS....................................................v

LIST OF FIGURES......................................................viii

LIST OF TABLES..............................................................

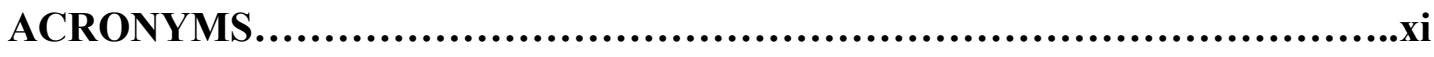

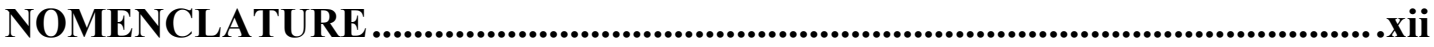

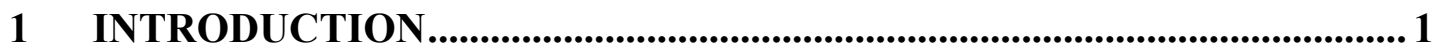

$1.1 \quad$ Background and Motivation............................................................. 1

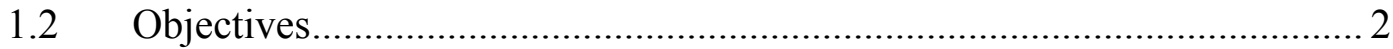

1.3 Organization of the Thesis .................................................................... 2

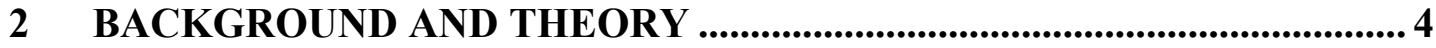

2.1 Optical Fibers and Fiber Optic Networks ........................................... 4

2.2 Wavelength Division Multiplexing Systems ....................................... 5

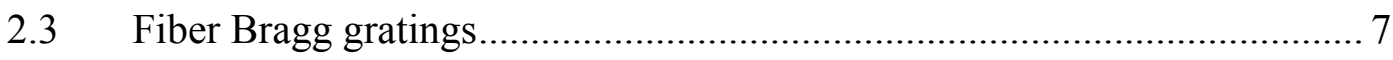

2.4 Bragg Grating Strain and Temperature Sensitivity .................................... 8

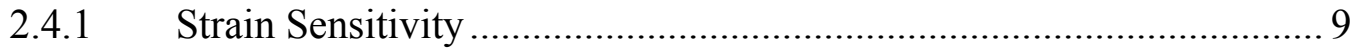

2.4.2 Temperature Sensitivity ......................................................... 10

2.4.3 Pressure Sensitivity .................................................................. 10

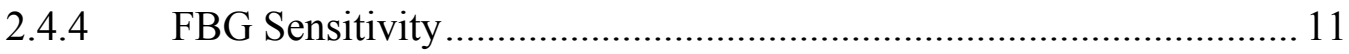

2.5 Tuning of FBG by Means of Strains ................................................... 11

2.6 Previous Work on Tunable FBG by Means of Strain ............................ 13

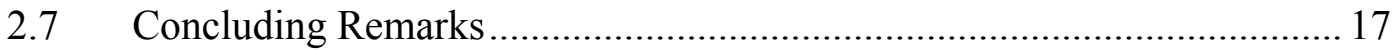

3 FBG TUNING DEVICE DESIGN AND ANALYSIS............................. 19 


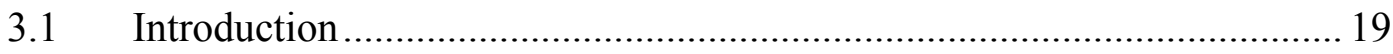

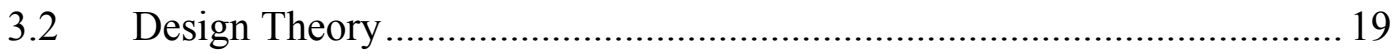

3.2.1 FBG Supported by Guiding Ferrule ................................................ 21

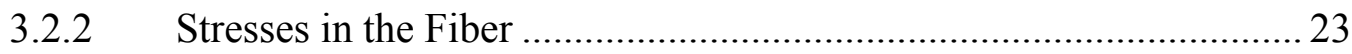

3.2.3 Effect of Curvature on FBG's Performance....................................... 26

3.2.4 Shortening Due to Waving ................................................................. 30

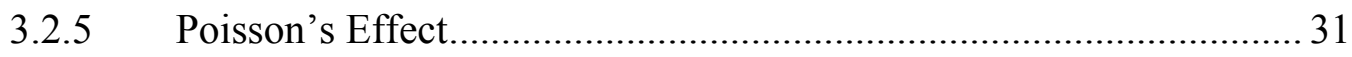

3.2.6 Shortening due to Glue Deformation ................................................. 32

3.2.7 Effect of Misalignment of Ferrules ...................................................... 32

3.3 Guiding System Design Details ............................................................... 34

3.3.1 Ferrule System Design for Stretching ................................................. 34

3.3.2 Ferrule System Design for Compression …………………………... 36

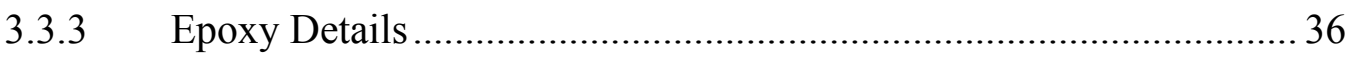

3.3.4 Calculation of Shear Strength of Epoxy.............................................. 37

3.3.5 Gluing Optical Fiber with Ferrule....................................................... 38

3.3.6 Mechanical Design for Stretching...................................................... 39

3.3.7 Mechanical Design for Compression ................................................ 41

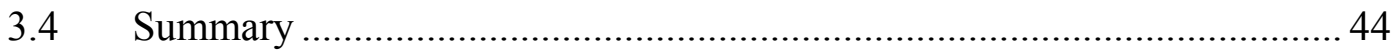

4 EXPERIMENTAL STUDY .............................................................................. 45

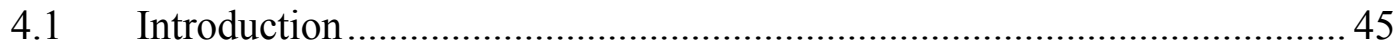

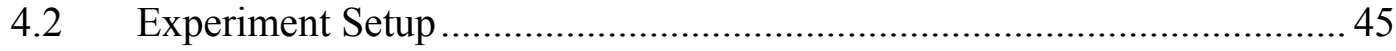

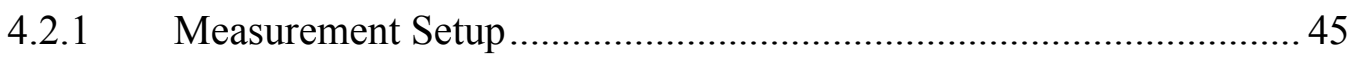

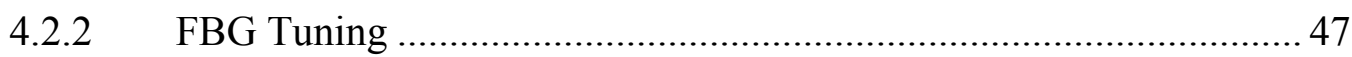

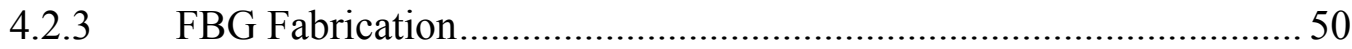

4.3 Results From the Testing of $12 \mathrm{~mm}$ FBG ……….................................... 51

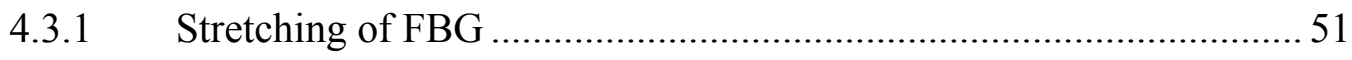

4.3.2 Compression of FBG Using the PZT Actuator ...................................5 54

4.3.3 Compression of FBG Using Micrometer Head....................................58

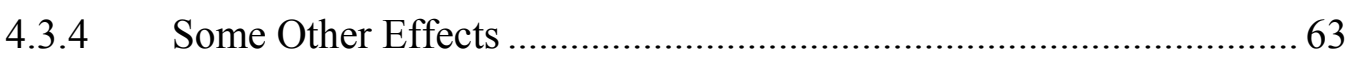

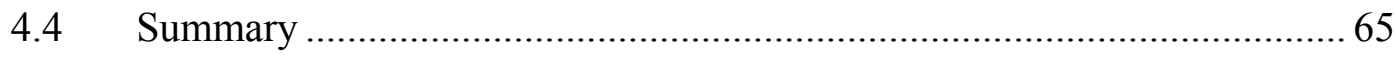


5 CONCLUSIONS AND SUGGESTIONS FOR FUTURE WORK ............. 66

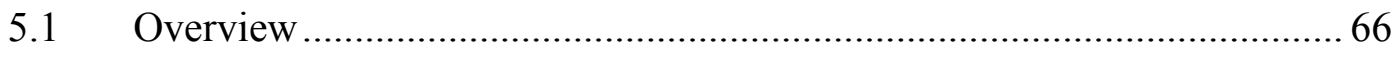

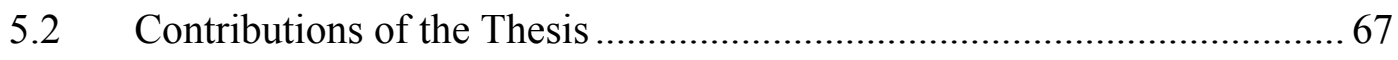

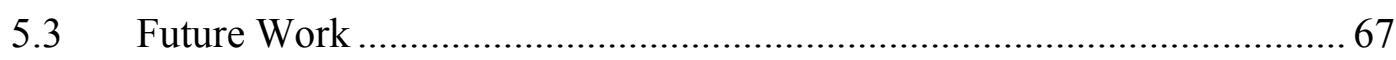

REFERENCES..........................................................68 


\section{LIST OF FIGURES}

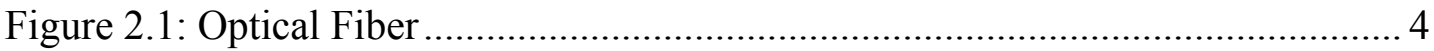

Figure 2.2: Wavelength Division Multiplexing Systems....................................... 6

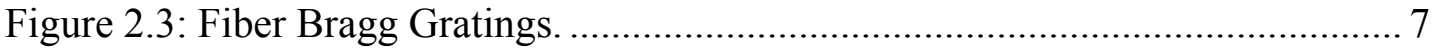

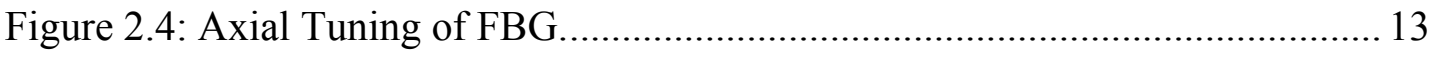

Figure 2.5: Schematic of a Magnetically Tunable FBG. ...................................... 14

Figure 2.6: Schematic of a Tunable FBG Based on Beam Bending ......................... 15

Figure 2.7: Schematic of a Tunable FBG Supported by Guiding Mechanism .......... 16

Figure 2.8: Stress-Strain Relationship for Optical Fiber...................................... 17

Figure 3.1: Buckling of FBG Under Compression. .............................................. 19

Figure 3.2(a): Support for Unguided Region under Compression........................... 21

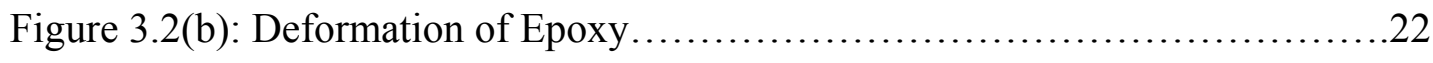

Figure 3.3: Factors Affecting the Ferrule's Design. ......................................... 23

Figure 3.4: Stress Distribution under Compression............................................. 24

Figure 3.5: Variation in Stresses with Variation in Ferrule's Internal Diameter........ 25

Figure 3.6: Optical Power Loss due to Bending. ................................................. 27

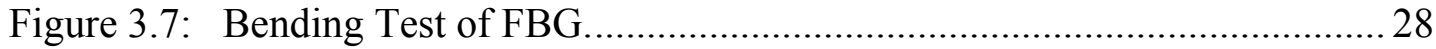

Figure 3.8: Reflection Spectrum for Various Bending Radii of FBG...................... 28

Figure 3.9: Effects of FBG Bending Radii on Reflective Power Loss. ................... 29

Figure 3.10: Effect of Fiber's Waving on the $\frac{\varepsilon_{m}}{\varepsilon_{a x}}$ Ratio. ........................................ 31

Figure 3.11: Misalignment Between Ferrules.................................................. 33

Figure 3.12: Effects of Ferrules' Misalignment on Reflective Power Loss............. 34

Figure 3.13: Schematic Diagram of Ferrule System for Stretching......................... 35

Figure 3.14: Schematic Diagram of Ferrule System for Compression ...................... 36

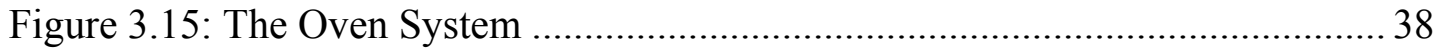

Figure 3.16: Mechanical Design for Stretching of FBG ..................................... 40

Figure 3.17: Adjustment for the PZT Actuator................................................ 41

Figure 3.18: Mechanical Design for Compression of FBG Using PZT Actuator...... 42 
Figure 3.19: Mechanical Design for Compression of FBG Using Micrometer Head 43

Figure 4.1: Schematic Diagram of Experimental Setup....................................... 46

Figure 4.2: Schematic Diagram of Data Acquisition System. ................................ 48

Figure 4.3: PZT Actuator Travel Using LabView Software................................... 49

Figure 4.4: Experimental Setup for Tuning of FBG.......................................... 50

Figure 4.5: Reflection Spectra of a 12mm FBG During Stretching........................ 51

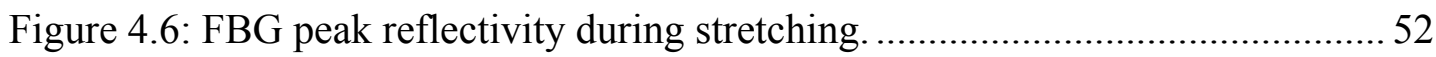

Figure 4.7: -3dB (FWHM) Bandwidth Variation ................................................. 52

Figure 4.8: Comparison Between the Theoretical and Experimental Results During

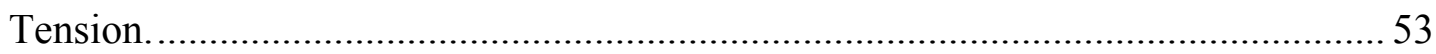

Figure 4.9: Device Hysteresis Obtained for 12mm FBG During Stretching ............. 54

Figure 4.10: Reflection Spectra of a 12mm FBG During Compression .................... 55

Figure 4.11: FBG Peak Reflectivity During Compression. ................................... 56

Figure 4.12: FWHM Bandwidth Variation During Compression............................. 56

Figure 4.13: Comparison Between the Theoretical and Experimental Results During

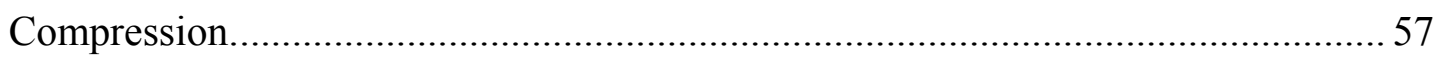

Figure 4.14: Device hysteresis obtained in compression..................................... 58

Figure 4.15: Reflection Spectra of a 12 mm FBG Under Compression .................... 59

Figure 4.16: Comparison Between Theoretical and Experimental Results from

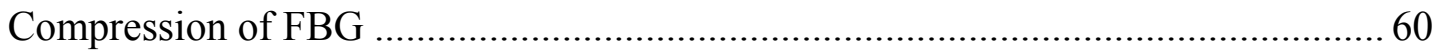

Figure 4.17: Comparison Between Theoretical and Experimental Results During

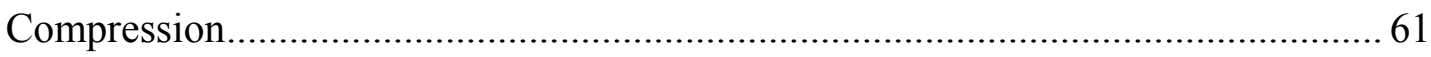

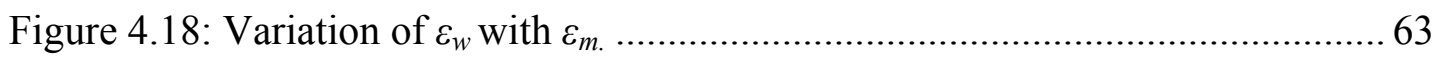

Figure 4.19: Variation in FBG Peak Reflectivity and FWHM Bandwidth During

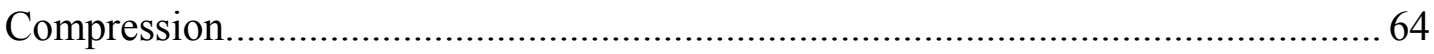

Figure 4.20: Device Hysteresis Obtained for 12mm FBG ..................................... 64 


\section{LIST OF TABLES}

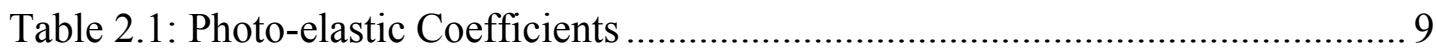

Table 2.2: Comparison of Strain Techniques............................................................ 11

Table 2.3: Tunable FBG Filters Performance Summary (t: Fiber Tension, c: Fiber

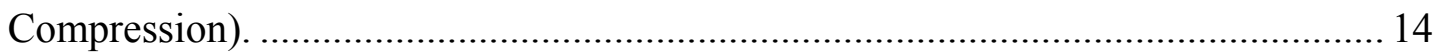




\section{ACRONYMS}

$\begin{array}{ll}\text { FBG } & \text { Fiber Bragg grating } \\ \text { WDM } & \text { Wavelength division multiplexing } \\ \text { EDFA } & \text { Erbium doped fiber amplifier } \\ \text { PZT } & \text { Piezoelectric transducer } \\ \text { BBS } & \text { Broad band light source } \\ \text { OSA } & \text { Optical spectrum analyzer } \\ \text { FWHM } & \text { Full wavelength half maximum } \\ \text { ArF } & \text { Argon-Fluorine }\end{array}$




\section{NOMENCLATURE}

$\lambda_{\text {Bragg }}$

$\Lambda$

$\mathrm{n}_{\mathrm{eff}}$

$\Delta L$

$\Delta T$

$\Delta \lambda$

$P_{e}$

$\varepsilon_{a x}$

$\Delta \lambda_{B}$

v

$d$

E

$\alpha_{t}$

$\zeta$

$\triangle P$

$L_{b}$

I

$F_{c r}$

$\sigma_{c r}$

A

i

$\varepsilon_{c r}$

$L_{o}$

$\Delta L_{m}$

$\Delta L_{a x}$

$\Delta L_{w}$
Bragg wavelength

Grating period

Effective refractive index of the transmitting medium

Change in grating length

Change in grating temperature

Wavelength shift of FBG

Effective photo-elastic constant

Axial strain

Bragg grating wavelength

Poisson's ratio

Optical fiber diameter

Modulus of elasticity of pure silica

Thermal expansion coefficient

Thermo-optic coefficient

Hydrostatic pressure variation

Unguided length of optical fiber

Geometrical moment of inertia

Compressive force

Critical stresses

Cross-section area of optical fiber

Radius of gyration of optical fiber

Critical Strain

Length of FBG

Measured displacement

Axial compression of the FBG

Shortening due to waving of the optical fiber 


$\begin{array}{ll}\Delta L_{g} & \text { Shortening due to deformation of the epoxy } \\ \varepsilon_{m} & \text { Measured axial strain } \\ D & \text { Internal diameter of ferrule } \\ \sigma_{c} & \text { Average axial compressive stress } \\ R & \text { Radius of curvature of optical fiber } \\ M & \text { Bending moment of optical fiber } \\ V_{m} & \text { Wave amplitude } \\ \alpha & \text { Coefficient of proportionality for glue deformation } \\ K_{m} & \text { Misalignment between the two ferrules } \\ \tau_{g} & \text { Lap shear strength of epoxy resin } \\ P_{e}^{\operatorname{Exp}} & \text { Experimental value of the photo-elastic constant } \\ M_{\max } & \text { Maximum bending moment }\end{array}$




\section{INTRODUCTION}

\subsection{Background and Motivation}

An optical fibre has many promising features, such as very less power loss and good robustness, when used as information carriers and transducers. Its form as a continuous thin material makes it very attractive for use as one of the building blocks as a distributed transducer. One of the working principles for achieving its promises is to have a means by which it is able to adjust the central wavelength of light travelling through the optical fiber in a real-time fashion. Further, during the central wavelength shift, the performance parameters such as power loss and bandwidth must be maintained.

As far as shift itself is concerned, two function indices are important namely: (1) the shift accuracy and precision and (2) the shift range. The former appears to be out of question at least in the telecommunication application while the latter is worth giving great attention in telecom applications. For instance, it is highly desirable in the telecommunication application that the total shift reaches $45 \mathrm{~nm}$.

The existing methods for the central wavelength shift can only achieve about the $30 \mathrm{~nm}$ shifting of the central wavelength without a significant degrading of the performance, specifically power loss. Therefore, the development of new methods or improvement on existing methods for achieving the desired $45 \mathrm{~nm}$ central wavelength shift was an interesting topic. This thesis was on this topic. 


\subsection{Objectives}

A preliminary study straightened out the direction of this research. Specifically, the research was focused on the method of straining the optical fiber to induce the change of the central wavelength. This preliminary study is presented in chapter 2 where some background knowledge of this research will be discussed. There are two main objectives defined for this study:

Objective 1: Develop some analytical equations upon which the device to strain the fiber can be designed and constructed in a rational way.

The preliminary study indicated that there were only a few analytical equations available in the literature regarding the straining of the fiber for the central wavelength shift. These equations were simplified. As such their use for better design of a device that can reach the best performance with the optical fiber is questionable.

Objective 2: Design and construct a device and an experimenalt test bed to improve the central wavelength shift up to $45 \mathrm{~nm}$.

The preliminary study concluded that a careful design of the device for the straining of the optical fiber could likely lead to $45 \mathrm{~nm}$ shift.

\subsection{Organization of the Thesis}

The remainder of the thesis is organized as follows:

Chapter 2 presents some background knowledge about optical fibers and central wavelength shift. This chapter will also present a further justification for this thesis with special attention to the two objectives defined for this study. 
Chapter 3 presents the specific design theory for the FBG tuning device based on straining approach. As well, detailed design of the FBG tuning device guided by the specific theory will be presented.

Chapter 4 presents the experimental study, including the test bed establishment and the results with discussion.

Chapter 5 concludes this thesis with a discussion of limitations of the thesis study and future work. 


\section{BACKGROUND AND THEORY}

In this chapter, background information is given for a better understanding of this thesis study with particular attention to the central wavelength shifting through fiber grating. The state-of-the-art of what and how the shift of central wavelength is achieved will be discussed as well.

\subsection{Optical Fibers and Fiber Optic Networks}

An optical fiber is a very thin strand of silica glass which in geometry is quite like a human hair. In reality it is a very narrow, long solid glass cylinder with special characteristics. When light enters one end of the fiber, it travels (confined within the fiber due to total internal reflection) until it leaves the fiber at the other end. Optical fiber offers with very little light loss at certain wavelengths. As shown in Figure 2.1, an optical fiber consists of two parts namely: the core and the cladding. The core is a narrow cylindrical strand of glass and the cladding is a tubular jacket surrounding it.

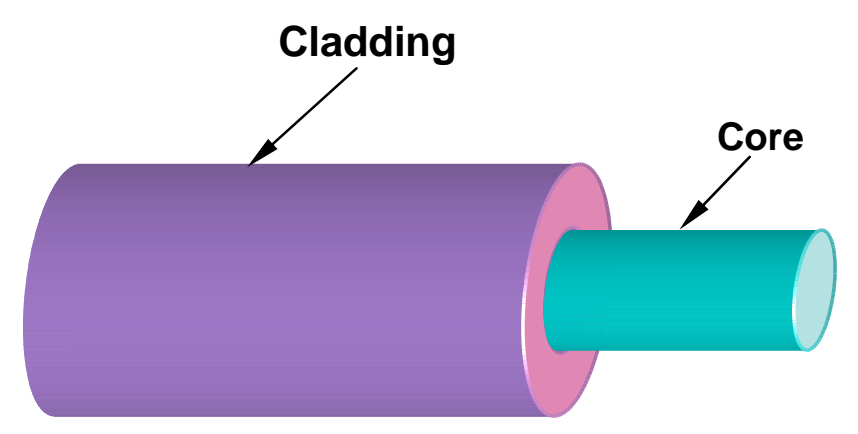

Figure 2.1: Optical Fiber 
The core has a slightly higher refractive index than the cladding. This means that the boundary (interface) between the core and the cladding acts as a perfect mirror. Light traveling along the core is confined by the mirror to stay within it. In modern telecommunication and sensing systems, the optical signal can travel at a rate of more than 10 Gigabits/second. Optical fibers offer low attenuation to light waves in the infrared region. The operating range of wavelength is from 1500 to $1600 \mathrm{~nm}$ due to the following reasons:

- Optical fibers offer the least attenuation of light waves $(\sim 0.26 \mathrm{~dB} / \mathrm{Km})$ in this wavelength range [1-3].

- When optical signals travel through the optical fiber the signal becomes weak due to attenuation of light waves. Therefore optical signals need amplification after traveling some distance. For this purpose optical amplifiers are used. One of the most efficient optical amplifiers currently in use is the Erbium doped fiber amplifier (EDFA). It gives a gain of more than 10 times the optical signal and offers amplification in the least attenuation range; i.e., 1525 to $1565 \mathrm{~nm}$ [1-5].

\subsection{Wavelength Division Multiplexing Systems}

One important property of an optical fiber is that light waves at several different wavelengths can be transmitted through a single optical fiber without interfering/mixing with each other. Such systems are called wavelength division multiplexing (WDM) systems. These systems have significantly increased the information carrying capacity of optical fibers.

In modern telecommunication systems, several channels (light waves at different wavelengths) can be transmitted simultaneously over a single optical fiber. Presently, the channel spacing is $0.4 \mathrm{~nm}$ or $50 \mathrm{GHz}$. 
Figure 2.2 shows a simple WDM system. Light waves at different wavelengths are placed on a single fiber by using a multiplexer and in the end the light waves are again separated by using a demultiplexer. Data signals can be added to or extracted from a WDM system by using Add/DROP multiplexers or filters as shown in Figure 2.2 $[1,2,5]$. Fiber Bragg gratings (FBGs) are being used as an Add/Drop multiplexer. These FBGs work as a fixed filter and can extract data signals passing at a specific wavelength [6-10]. One of the important requirements of the WDM system is that data signals at any wavelength within the operating range should possibly be filtered out from the network. Therefore, a (continuously) tunable filter is needed for the WDM system. The FBGs can shift the center wavelength of a light wave (see discussion below).

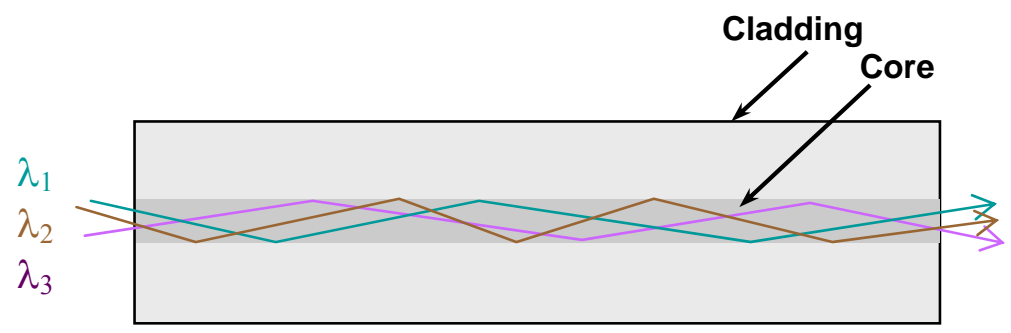

\section{Optical signal}

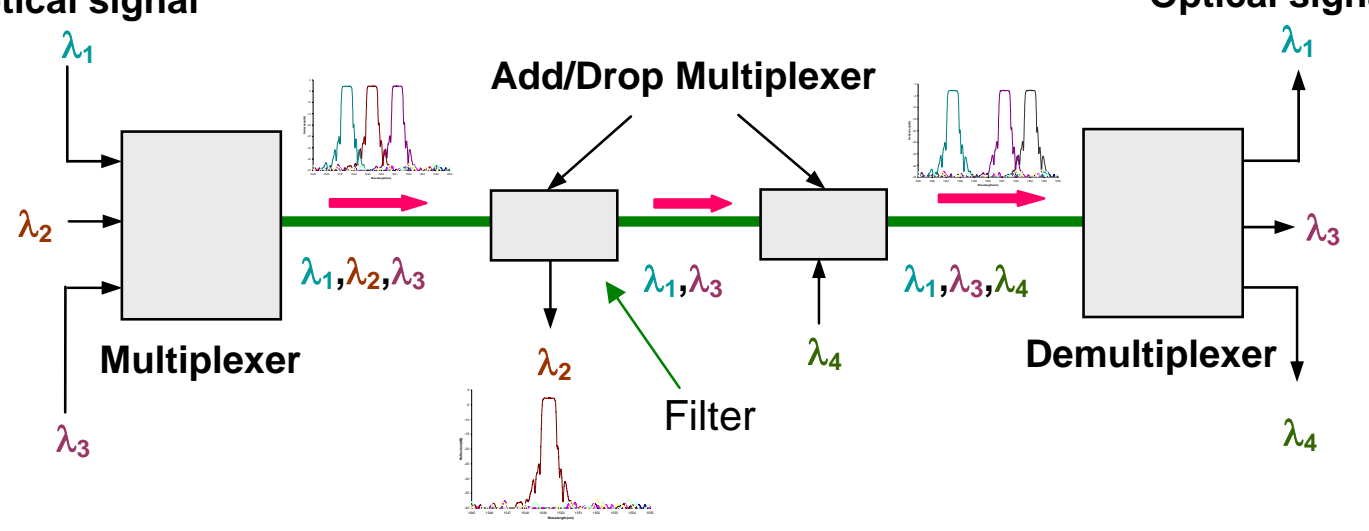

Figure 2.2: Wavelength Division Multiplexing Systems. 


\subsection{Fiber Bragg gratings}

A fiber Bragg grating is a piece of optical fiber with periodic variation of the index of refraction along the fiber axis. Such a phase grating acts as a band rejection filter reflecting wavelengths that satisfy the Bragg condition and transmitting the others. Fiber Bragg gratings act like tiny mirrors in a fiber that reflect specific wavelengths due to periodic changes in the index of the fiber core.

Fiber Bragg gratings couple light from a forward propagating guided mode into a backward or counter propagating guided mode at the Bragg wavelength $\left(\lambda_{\text {Bragg }}\right)$. This is the wavelength for the Bragg reflection, which is the phenomenon by which a single large reflection can result from coherent addition of many small reflections from weakly reflecting mirrors spaced a multiple of half of the wavelength apart [6-10]. The equation relating the grating periodicity and the Bragg wavelength depends on the effective refractive index of the transmitting medium, $\mathrm{n}_{\mathrm{eff}}$, and is given by

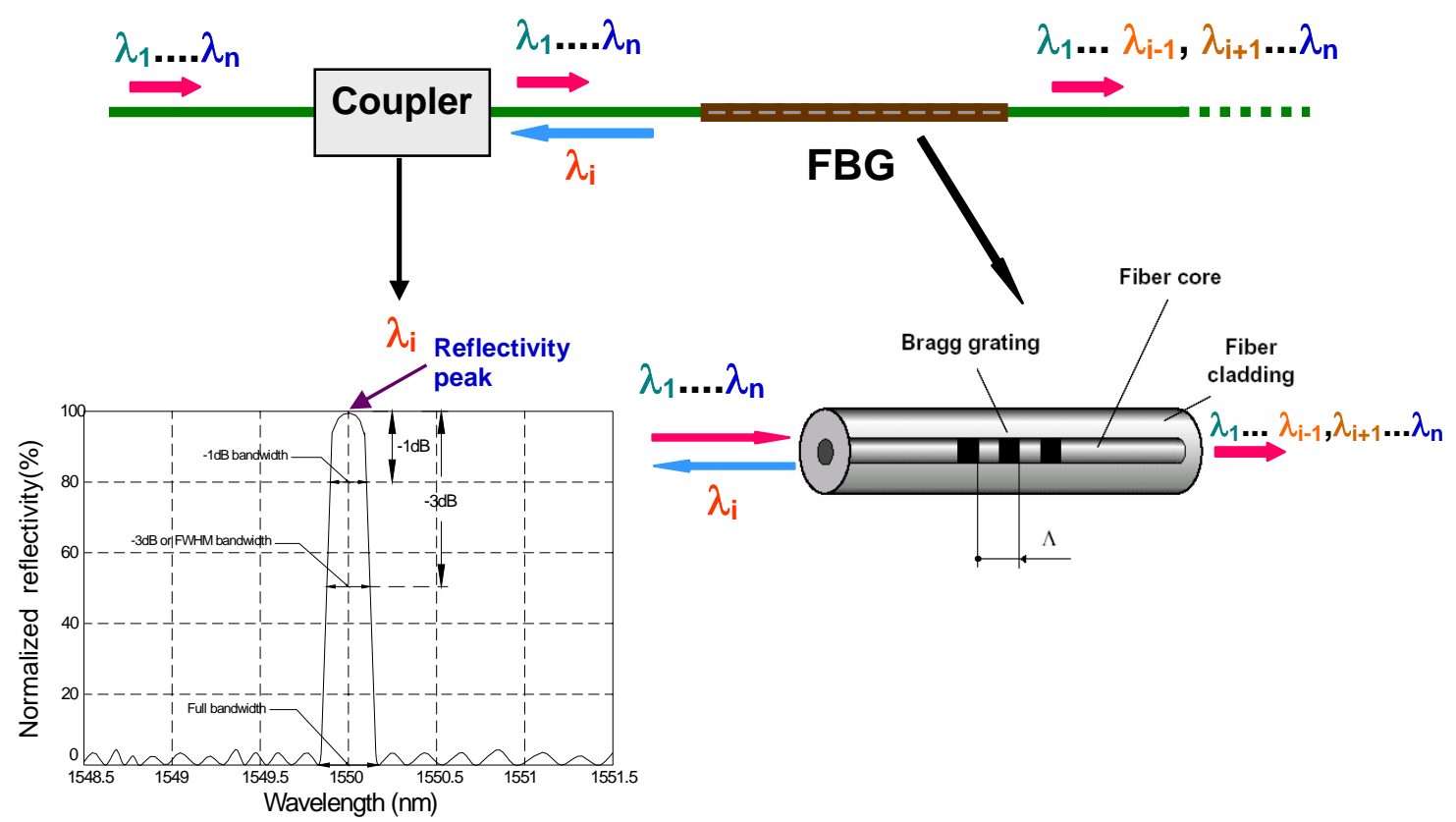

Figure 2.3: Fiber Bragg Gratings. 


$$
\lambda_{\text {Bragg }}=2 n_{\text {eff }} \Lambda
$$

where

$\lambda_{\text {Bragg }}=$ Bragg wavelength;

$\Lambda=$ Grating period;

$\mathrm{n}_{\text {eff }}=$ Effective refractive index of the transmitting medium.

Figure 2.3 also shows the application of a FBG as a filter. Light waves at several different wavelengths are traveling through the optical fiber and entering into the FBG. One of the wavelengths ( $\lambda_{\text {Bragg }}$ ) is reflected back by the FBG which comes back to the coupler [1]. The coupler separates the Bragg wavelength from the incoming wavelengths and the reflection spectra of this reflected wavelength can be seen on an optical spectrum analyzer (see Chapter 4 for more discussion).

\subsection{Bragg Grating Strain and Temperature Sensitivity}

The wavelength sensitivity of Bragg gratings is governed by the elastic, elasto-optic and thermo-optic properties and by the nature of the load or strain which is applied to the optical fiber. According to equation (2.1) the Bragg wavelength is dependent on the grating periodic spacing and on the effective refractive index of optical fiber. Differentiating this equation and neglecting higher order terms, the shift of the Bragg grating wavelength, $\Delta \lambda_{B}$, is given by $[6-9,11]$ :

$$
\Delta \lambda_{B}=2\left(\Lambda \frac{\partial n_{e f f}}{\partial L}+n_{e f f} \frac{\partial \Lambda}{\partial L}\right) \Delta L+2\left(\Lambda \frac{\partial n_{e f f}}{\partial T}+n_{e f f} \frac{\partial \lambda}{\partial T}\right) \Delta T
$$

where $\Delta L$ is the change in grating length and $\Delta T$ is the change in grating temperature. Thus the wavelength shift of the FBG can be generated by changing its strain $(\Delta L)$ and/or its temperature $(\Delta T)$. In modern telecommunication and wavelength division 
multiplexing (WDM) systems a tuning range, or a wavelength shift of around $45 \mathrm{~nm}$ $\left(\Delta \lambda_{B} \cong 45 \mathrm{~nm}\right)$ or more, is required for a high bandwidth.

\subsubsection{Strain Sensitivity}

In practice, the axial strain sensitivity of a fiber Bragg grating is governed by the following equation $[8,34]$ :

$$
\frac{\Delta \lambda}{\lambda_{B}}=\left(1-P_{e}\right) \varepsilon_{a x}
$$

where $\Delta \lambda$ is the wavelength shift (the subscript $a x$ is omitted for convenience), $P_{e}$ is the effective photoelastic constant, and $\varepsilon_{a x}=\Delta L_{a x} / L_{o}$ is the axial strain (tensile or compressive) imposed on the FBG. The value of $\lambda_{B}$ currently in use is around $1550 \mathrm{~nm}$. The average value of $P_{e}$ is about 0.22 [13-15]. From equation (2.3), for a wavelength shift of $45 \mathrm{~nm}$ the required axial strain change $\left(\varepsilon_{a x}\right)$ will be around $4 \%$.

Table 2.1 summarizes different values of Poisson's ratio, $v$, and $\mathrm{P}_{\mathrm{e}}$ for different wavelengths and materials [12-17].

Table 2.1: Photo-elastic Coefficients

\begin{tabular}{|c|c|c|c|c|c|}
\hline Reference & $\boldsymbol{\lambda} \mathbf{( n m )}$ & $\mathbf{n}_{\text {eff }}$ & $\mathbf{P}_{\mathbf{e}}$ & $\boldsymbol{v}$ & Material \\
\hline Yariv [12] & 630 & 1.46 & 0.20 & 0.21 & Fused silica \\
\hline Primak [13] & 589.2 & 1.458 & 0.219 & 0.164 & Vitreous silica \\
\hline Bertholds [14] & 633 & 1.458 & 0.206 & 0.16 & Optical fiber \\
\hline Borrelli [15] & 632.8 & 1.457 & 0.207 & 0.168 & Fused silica \\
\hline $\mathrm{Xu}[16]$ & 1533.3 & 1.465 & 0.218 & 0.17 & Optical fiber \\
\hline Hocker [17] & 633 & 1.456 & 0.216 & 0.17 & Optical fiber \\
\hline
\end{tabular}


For fiber diameter $d \cong 0.125 \mathrm{~mm}$ and modulus of elasticity of pure silica $E \cong 72.5 \mathrm{GPa}$, the force required to achieve $4 \%$ of axial strain (from the unstrained configuration) is $F=\sigma A_{f}=E \varepsilon_{a x} \frac{\pi}{4} d^{2} \cong 35.6 \mathrm{~N}$. Such a force is relatively small and can easily be achieved using conventional stepper motors or piezoelectric (PZT) actuators.

\subsubsection{Temperature Sensitivity}

The temperature sensitivity of a fiber Bragg grating is governed by the following equation [6 - 9]:

$$
\frac{\Delta \lambda}{\lambda_{B}}=\left(\alpha_{t}+\zeta\right) \Delta T
$$

where $\alpha_{t}=\frac{1}{\Lambda} \frac{\partial \Lambda}{\partial T} ; \quad \zeta=\frac{1}{n_{\text {eff }}} \frac{\partial n_{\text {eff }}}{\partial T}$

For silica the values of thermal expansion coefficient $\left(\alpha_{t}\right)$ and thermo-optic coefficient (ऽ) are $0.55 \cdot 10^{-6}{ }^{\circ} \mathrm{C}^{-1}$ and $8.6 \cdot 10^{-6}{ }^{\circ} \mathrm{C}^{-1}$, respectively. Substituting these values into equation (2.4) the temperature difference required for a wavelength shift of $45 \mathrm{~nm}$ is roughly $3173{ }^{\circ} \mathrm{C}$. Such a temperature difference is essentially impossible to apply in practice. For example, temperatures of about $500{ }^{\circ} \mathrm{C}$ will damage the fiber coating, substantially reduce the reflectivity of FBG and may even erase it [26].

\subsubsection{Pressure Sensitivity}

The required wavelength shift may also be achieved by hydrostatically compressing the FBG. The pressure sensitivity of a Bragg grating is given by the following equation [17]: 


$$
\frac{\Delta \lambda}{\lambda_{B}}=\left[-\frac{(1-2 v)}{E}+\frac{n_{e f f}^{2}}{2 E}(1-2 v)\left(2 p_{12}+p_{11}\right)\right] \Delta P
$$

where $\Delta P$ is the hydrostatic pressure variation, $n_{\text {eff }} \cong 1.45, v \cong 0.165, p_{11} \cong 0.121$ and $p_{12} \cong 0.27$ are the refractive index, Poisson's ratio, and components of the strain optic tensor, respectively. Substituting the above values into equation (2.5) for a wavelength shift of $45 \mathrm{~nm}$, the pressure required will be around $10.3 \times 10^{3} \mathrm{MPa}$, which is practically impossible (admissible compressive stress of optical fiber is about $3.5 \cdot 10^{3} \mathrm{MPa}$ ). Additionally, this technique, when used for smaller $\Delta \lambda$, is very complicated and expensive to implement $[8,17,35]$.

\subsubsection{FBG Sensitivity}

To obtain a shift of the Bragg wavelength both thermal variations and axial strains can be applied. Nevertheless, for a Bragg grating at $1550 \mathrm{~nm}$ the following values of sensitivities can be obtained [17-25].

Table 2.2: Comparison of Strain Techniques

\begin{tabular}{|c|c|}
\hline Wavelength shift technique & Sensitivity \\
\hline Axial strain & $12 \mathrm{~nm} / 1 \% \varepsilon$ \\
\hline Thermal & $1.4 \mathrm{~nm} / 100^{\circ} \mathrm{C}$ \\
\hline Pressure & $4.37 \mathrm{pm} / \mathrm{MPa}$ \\
\hline
\end{tabular}

\subsection{Tuning of FBG by Means of Strains}

Fiber Bragg gratings are emerging as very important elements for both optical fiber communications and sensing fields due to their properties. FBGs are lightweight, offer low power consumption, multiplexing capability, resistant to electromagnetic waves, 
and offer high sensitivity to temperature and strain. FBG sensors are ideally suited for health monitoring of smart structures since they can be easily embedded inside structural members because of their small size. Health monitoring includes monitoring of variation in temperature, strain, and vibration in the structure. Some of the important applications of FBGs are [24-27, 28, 34, 35, 36-38]:

1. Narrowband and broadband tunable filters

2. Optical fiber mode converters

3. Wavelength selective filters and multiplexers

4. Dispersion compensation in long-distance telecommunication networks

5. Gain equalization in erbium-doped fiber amplifiers

6. Specialized narrowband lasers

7. Optical strain gauges in bridges, building structures, elevators, reactors, composites, mines and smart structures.

When strain is applied on a fiber Bragg grating the Bragg wavelength $\left(\lambda_{\text {Bragg }}\right)$ shifts to a different value due to either change in the grating period or in the refractive index of the FBG. Figure 2.4 shows an example of the wavelength shift due to both axial and compressive strains. Suppose Bragg wavelength of a FBG without any strain is 1547.5 $\mathrm{nm}$. When a tensile axial strain of $0.3 \%$ is applied on the unstrained FBG, according to equation (2.3), the grating period will increase and the peak reflectivity will shift towards the right side to a new Bragg wavelength of $1551.25 \mathrm{~nm}$. Theoretically, a positive wavelength shift of $3.75 \mathrm{~nm}$ can be achieved for $0.3 \%$ of strain applied. When a compressive axial strain of the same value is applied to the unstrained FBG, theoretically the same wavelength shift will be achieved but, in this case, the grating period will decrease which will cause the reflectivity peak to shift towards the left side to a new Bragg wavelength value of $1543.75 \mathrm{~nm}$; i.e., a negative wavelength shift will be achieved. 

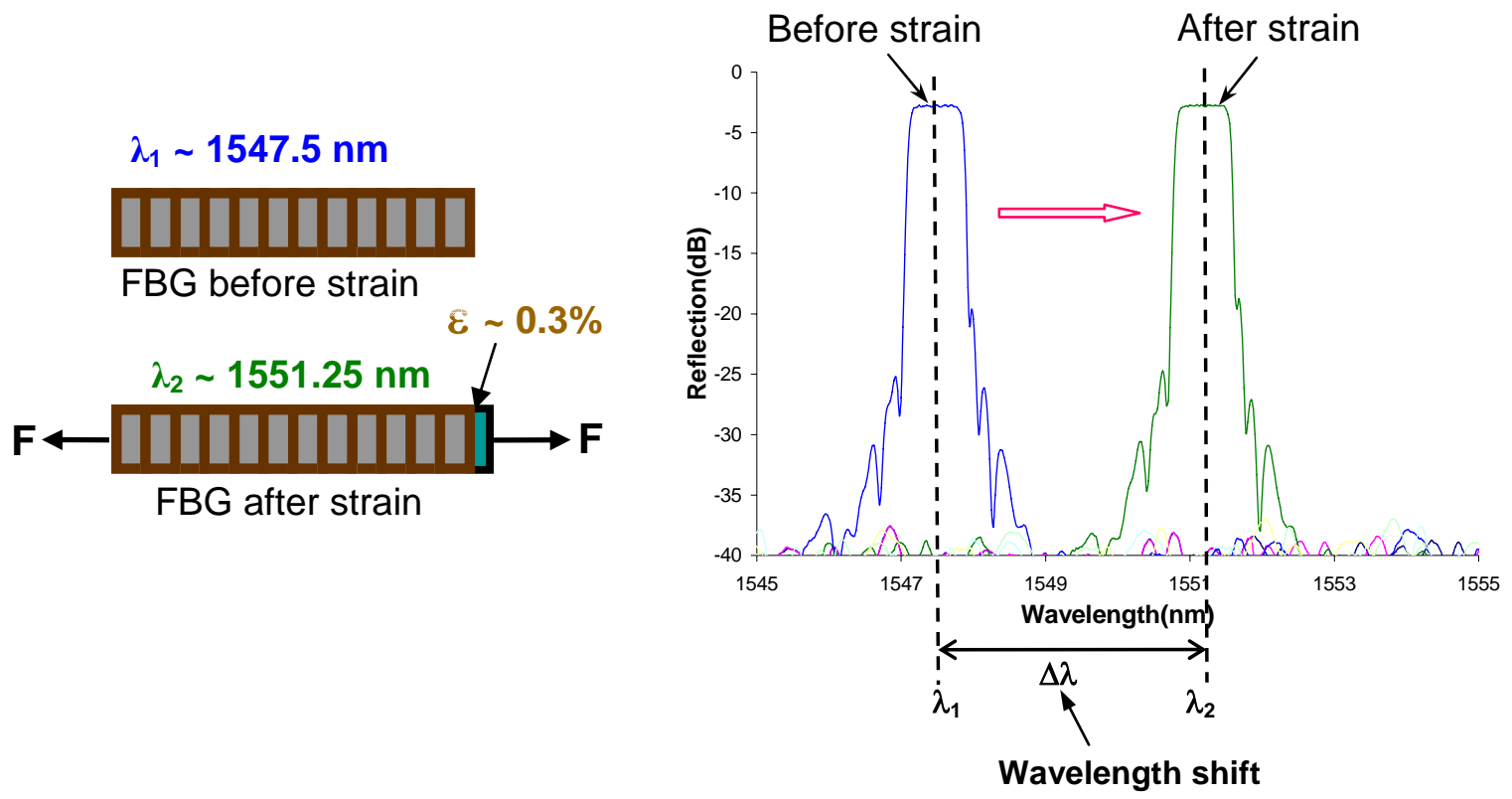

Figure 2.4: Axial Tuning of FBG.

\subsection{Previous Work on Tunable FBG by Means of Strain}

As already mentioned, the required wavelength shift of around $45 \mathrm{~nm}$ cannot be achieved either by heating or by hydrostatic pressure techniques. However, only about $4 \%$ axial strain change is required if axial tuning is used. It corresponds to an axial stress change of about $2900 \mathrm{MPa}$. Both the strain and the stress ranges are achievable for the FBGs presently used. Therefore, the axial strain technique seems to be the only viable option to get the required tuning range. Table 2.3 summarizes some of the important developments done previously for tuning of FBG.

A wavelength shift of approximately $15 \mathrm{~nm}$ has been obtained [28] by stretching FBG with the help of magnetic actuator as shown in Figure 2.5. The FBG was firmly attached between a pair of magnets by bonding so that magnetic force (repulsive or attractive) applied to the magnets is transmitted to the grating. However, the wavelength shift was 
not linear with respect to the applied magnetic field. Also, high magnetic fields had to be applied to obtain that tuning range.

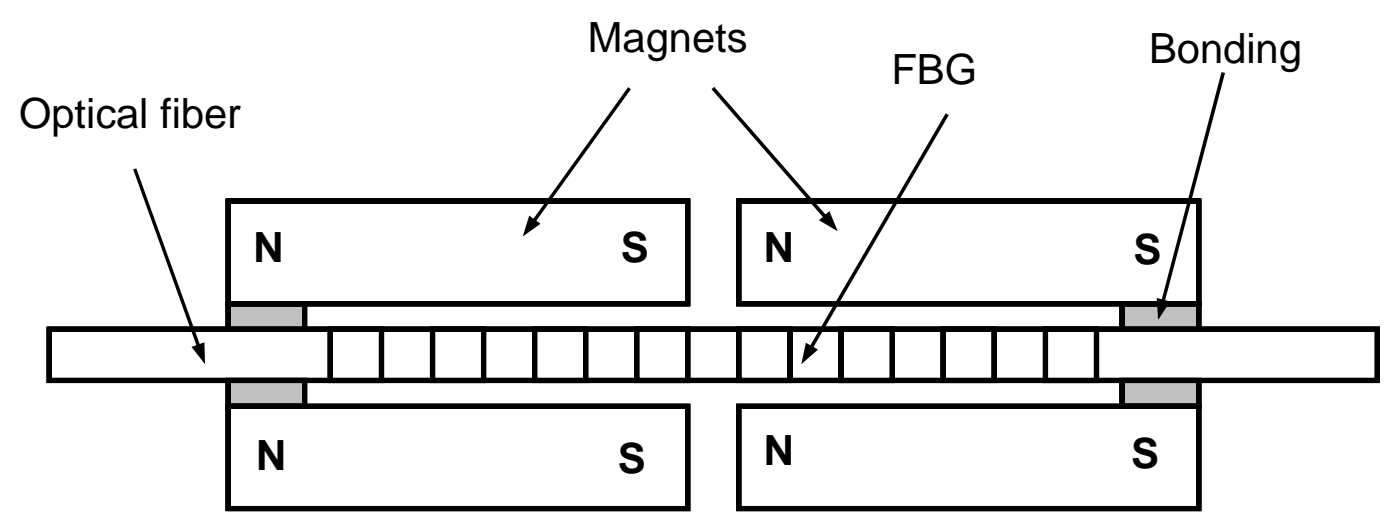

Figure 2.5: Schematic of a Magnetically Tunable FBG.

Table 2.3: Tunable FBG Filters Performance Summary (t: Fiber Tension, c: Fiber Compression).

\begin{tabular}{|c|c|c|}
\hline Reference & $\begin{array}{c}\text { Tuning Range } \\
(\mathbf{n m})\end{array}$ & Working principle \\
\hline S. Jin[28] & 15 & $\begin{array}{c}\text { Axial strain }(\mathrm{t}) \\
\text { Magnetic actuator }\end{array}$ \\
\hline Y. Yu [29] & 4.52 & Beam bending \\
\hline Z. Qin [30] & 12.52 & Beam bending \\
\hline A. Iocco [25] & 45 & $\begin{array}{c}\text { Axial strain (c) } \\
\text { Piezoelectric actuator }\end{array}$ \\
\hline W. Chung [32] & 20 & $\begin{array}{c}\text { Axial strain (c) } \\
\text { Motorized actuator, LVDT }\end{array}$ \\
\hline C. S. Goh [33] & 90 & Beam bending \\
\hline
\end{tabular}


An overall wavelength shift of $4.52 \mathrm{~nm}$ was reported in [29]. The tuning was achieved by bending a beam with the FBG epoxied on its top surface as shown in Figure 2.6. Tension/compression was induced to the grating by applying a force to the end of the beam in the downward/upward direction. The length of FBG used was $15 \mathrm{~mm}$. The wavelength shift was not linear to the applied force. Also, a tuning range of about 12.52 $\mathrm{nm}$ was reported [30] by applying axial compressive and tensile strains on the FBG using the bending of a trapezoidal beam. A large beam deflection of $11.17 \mathrm{~mm}$ was observed to achieve the desired wavelength shift. The actuator travel required to compress a standard $12 \mathrm{~mm}$ FBG to get the same wavelength shift using this technique was 90 times more than that required for axial strain technique. Some discrepancies were reported between theoretical and experimental results due to non-rigid coupling between the fiber, the epoxy and the beam.

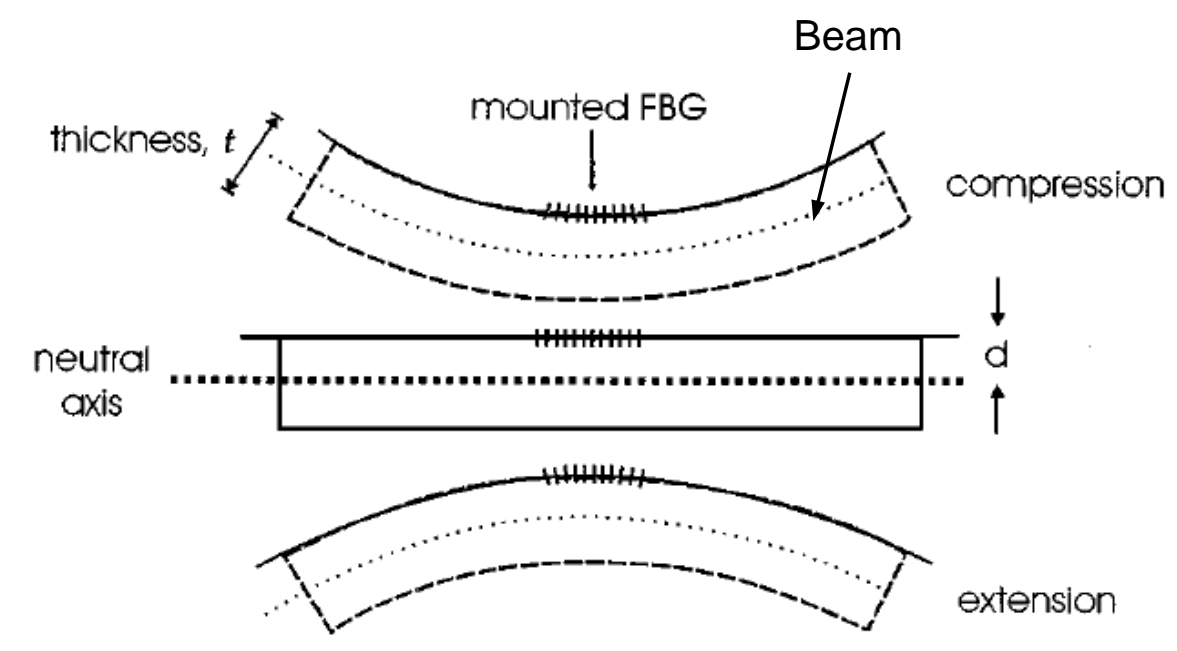

Figure 2.6: Schematic of a Tunable FBG Based on Beam Bending

A wavelength shift of around $45 \mathrm{~nm}$ was reported in [25]. It was achieved by axial compression of FBG with PZT actuators mounted at both ends (Figure 2.7). A guiding mechanism was used to minimize bending of FBG. For up to $30 \mathrm{~nm}$ the optical power loss was negligible but, beyond that, a significant optical power loss was observed. For example, close to $45 \mathrm{~nm}$ the loss was more than $50 \%$ (3.5 dB). Also, the wavelength shift was not linear with the PZT actuator travel and a large device hysteresis of up to 6 
nm was reported. To compensate for the hysteresis in PZT actuators, a motorized actuator with a linear variable differential transformer was used [32] and a tuning range of about $20 \mathrm{~nm}$ was achieved with a readout wavelength accuracy of better than $\pm 0.05 \mathrm{~nm}$.

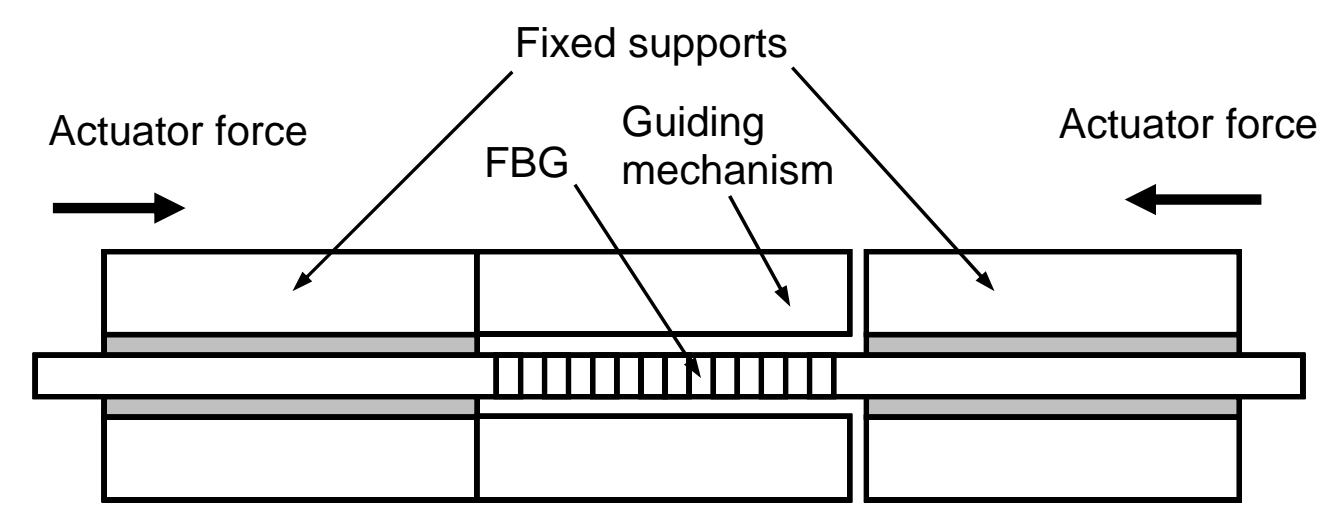

Figure 2.7: Schematic of a Tunable FBG Supported by Guiding Mechanism

Most recently, a wavelength shift of about $90 \mathrm{~nm}$ was reported in [33] by using a combination of axial compressive and tensile strains provided from a beam bending technique (Figure 2.6). A $3 \mathrm{~mm}$ long FBG was adhered onto a $100 \mathrm{~mm}$ long elastic beam. $20 \mathrm{~nm}$ of wavelength shift was achieved in tensile mode and $70 \mathrm{~nm}$ in compression mode. Negligible power loss and a variation of $0.1 \mathrm{~nm}$ in FWHM bandwidth were reported. A beam deflection of $3.5 \mathrm{~mm}$ was observed to achieve a 70 $\mathrm{nm}$ wavelength shift in compression. The actuator travel required to compress $3 \mathrm{~mm}$ FBG to get the same wavelength shift using this technique was 20 times more than that required for axial strain technique. The wavelength shift was non linear with respect to the beam deflection. 


\subsection{Concluding Remarks}

Typical mechanical properties of FBG are indicated in Figure 2.8. Although a tensile breaking strength of an optical fiber without writing the grating is up to $6000 \mathrm{MPa}$, it drops to about $700 \mathrm{MPa}$ during the grating process [39 - 41]. The tensile strength is reduced by the fiber's exposure to high intensity ultra violet radiations during manufacturing using phase mask technique, which is being widely used to manufacture fiber Bragg gratings due to its simplicity $[6,7]$. The $700 \mathrm{MPa}$ tensile strength gives a strain of only around $1 \%$ in tension, which can theoretically give a wavelength shift of about $12 \mathrm{~nm}$ according to equation (2.3). As already mentioned, the tensile range of FBG's strain was completely made use of in Ref [28], which leads to a $15 \mathrm{~nm}$ wavelength shift.

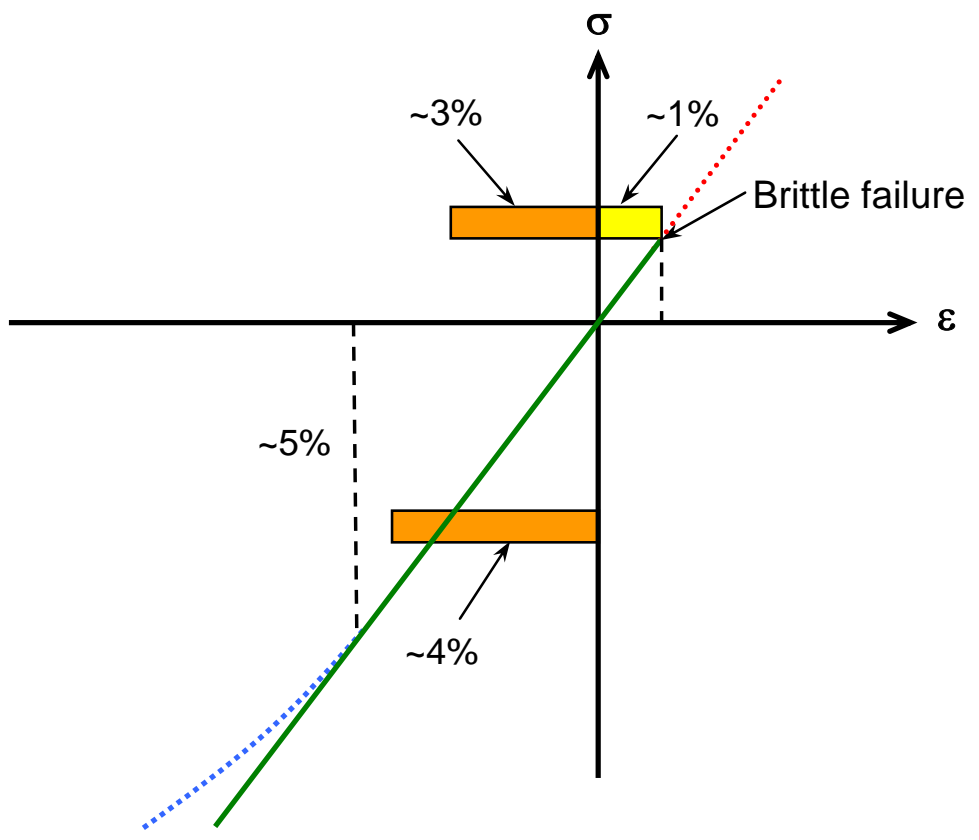

Figure 2.8: Stress-Strain Relationship for Optical Fiber.

Typically, an optical fiber is up to 20 times stronger in compression than that in tension. Also, the strain up to $5 \%$ in compression remains linear $[19,39]$. Therefore, in order to 
achieve the $4 \%$ strain change range, the remaining 3\% strain must be obtained from compression. Also, $4 \%$ of strain can be achieved in compression. The high compressive strength of optical fibers should theoretically permit such a strain. The only technical problem is that it is very difficult to compress a thin optical fiber because of buckling. The difficulties related to optical fiber compression and the design of a device to achieve large compression is presented in the next chapter. 


\section{FBG TUNING DEVICE DESIGN AND ANALYSIS}

\subsection{Introduction}

This chapter describes the design and development of a state of the art device for axial tension/compression of FBGs. Section 3.2 presents the design theory for this device. Section 3.3 presents detailed design of the device for both stretching and compression in which the application of the design theory leading to a rational device design will be illustrated. Section 3.4 is a summary.

\subsection{Design Theory}

From the buckling theory, a fiber of an unguided length $L_{b}$ (also referred to as the buckling length) and the geometrical moment of inertia (I), will buckle if the compressive force $\left(F_{c r}\right)$ reaches [42]:

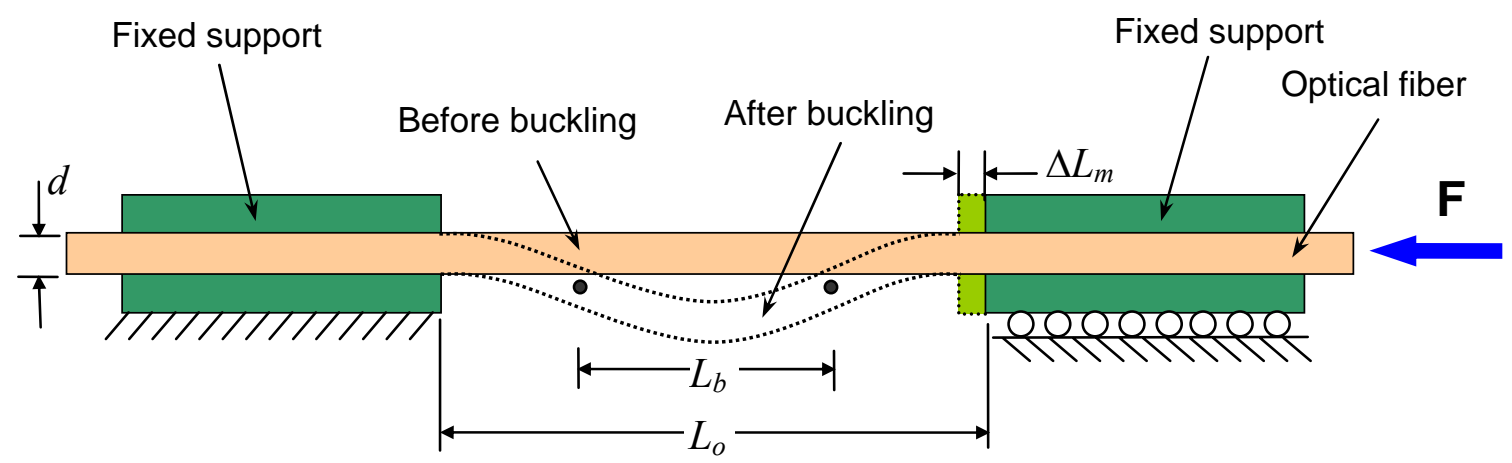

Figure 3.1: Buckling of FBG Under Compression. 


$$
F_{c r}=\frac{\pi^{2} E I}{L_{b}{ }^{2}}
$$

where

$E=$ Modulus of Elasticity of optical fiber $=72.5 \mathrm{GPa}$

The critical stresses $\left(\sigma_{c r}\right)$ can be calculated as

$$
\sigma_{c r}=\frac{F_{c r}}{A}=\frac{\pi^{2} E i^{2}}{L_{b}{ }^{2}}=\frac{\pi^{2} E}{S^{2}}
$$

where

A $=$ Cross-section area of optical fiber $=\frac{\pi}{4} d^{2}$

$\mathrm{i}=$ Radius of gyration of optical fiber $=i^{2}=\frac{I}{A}=\frac{d^{2}}{16}$

and $S=$ Slenderness $=\frac{L_{b}}{i}=\frac{L_{b}}{\sqrt{I / A}}=4 \frac{L_{b}}{d}$

The critical Strain $\left(\varepsilon_{c r}\right)$ will be

$$
\varepsilon_{c r}=\frac{\sigma_{c r}}{E}=\frac{\pi^{2}}{S^{2}}=\frac{\pi^{2} d^{2}}{16 L_{b}}
$$

Rearranging equation (3.2), the fiber's maximum unsupported buckling length for a given axial strain can be determined from:

$$
L_{b}=\frac{\pi d}{4 \sqrt{\varepsilon_{c r}}}
$$

If both ends of the FBG are fixed as shown in Figure 3.1, then $L_{b}=0.5 L_{o}$, where $L_{o}$ is the length of FBG, typically about $12 \mathrm{~mm}$. For $L_{o}=12 \mathrm{~mm}$, the amount of compressive 
strain that can be carried without buckling of an optical fiber of $125 \mu \mathrm{m}$ diameter is only about $0.02 \%$, which is much less than the required strain (i.e., $4 \%$ ). On the other hand, to carry an axial compressive strain of $4 \%$ without buckling, the unguided length should not be more than about $0.5 \mathrm{~mm}$. Therefore, it is clear that a fiber guiding system is needed in order to achieve the required strain without buckling of the fiber.

\subsubsection{FBG Supported by Guiding Ferrule}

A simple way of guiding the unsupported FBG is with the help of a cylindrical guiding ferrule. The ends of the FBG will be glued to the ferrules as shown in Figure 3.2(a). Inside the guiding ferrule the fiber will buckle but its lateral deflection will be limited by the gap $D-d$, where $D$ is the inside diameter of the ferrule and $d$, as before, is the diameter of the fiber. Some clearance $(\Delta L)$ will be required between the guiding ferrule and the moving fixed ferrule for the required compression; see Figure 3.2(a).

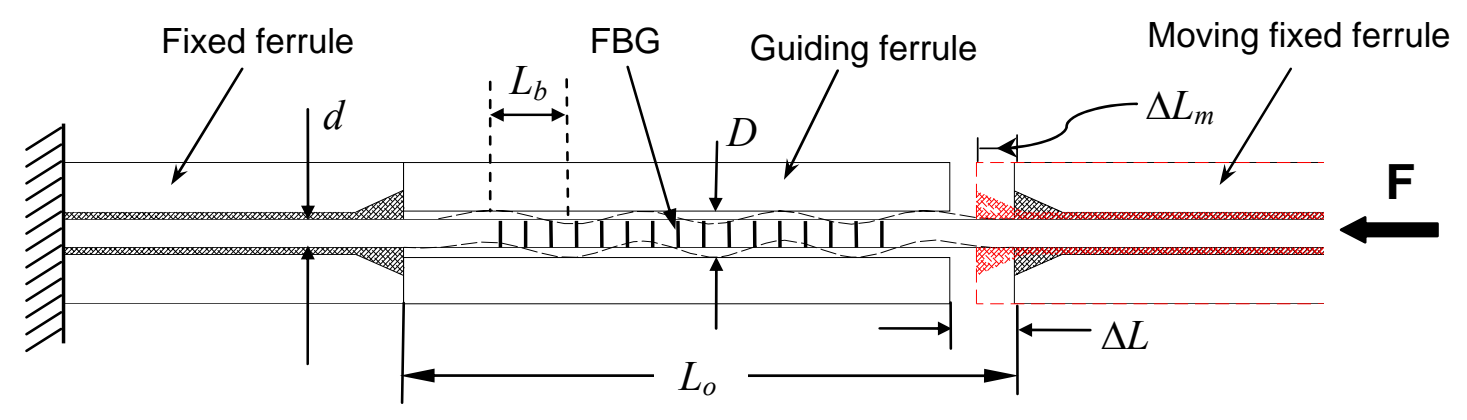

Figure 3.2(a): Support for Unguided Region under Compression. 


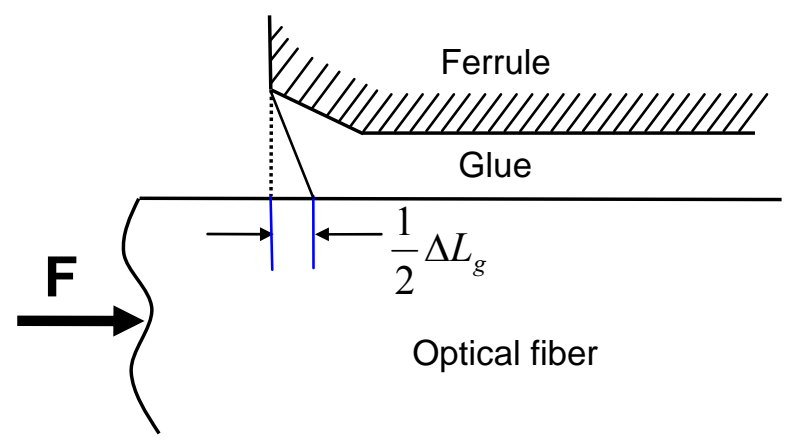

Figure 3.2(b): Deformation of Epoxy.

The axial strain in the fiber $\left(\varepsilon_{a x}\right)$ will be monitored by measuring the displacement $\left(\Delta L_{m}\right)$ of the moving ferrule on the right hand side. The measured displacement results from the combination of the axial compression of the FBG $\left(\Delta L_{a x}\right)$, the shortening due to waving of the optical fiber $\left(\Delta L_{w}\right)$ and the deformation of the epoxy $\left(\Delta L_{g}\right)$ (Figure 3.2(b)):

$$
\Delta L_{m}=\Delta L_{a x}+\Delta L_{g}+\Delta L_{w}
$$

The measured axial $\left(\varepsilon_{m}\right)$ strain is defined as

$$
\varepsilon_{m}=\frac{\Delta L_{m}}{L_{0}}=\varepsilon_{a x}+\varepsilon_{g}+\varepsilon_{w}
$$

Theoretically, the clearance between the internal diameter $(D)$ of ferrule and the diameter of the optical fiber $(d)$ should be as small as possible to minimize buckling of the optical fiber for minimum optical power loss from the optical fiber. But it is practically impossible due to Poisson's effect. In particular, the tolerance of both the diameter of the optical fiber and the internal diameter of the guiding ferrule below \pm 1 $\mu \mathrm{m}$ is expensive to achieve. The relationship of the cost of manufacturing versus the tolerance is shown in Figure 3.3. 


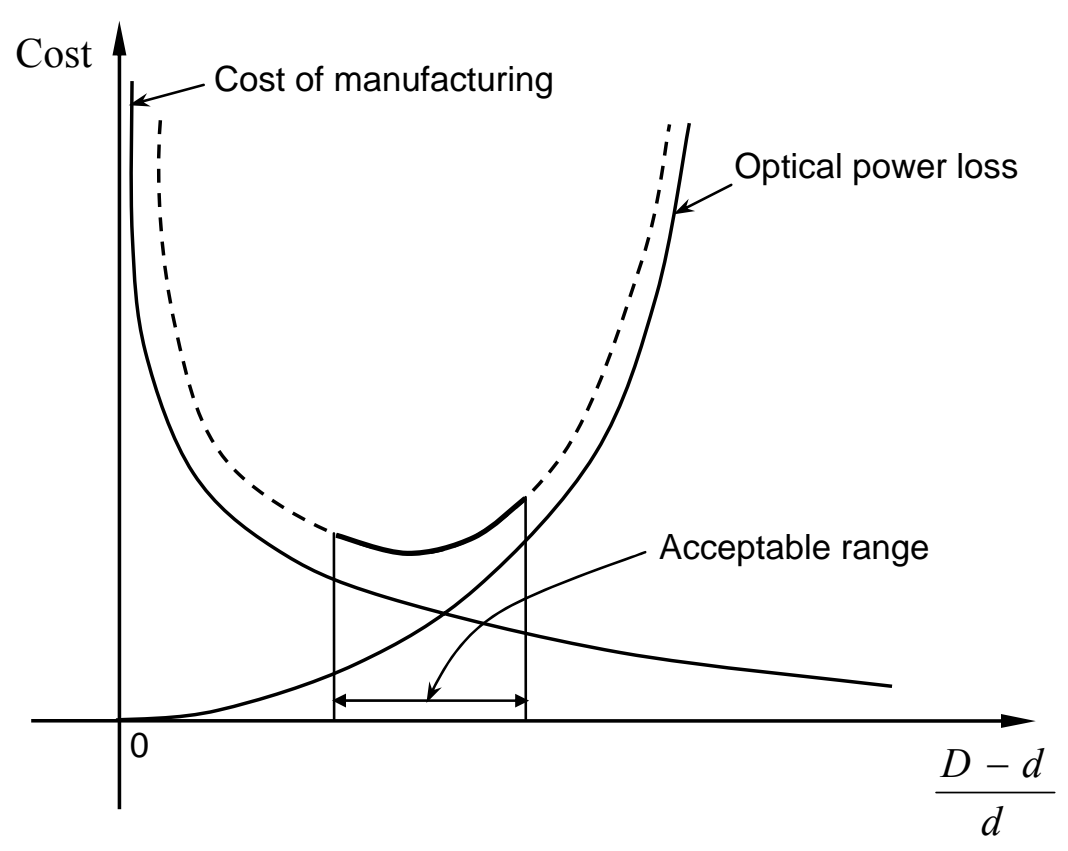

Figure 3.3: Factors Affecting the Ferrule's Design.

On the other hand, the optical properties of the fiber are related to the waving and will deteriorate with increase in the tolerance. A large clearance may result in significant optical power loss. Therefore, some compromise is required in which acceptable results can be achieved with reasonable manufacturing cost. As will be discussed in Section 3.2.2, the range of $D$ from 126 to $128 \mu \mathrm{m}$ seems acceptable to guide a $125 \mu \mathrm{m}$ fiber. In the particular device designed in this thesis study, $\mathrm{D}=127 \mu \mathrm{m}$, the reason for which will be given later in this thesis.

\subsubsection{Stresses in the Fiber}

The optical fiber inside the ferrule will buckle under a compressive force causing axial and lateral deformations. The average axial compressive stress $\left(\sigma_{c}\right)$ is given by

$$
\sigma_{c}=-\varepsilon_{a x} E
$$




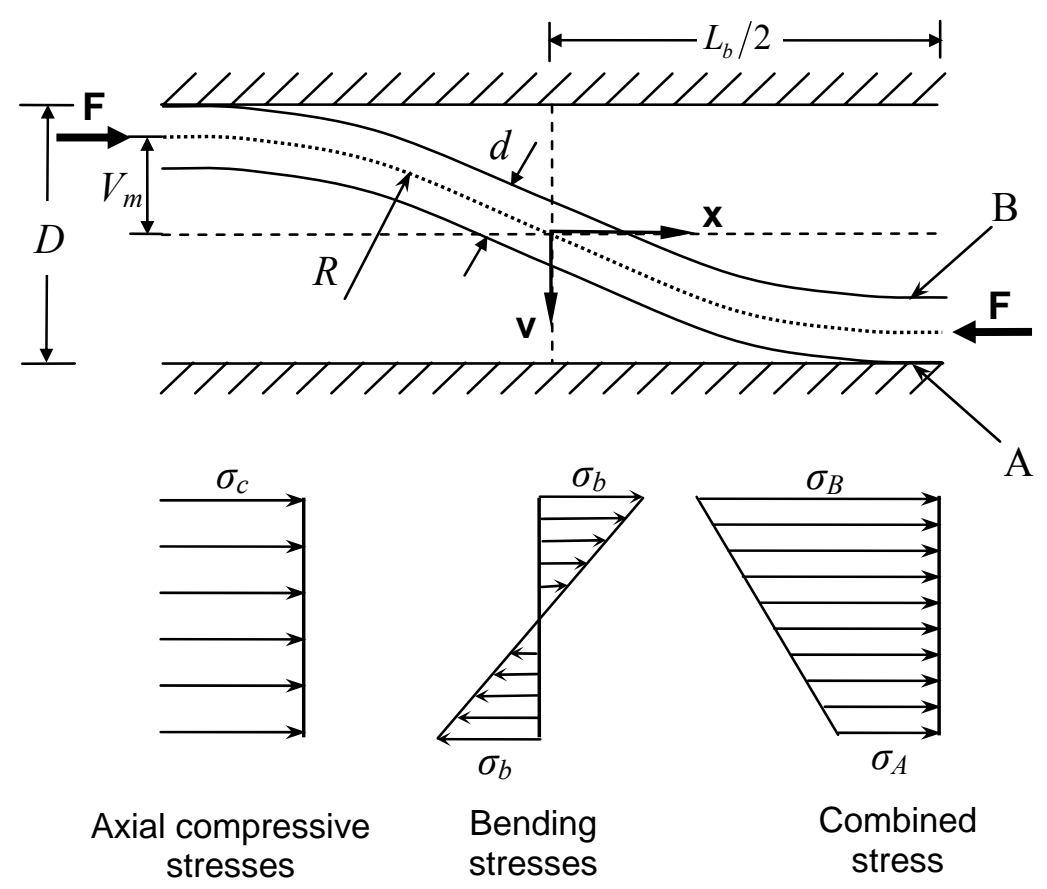

Figure 3.4: Stress Distribution under Compression.

According to structural stability theory [42], the axial strain in the fiber (of length $L_{b}$ ) at the moment of buckling remains almost unchanged, i.e. $\varepsilon_{a x} \cong \varepsilon_{c r}$, as long as the deflections are moderate. The bending stresses can be estimated by assuming that the buckling takes place in one plane (Figure 3.4).

From bending theory, we have

$$
\frac{1}{R}=\frac{d^{2} v}{d x^{2}}=\frac{M}{E I}
$$

where the buckled shape can be assumed to be 


$$
v=V_{m} \sin \left(\pi \frac{x}{L_{b}}\right)
$$

where $V_{m}=\frac{D-d}{2}$ is the wave's amplitude and $L_{b}$ is its length that depends on the axial strain (see equation (3.3)). After substituting equation (3.7) into equation (3.6) the maximum bending moment at $x=L_{b} / 2$ is

$$
\frac{M_{\max }}{E I}=V_{m} \frac{\pi^{2}}{L_{b}^{2}}
$$

and the corresponding maximum bending stresses are

$$
\sigma_{b}= \pm \frac{M_{\max } d}{2 I}= \pm E \frac{V_{m} d}{2} \frac{\pi^{2}}{L_{b}^{2}}= \pm 4 E\left(\frac{D}{d}-1\right) \varepsilon_{a x}
$$

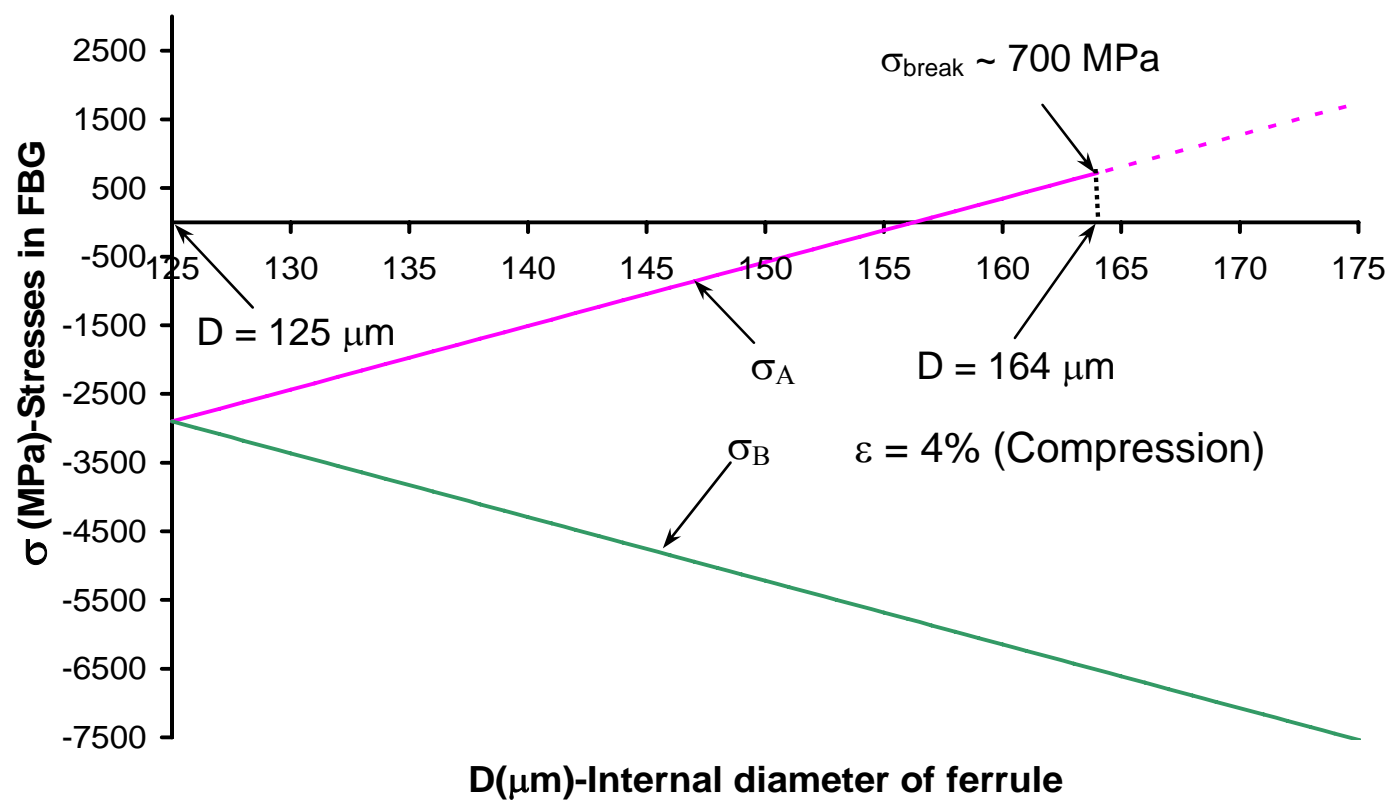

Figure 3.5: Variation in Stresses with Variation in Ferrule's Internal Diameter. 
Point $\mathrm{B}$ of the fiber will be under compressive bending stresses and point $\mathrm{A}$ will be under tensile bending stresses. From equation (3.5) and equation (3.9), the combined stress at point $\mathrm{A}$ is:

$$
\sigma_{A}=\sigma_{c}+\sigma_{b}=-E \varepsilon_{a x}+4 E\left(\frac{D}{d}-1\right) \varepsilon_{a x}=\varepsilon_{a x} E\left(4 \frac{D}{d}-5\right)
$$

and the combined stress at point $\mathrm{B}$ is:

$$
\sigma_{B}=\sigma_{c}-\sigma_{b}=-E \varepsilon_{a x}-4 E\left(\frac{D}{d}-1\right) \varepsilon_{a x}=-\varepsilon_{a x} E\left(4 \frac{D}{d}-3\right)
$$

For an optical fiber diameter $(d)$ of $125 \mu \mathrm{m}$, modulus of elasticity $(E)$ of $72.5 \mathrm{GPa}$ and an axial strain of 4\%, the equations (3.10) and (3.11) are plotted in Figure 3.5 in terms of the internal diameter $(D)$ of the guiding ferrule. For an internal diameter of $164 \mu \mathrm{m}$, the tensile stresses at point A will theoretically reach $700 \mathrm{MPa}$, which may cause the fiber Bragg grating to break at this point. Theoretically, the stress at points A and B will be identical for $D=d$. Note that when $\mathrm{D}=127 \mu \mathrm{m}$, the stresses at both point A and B are compressive.

\subsubsection{Effect of Curvature on FBG's Performance}

Light waves transmit through an optical fiber due to total internal reflection. Bending of the optical fiber causes them to escape from the core of the optical fiber because of change in the reflected and refracted angels of the light waves. The escape of light waves from the core results in optical power loss. The larger the curvature of the fiber the more will be the optical power loss. Note that the optical power loss should not be more than $0.5 \mathrm{~dB}$ for telecommunication applications [43]. 


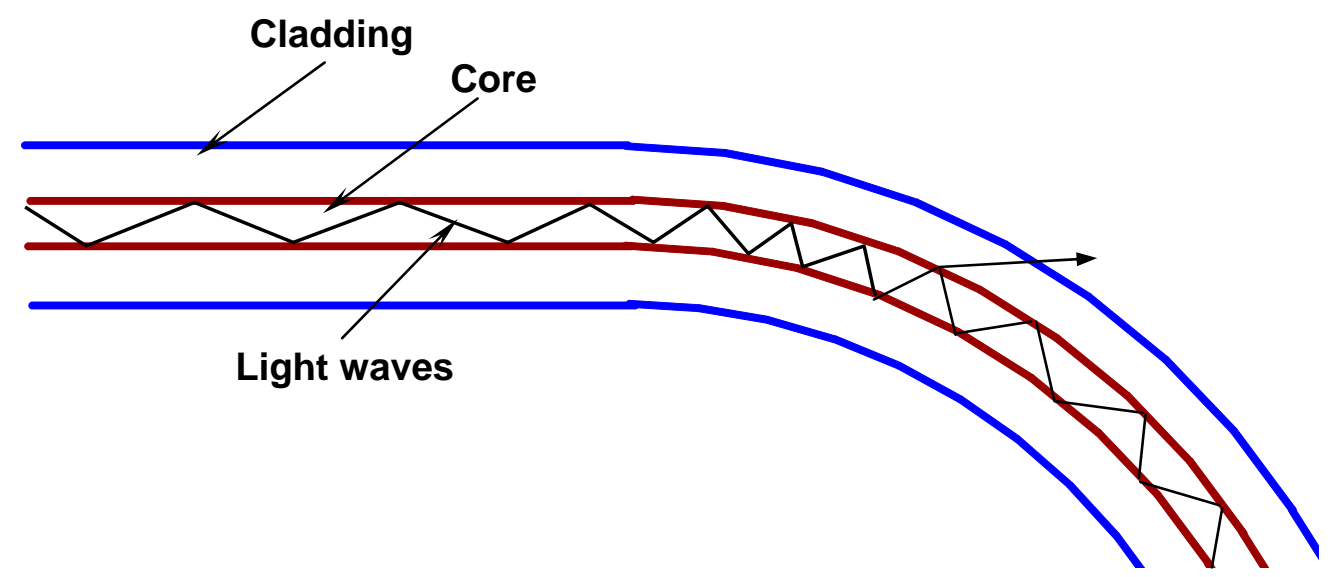

Figure 3.6: Optical Power Loss due to Bending.

A test was performed to observe the effect of curvature of the FBG on the optical power loss from the fiber. The overall setup of the test bed is shown in Figure 3.7. A broad band light source (BBS) [50] was used which has a bandwidth range of 1500 to 1600 $\mathrm{nm}$. The BBS sends light waves into the optical fiber carrying a fiber Bragg grating. A 3 $\mathrm{dB}$ coupler was used to separate the light waves reflected from the FBG. An optical spectrum analyzer (OSA) with wavelength range of 600 to $1750 \mathrm{~nm}$ (accuracy was $\pm 0.02 \mathrm{~nm}$, and the maximum resolution was $0.015 \mathrm{~nm}$ ) was used to observe the variation in the reflection spectrum of the FBG. The reflection spectrum data at different bending radii were extracted and stored in a computer connected to the OSA. The FBG used for the bending test was $12 \mathrm{~mm}$ long and had a Bragg wavelength of $1592.75 \mathrm{~nm}$, a reflectivity of about $99.97 \%$ (transmission depth of $-35 \mathrm{~dB}$ ) and a full wavelength half maximum (FWHM) bandwidth of $0.5 \mathrm{~nm}$.

The FBG was bent on cylinders of different radii ranging from $9.5 \mathrm{~mm}$ to $50 \mathrm{~mm}$. For each case the reflection spectrum was obtained. The results are plotted in Figure 3.8. A drop in the reflectivity (reflective power loss) was observed as the radius of curvature of the FBG was reduced. The accompanying shift in the Bragg wavelength was negligible. 


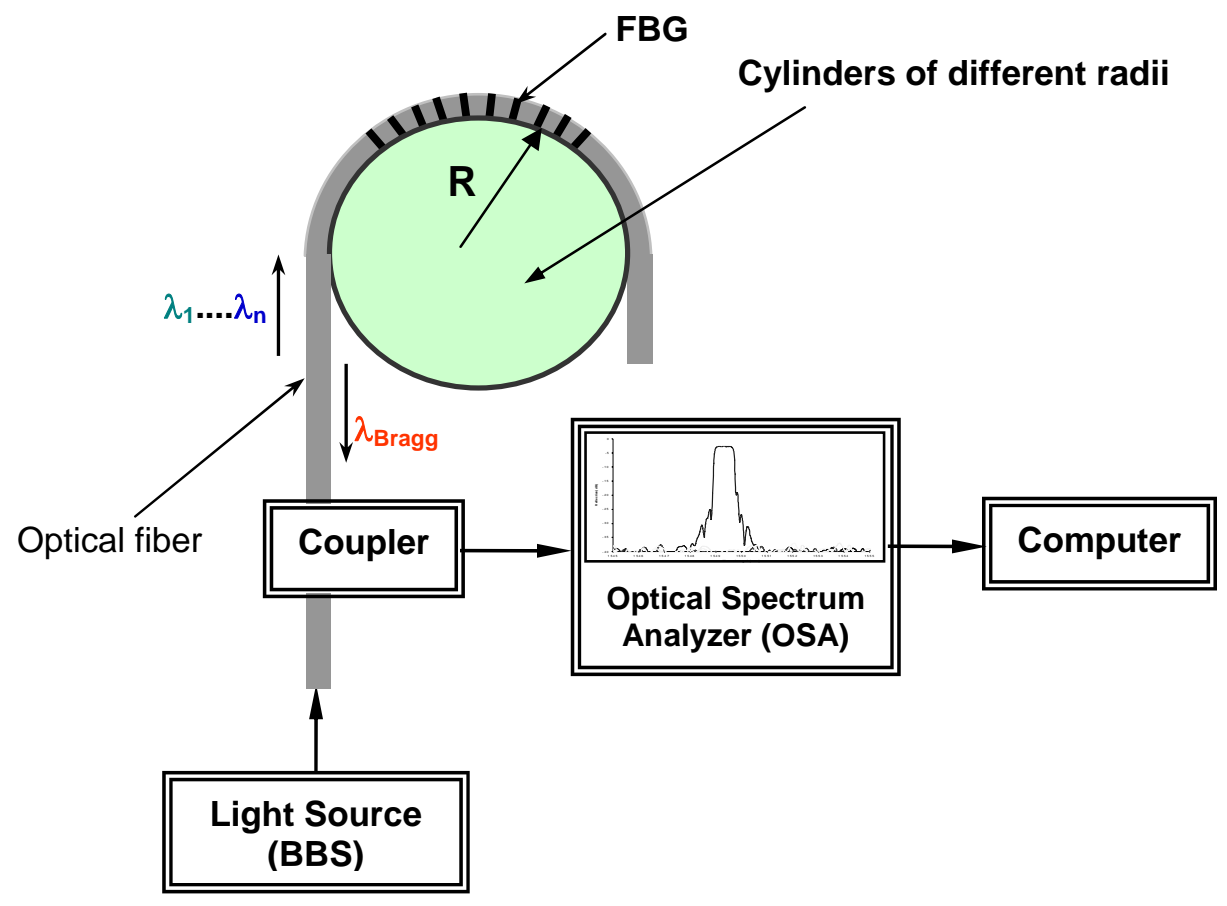

Figure 3.7: Bending Test of FBG.

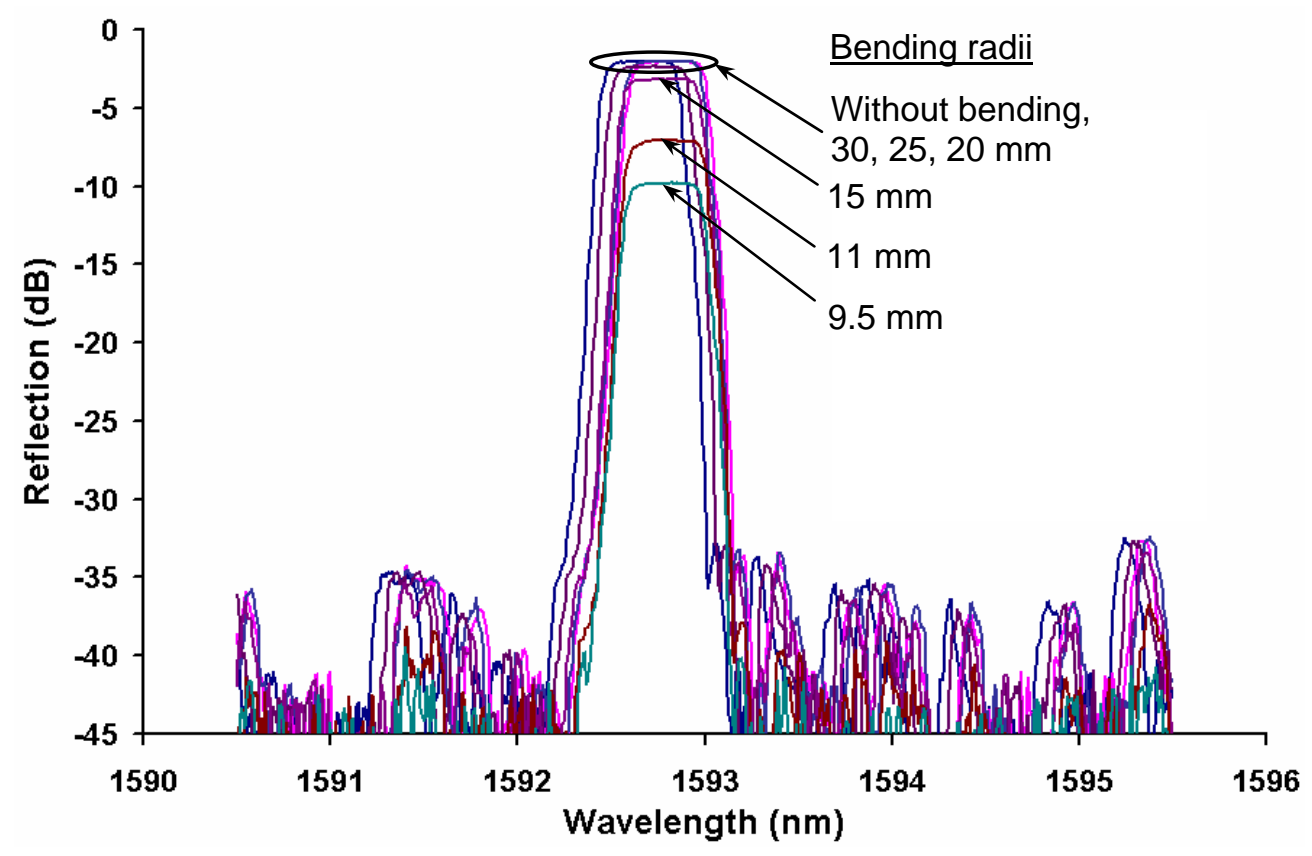

Figure 3.8: Reflection Spectrum for Various Bending Radii of FBG 
The reflective power loss in terms of the bending radius of the FBG is shown in Figure 3.9. The power loss was minimum for a radius of curvature higher than $25 \mathrm{~mm}$. For example, a reflective power loss of about $0.35 \mathrm{~dB}$ was observed at a radius of curvature of $20 \mathrm{~mm}$. Specifically as the radius reduces the power loss increases up to $7.76 \mathrm{~dB}$ for a radius of curvature of $9.5 \mathrm{~mm}$.

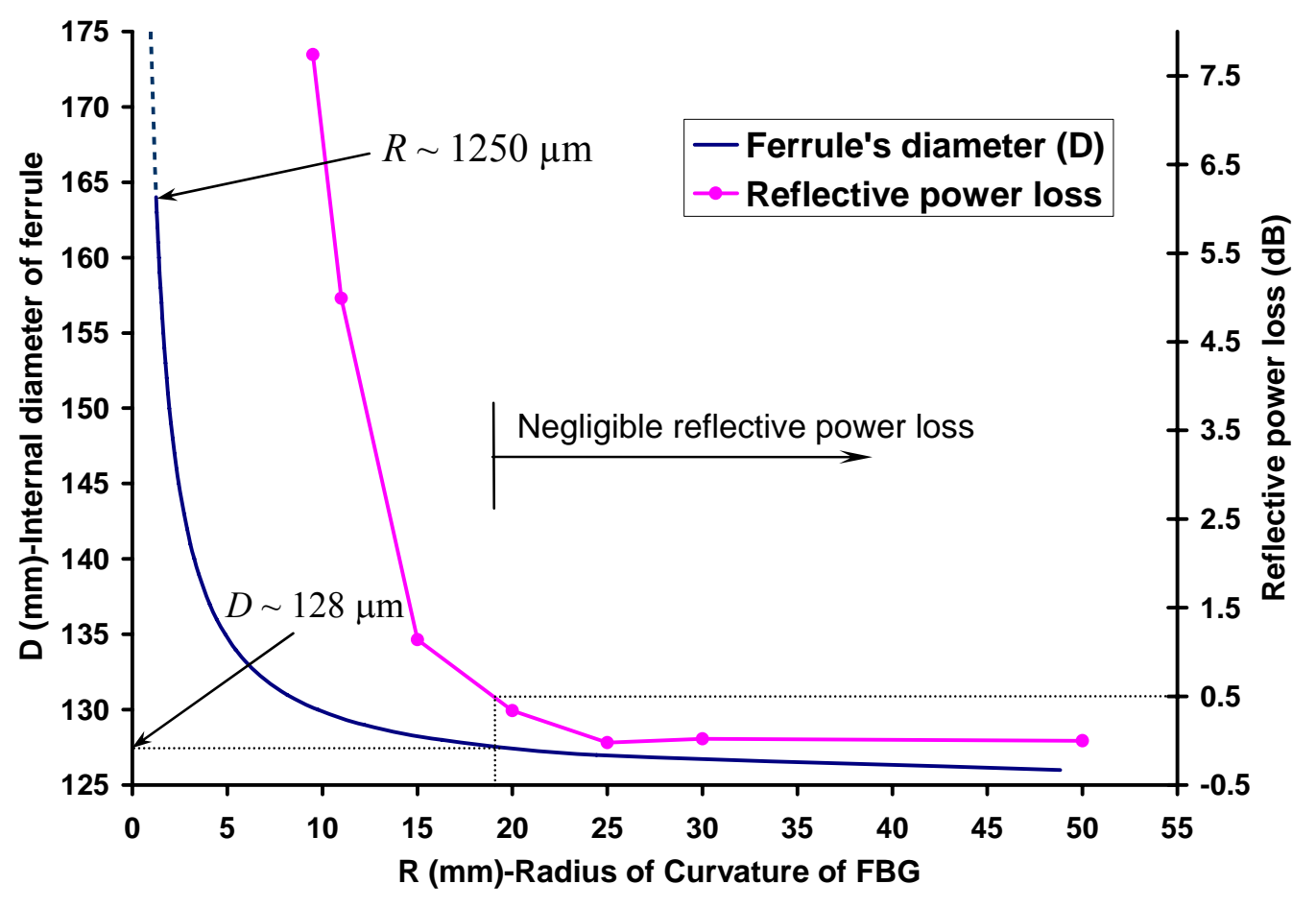

Figure 3.9: Effects of FBG Bending Radii on Reflective Power Loss.

The minimum radius of curvature of the fiber inside the ferrule can be obtained by letting $M$ in equation (3.6) as $M_{\max }$ and substituting equation (3.8) into equation (3.6), yielding

$$
R_{\min }=\frac{L_{b}^{2}}{V_{m} \pi^{2}}=\frac{1}{8 \varepsilon_{a x}} \frac{d^{2}}{D-d}
$$


Equation (3.12) is also plotted in Figure 3.9 for $d=125 \mu \mathrm{m}$ and $\varepsilon_{a x}=4 \%$. The figure shows how the radius of curvature $(R)$ of the fiber is related to the internal diameter $(D)$ of the guiding ferrule. The radius of curvature at which the stresses reach breaking tensile stress value of $700 \mathrm{MPa}$ is $1250 \mu \mathrm{m}(1.25 \mathrm{~mm})$, which is 10 times greater than the diameter of the optical fiber.

For an optical power loss less than $0.5 \mathrm{~dB}$ the radius of curvature should be more than about $20 \mathrm{~mm}$, which requires the internal diameter of the ferrule to be less than about $128 \mu \mathrm{m}$. This appears to be the upper limit of $D$ that can be used in the guiding system design discussed. Note that when $\mathrm{D}=127 \mu \mathrm{m}$, the minimum radius of curvature of the optical fiber inside the guiding ferrule, calculated from equation (3.12), was $24.4 \mathrm{~mm}$.

\subsubsection{Shortening Due to Waving}

Shortening $\Delta L_{w}$ is the decrease in the distance between two fixed ferrules due to buckling (which theoretically occurs without any change in the axial strain in the fiber). For the in-plane buckling the shortening due to one wave, $\Delta L_{w s}$, can be calculated from

$$
\Delta L_{w s}=2 \int_{0}^{0.5 L_{b}} \frac{1}{2}\left(\frac{d v}{d x}\right)^{2} d x
$$

After substituting equation (3.7) to equation (3.13a) and integrating it, we get

$$
\Delta L_{w s}=\frac{1}{4} \frac{\pi^{2} V_{m}{ }^{2}}{L_{b}}
$$

The shortening for the total length of FBG will be:

$$
\Delta L_{w}=\Delta L_{w s} \frac{L_{o}}{L_{b}}=L_{o} \varepsilon_{a x}\left(\frac{D}{d}-1\right)^{2}
$$


and the corresponding measured axial strain due to waving is:

$$
\varepsilon_{w}=\frac{\Delta L_{w}}{L_{o}}=\varepsilon_{a x}\left(\frac{D}{d}-1\right)^{2}
$$

Equation (3.13d) is plotted in Figure 3.10 for $d=125 \mu \mathrm{m}$ and $\varepsilon_{a x}=4 \%$. The graph shows a parabolic variation of $\varepsilon_{w} / \varepsilon_{a x}$ with respect to $D$. For $D=164 \mu \mathrm{m}$, i.e. the condition at which the stresses reach breaking tensile stress value of $700 \mathrm{MPa}$, the value of $\varepsilon_{w} / \varepsilon_{a x}$, is 0.097 . For a value of $D=127 \mu \mathrm{m}, \varepsilon_{w} / \varepsilon_{a x}=0.00026$.

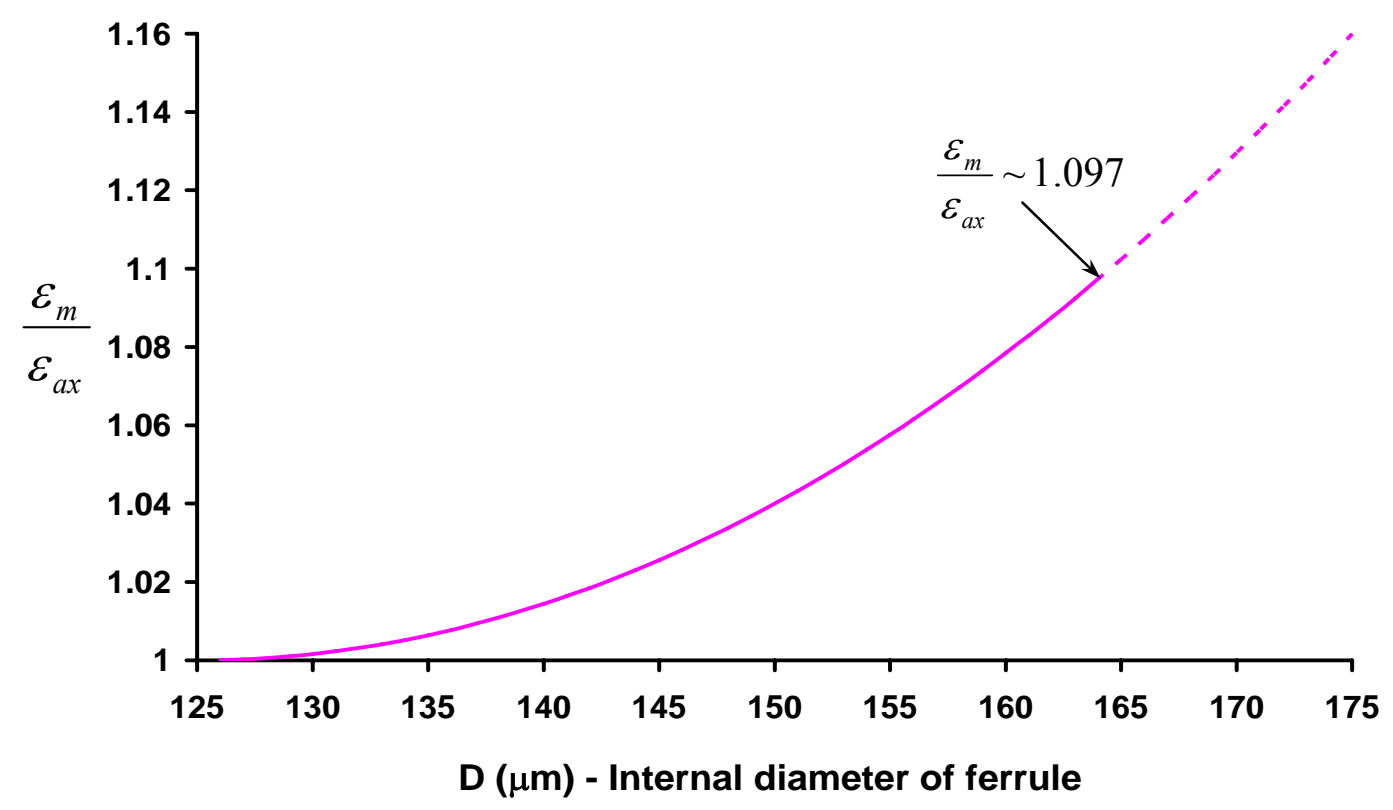

Figure 3.10: Effect of Fiber's Waving on the $\frac{\varepsilon_{m}}{\varepsilon_{a x}}$ Ratio.

\subsubsection{Poisson's Effect}

Due to compression of the fiber its diameter will increase according to: 


$$
\frac{\Delta d}{d}=-v \varepsilon_{a x}
$$

where the Poisson's ratio (v) for optical fiber is 0.165 [12-17].

For $4 \%$ axial strain, the diameter of optical fiber $(d)$ will increase from $125 \mu \mathrm{m}$ to 125.8 $\mu \mathrm{m}$. Therefore, the minimum admissible ferrule's diameter $(D)$ should be about $126 \mu \mathrm{m}$. Combining it with the findings from previous sections, one should conclude that $D$ should be within the range of $126-128 \mu \mathrm{m}$.

\subsubsection{Shortening due to Glue Deformation}

There is some axial motion of the fiber inside the fixed ferrules due to deformation of the glue (Figure 3.2(b)). It is assumed that the glue's deformation is elastic i.e. it is proportional to the axial force exerted on the fiber. According to this assumption,

$$
\varepsilon_{g}=\alpha \varepsilon_{a x}
$$

where $\alpha$ is a coefficient of proportionality which can be determined experimentally. In Chapter 4 the validation of this assumption will be given.

\subsubsection{Effect of Misalignment of Ferrules}

Misalignment between the middle and end ferrules will cause the optical fiber to bend, which can result in optical power loss.

Equation (3.12) can be rewritten as

$$
R_{\min }=\frac{L_{b}^{2}}{V_{m} \pi^{2}}=\frac{1}{8 \varepsilon_{a x}} \frac{d^{2}}{D_{m}-d}
$$


where

$$
D_{m}=D+K_{m}
$$

and $K_{m}$ is the misalignment between the two ferrules.

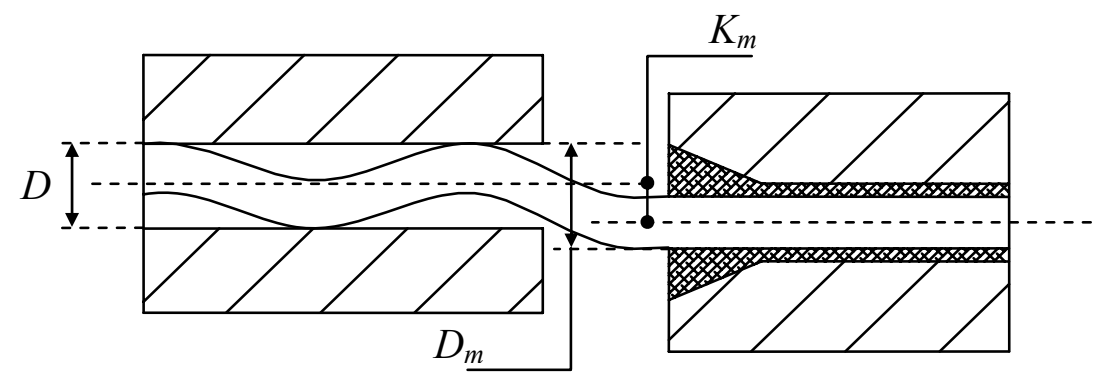

Figure 3.11: Misalignment Between Ferrules.

The reflective power loss in terms of the bending radius of the FBG is shown in Figure 3.12. Substituting the value of $D_{m}$ from equation (3.17) into equation (3.16) and plotting in Figure 3.12 for $d=125 \mu \mathrm{m}$ and $\varepsilon_{a x}=4 \%$. The figure shows how the radius of curvature $(R)$ of the fiber is related to the misalignment between the ferrules. The misalignment $\left(K_{m}\right)$ at which the stresses reach breaking tensile stress value of $700 \mathrm{MPa}$ is $37 \mu \mathrm{m}$. For an optical power loss less than $0.5 \mathrm{~dB}$ the radius of curvature should be more than about $20 \mathrm{~mm}$, which requires that $K_{m}$ be not more than $1 \mu \mathrm{m}$. 


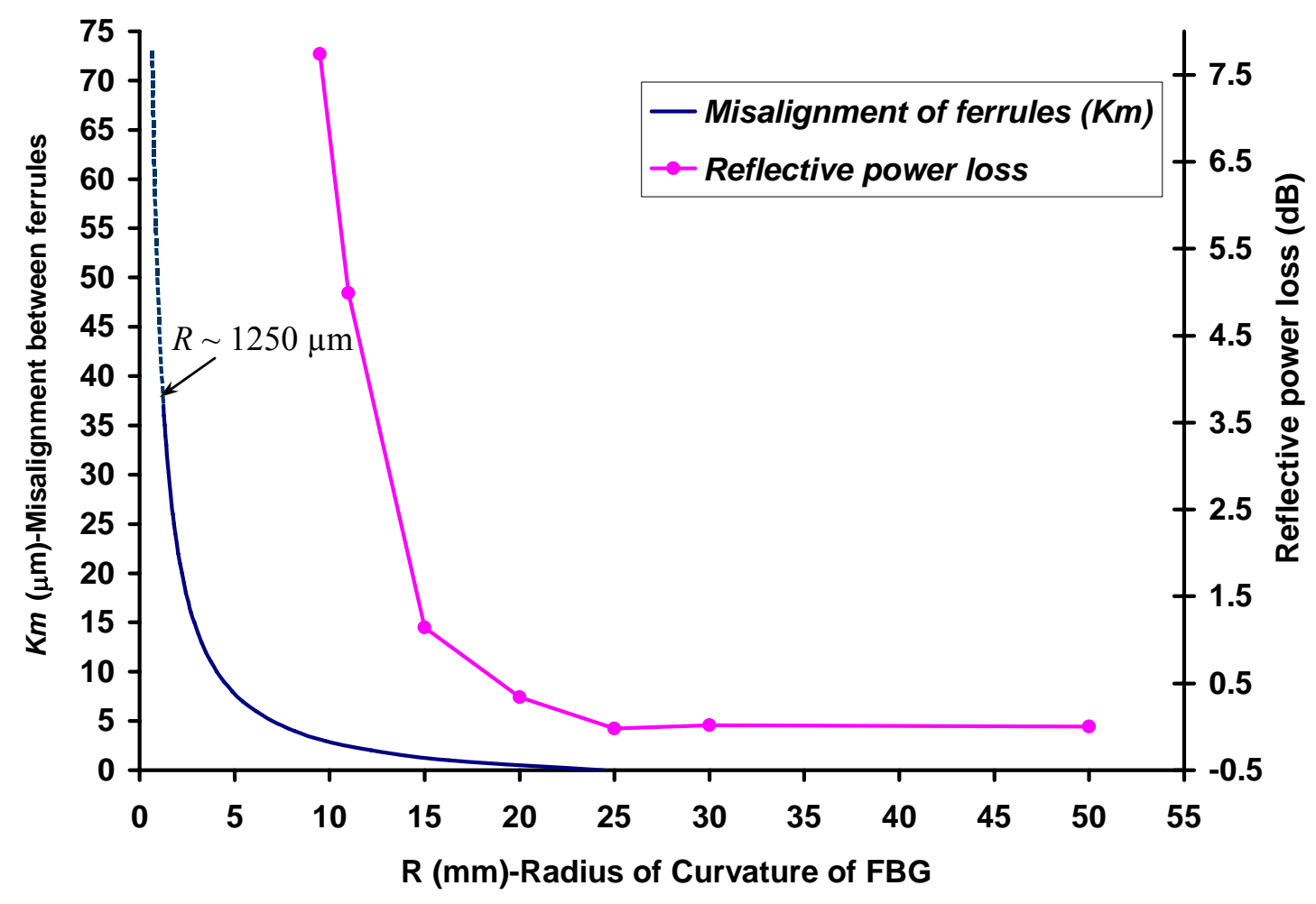

Figure 3.12: Effects of Ferrules' Misalignment on Reflective Power Loss.

\subsection{Guiding System Design Details}

Based on the theoretical and experimental analysis described above, the guiding system is designed for both axial stretching and compression of FBG. The design is basically divided into two systems: (1) Ferrule system design and (2) Mechanical design.

\subsubsection{Ferrule System Design for Stretching}

Figure 3.13 shows the ferrule system design, which has been designed and realized for stretching of optical fibers. It is composed mainly of two ceramic ferrules (Microlap Technologies Inc.,USA). Ferrules were $12.7 \mathrm{~mm}$ in length. The outside and inside diameters of each ferrule were $2.5 \mathrm{~mm}$ and $127 \mu \mathrm{m}$, respectively. The ferrule was provided with an insertion hole around $0.5 \mathrm{~mm}$ in depth. 


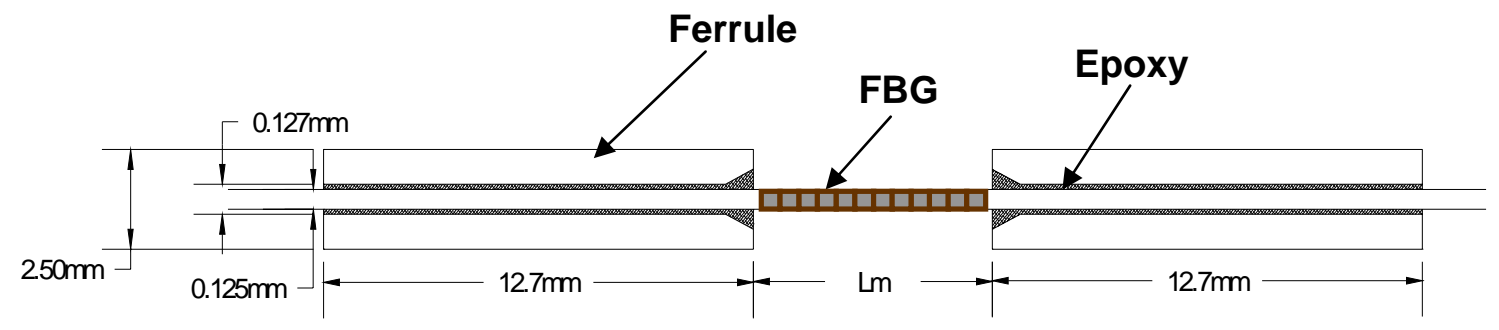

Figure 3.13: Schematic Diagram of Ferrule System for Stretching.

The diameter of the FBG without the polymer coating was $125 \mu \mathrm{m}$. The fiber was glued to the ceramic ferrule with a thermal curing epoxy resin. The length stretched was longer than the length of FBG so that the whole FBG is stretched and the stress distribution is uniform. Since the outside diameter of an optical fiber with the coating is around $245 \mu \mathrm{m}$ [44], the coating from one end of the optical fiber was totally removed up to the FBG so that the ferrule can be inserted. The coating material normally used is acrylic, which was removed by using a chemical stripper (Sulphuric acid). A chemical stripper was used instead of a mechanical stripper since mechanical stripping further reduces the mechanical strength of fiber Bragg gratings [45].

The epoxy used was EPO-TEK ${ }^{\circledR} 353$ ND, AngstromBond ${ }^{\circledR}$ (Fiber optic center Inc., New Bedford, USA). The epoxy has been widely used for packaging of fiber Bragg gratings. It has long curing time therefore the epoxy shrinks less and produces less additional stresses on the optical fiber. Also, the epoxy has low viscosity so that it can penetrate in the gap between the ferrule and the fiber. The gap between the ferrule and the fiber was $2 \mu \mathrm{m}$.

The process of gluing the optical fiber with the ferrule was done by using a Nikon SMZ1B microscope which gives a magnification of up to 231 times [46]. Since during fabrication of FBGs the positioning tolerance of the FBG is $\pm 0.5 \mathrm{~mm}$, therefore, for 12 $\mathrm{mm}$ of FBG the length stretched was around $13 \mathrm{~mm}$ to make certain that the whole grating is stretched. 


\subsubsection{Ferrule System Design for Compression}

Figure 3.14 shows the ferrule system design, which has been designed to minimize the bending of fiber Bragg grating under compression. It is composed mainly of three ceramic ferrules. The guiding ferrule is used mainly as a guide to minimize bending effects. The procedure of making the ferrule system in this case is the same as that for the stretching system. The only difference is that after gluing the ferrule A, guiding ferrule will be inserted followed by the other end ferrule. The dimensions of the end ferrules are the same as that for ferrule system in stretching.

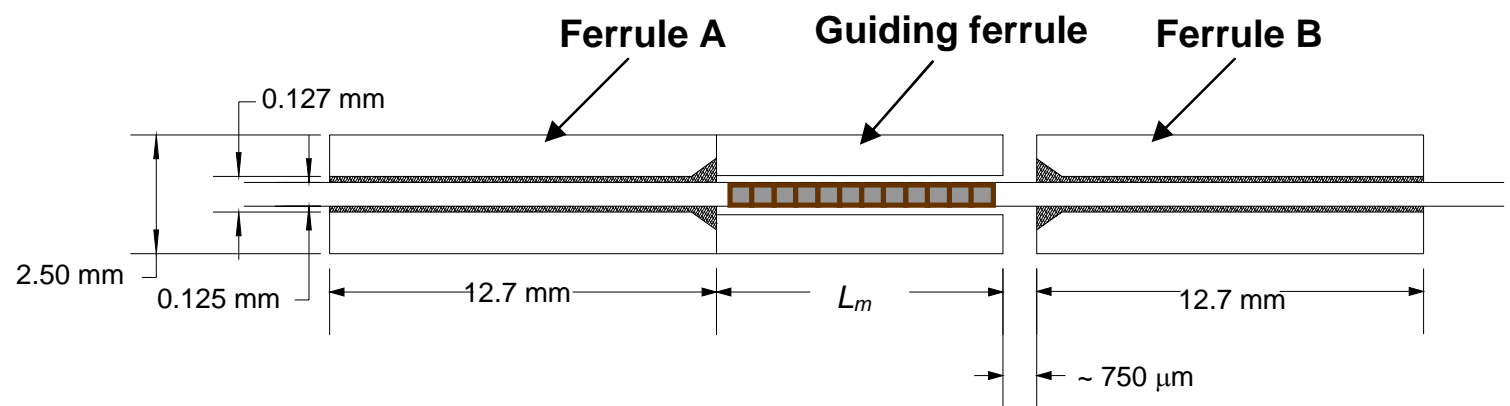

Figure 3.14: Schematic Diagram of Ferrule System for Compression

As mentioned in section 3.2, the unguided length of optical fiber should not be more than $0.5 \mathrm{~mm}$ to avoid buckling. The distance between the guiding ferrule and end ferrule $B$ ranged 0.75 to $1 \mathrm{~mm}$. The reason for keeping this distance was that during gluing, the epoxy may flow from end ferrule B and enter into the guiding ferrule. To compress 12 $\mathrm{mm}$ FBG, the guiding ferrule used was around $12.25 \mathrm{~mm}$ in length. So, the total compressed length in this case was $13 \mathrm{~mm}$.

\subsubsection{Epoxy Details}

EPO-TEK 353ND is a two component, 100\% solids, heat curing epoxy, designed for high temperature applications. It has excellent resistance to many types of solvents and 
chemicals and is ideal for bonding fiber optics, metals, glass, ceramics and most plastics. It changes color from amber to red upon cure. The epoxy has two components: Part A (epoxy resin), and Part B (hardener). The suggested mixing ratio to be used was $\mathrm{A}: \mathrm{B}=10: 1$ (parts by weight) [47].

\subsubsection{Calculation of Shear Strength of Epoxy}

The lap shear strength of EPO-TEK 353ND epoxy is $13.79 \mathrm{MPa}$ and the modulus of elasticity is $3 \mathrm{GPa}$ [47]. The lap shear strength ensures the force/motion transmission between the ferrules and the fiber. It acts tangential to the surface of the material. The size of glue length required for the transmission of force can be calculated.

This calculation is for both stretching and compression of FBG. Note that the axial strain of about $4 \%$ is needed to get Bragg wavelength shift of about $45 \mathrm{~nm}$. The axial force on the optical fiber $\left(F_{n d}\right)$ is given by

$$
F_{n d}=A \cdot E \cdot \varepsilon_{z}
$$

where

$A=$ cross-sectional area of the optical fiber $=0.01227 \mathrm{~mm}^{2}$,

$E=$ Modulus of elasticity of the optical fiber $=72.5 \mathrm{GPa}$, and

$\varepsilon_{z}=$ Axial strain $=0.04$.

This is the force which is to be transmitted through shear stress. Therefore, we have:

$$
\begin{aligned}
& F_{n d}=\tau_{g} A_{g} \\
& A_{g}=2 \pi r L_{\text {min }} \\
& L_{\text {min }}=\frac{F_{n d}}{2 \pi r \tau_{g}}
\end{aligned}
$$

where 
$\tau_{g}=$ Lap shear strength of epoxy resin $=13.79 \mathrm{MPa}$

$r=$ Radius of optical fiber $=62.5 \mu \mathrm{m}$

$L_{\text {min }}=$ Length of area in contact

From equation (3.19) $L_{\min }$ required is $6.6 \mathrm{~mm}$. In the ferrule system, both end ferrules were fully glued with the fiber with a glued length on each side of $12.7 \mathrm{~mm}$. After the gluing procedure was finished, the guiding system was positioned in the V-groove on the mechanical device and finally fixed by screws.

\subsubsection{Gluing Optical Fiber with Ferrule}

In order to glue the optical fiber to the ferrule, coating from one side of the optical fiber was removed so that it can pass through the ferrule. Some portion of coating from the other side of optical fiber was also removed to allow space for the other ferrule to be glued. The optical fiber was first cleaned by using Methanol and then it was inserted into the ferrule. The optical fiber was then clamped by using the clamps as shown in Figure 3.15 .

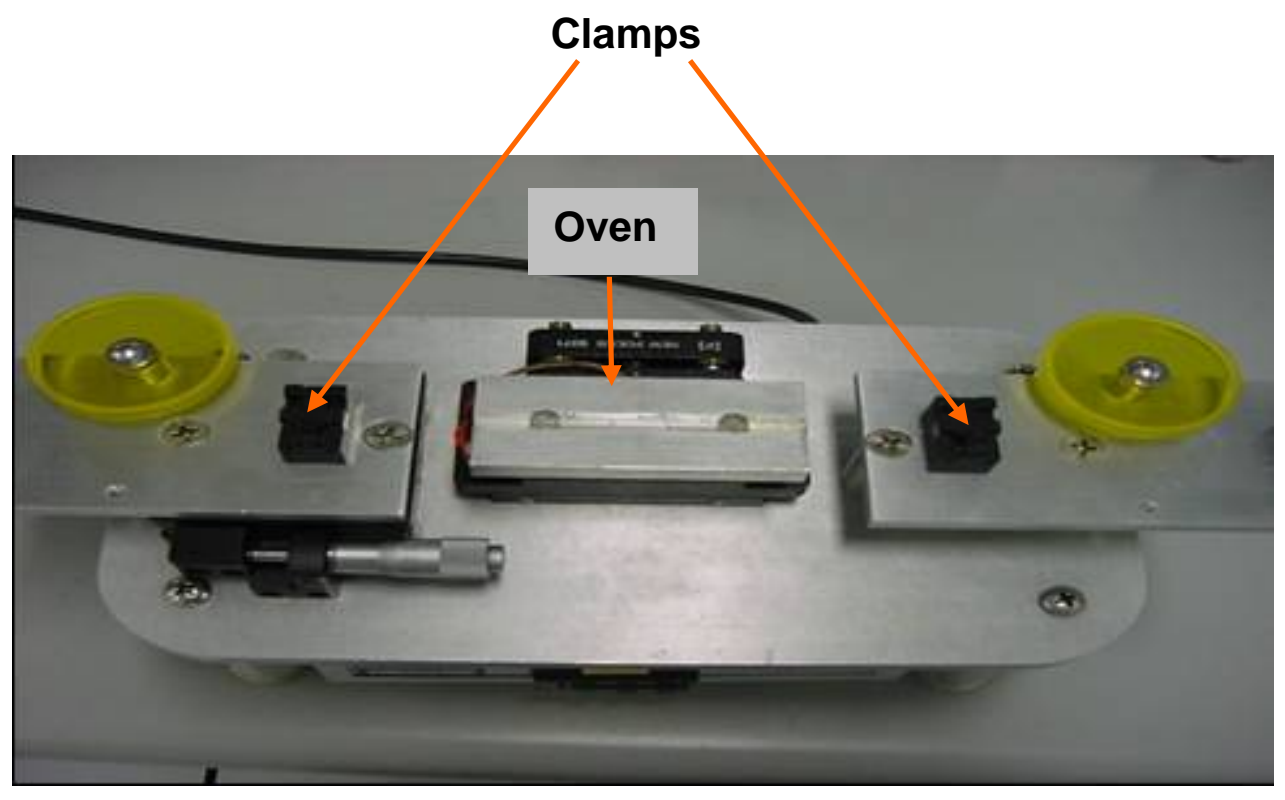

Figure 3.15: The Oven System 
The epoxy was applied to fix the optical fiber to the ferrules at specified positions (Figure 3.13). In order to cure the epoxy an oven was also provided in the stage shown in Figure 3.15. The curing procedure was as described in [47]. First, the oven was maintained at $85{ }^{\circ} \mathrm{C}$ for 30 minutes and the temperature was raised to $100{ }^{\circ} \mathrm{C}$ for 30 minutes, and then the temperature was raised to $120^{\circ} \mathrm{C}$ for 30 minutes. Finally, the oven was put off and the system was allowed to cool down to room temperature.

\subsubsection{Mechanical Design for Stretching}

In this design two translation stages were used as shown in Figure 3.16. The description is as follows:

1. All parts were attached to a common base as shown in Figure 3.16. Two single-axis translation stages (Melles Griot, 07 TAS 504 slide drive aluminum translation stage with ball bearing [48]) were used. These translation stages had a travel of $13 \mathrm{~mm}$ with resolution better than $3 \mu \mathrm{m}$ [48]. The translation stage A was placed to provide adjustment in the Z-direction by using a micrometer head while translation stage $\mathrm{B}$ was connected to a PZT actuator to provide axial strain to the FBG.

2. A single V-groove plate was manufactured and then cut into two pieces so that both V-grooves will have similar dimensions which will minimize misalignment effects. Each V-groove plate was mounted on each of the translation stages. The purpose of the $\mathrm{V}$-groove is to fix the ferrule system explained above. Since the ferrule system contains two ferrules, each ferrule was mounted on each V-groove and clamped by using top plates as shown in Figure 3.16.

3. It is suggested that PZT stack actuators must only be stressed axially. Tilting and shearing forces should be avoided since these forces can damage the actuator and reduce the efficiency. Tilting and shearing forces can be avoided by use of ball tips 
and flexible tips [49]. Therefore, a translation stage was used to eliminate any tilting and to provide a ball contact with the actuator which is normally suggested [49].

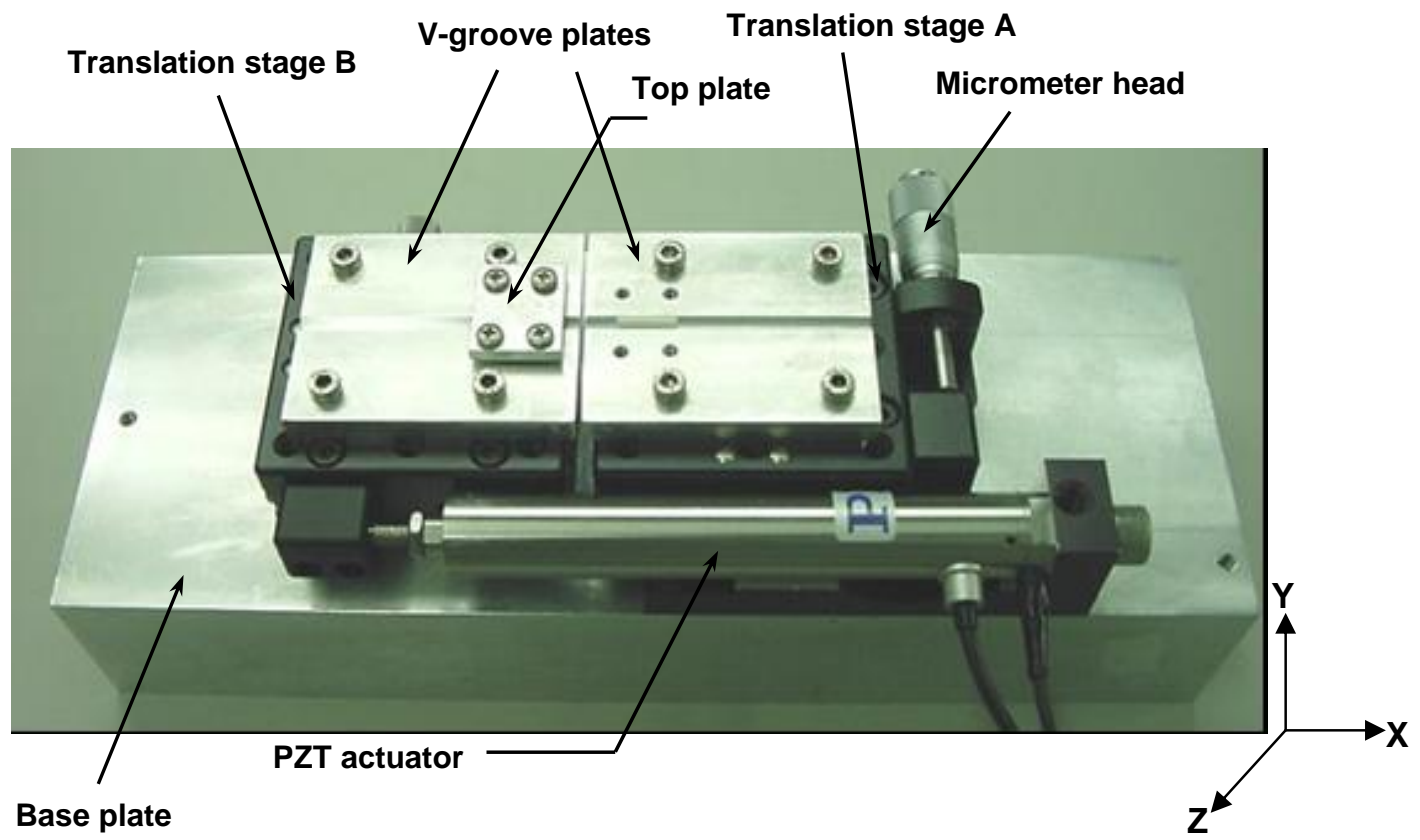

Figure 3.16: Mechanical Design for Stretching of FBG

4. The translation stage block is a single axis translation stage which consists of two parts, bottom fixed part and upper moving part. A ball bearing was used between the moving and fixed parts of the stage to provide smooth and accurate linear motion. Also, the translation stage was spring-loaded to facilitate good contact with the PZT actuator [48]. The tip of the PZT actuator was in touch with the moving part of translation stage $B$ with a ball tip to move it away from translation stage A to facilitate the stretching of optical fiber. PZT actuator was mounted as shown in the Figure 3.16.

5. A small threaded cylindrical piece of aluminum was also mounted on the tip of the PZT actuator (which was also provided with a small hole on the top) which comes in contact with the ball tip mounted on the translation stage B as shown in Figure 3.17. The location of the threaded cylinder is fixed by using a nut. This mechanism is used 
to vary the position of the PZT to adjust the distance between the translation stage and fixed stage before starting the experiment.

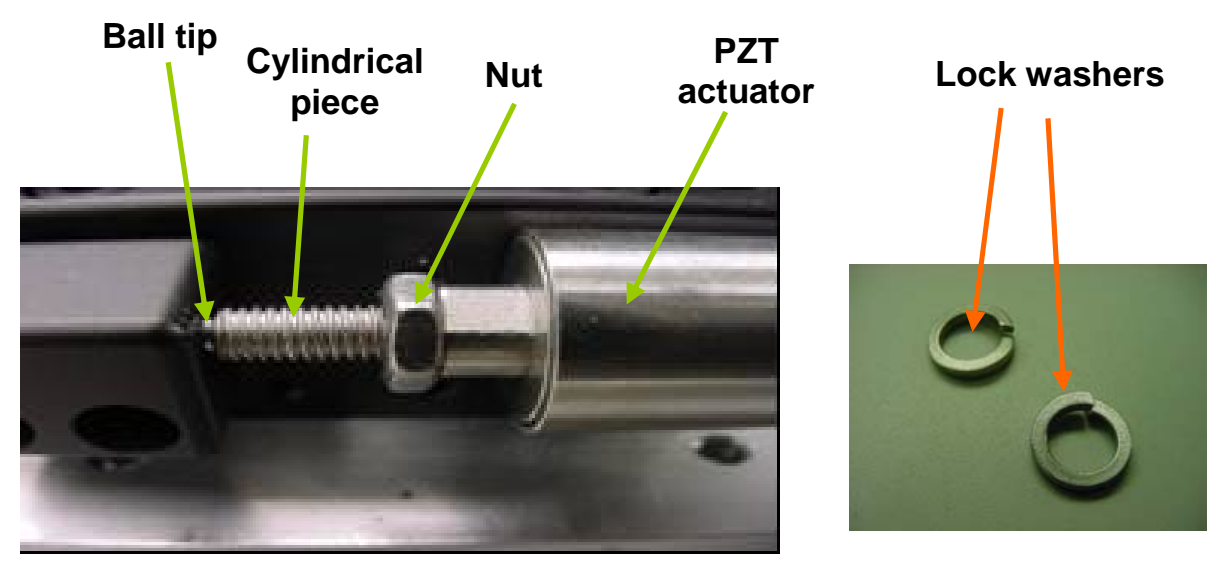

Figure 3.17: Adjustment for the PZT Actuator.

\subsubsection{Mechanical Design for Compression}

The PZT actuator used in the experiments gives a total displacement of 120 um which corresponds to a FBG strain of about $1 \%$ and a wavelength shift of about $12 \mathrm{~nm}$. In order to achieve the required axial strain of $4 \%$, a displacement of about $500 \mathrm{um}$ is required. With the PZT actuator available, there is a need to have an amplification mechanism. In this thesis, the focus was on achieving such range of compression and not on the dynamic behavior of the component which actually does the compression. Therefore, a micrometer screw gauge was used which can certainly achieve more than $500 \mu \mathrm{m}$ range of compression. The PZT actuator was still used for the stretching and compression for up to $1 \%$ strain. 


\subsubsection{V-grooves System with the PZT Actuator}

During the stretching of the FBG, misalignment in V-grooves may cause the minimum optical power loss. But during the compression of the FBG, misalignment in the Vgrooves can cause significant misalignment of the ferrules and hence result in the bending of the FBG (see discussion in Section 3.2). V-grooves have to be properly aligned. This is achieved by designing the following process/procedure:

1. Two translation stages were used as shown in Figure 3.18. Specifically, translation stage A was placed to provide an adjustment in the Z-direction while translation stage B was connected to the PZT actuator to provide axial strain of the optical fiber.

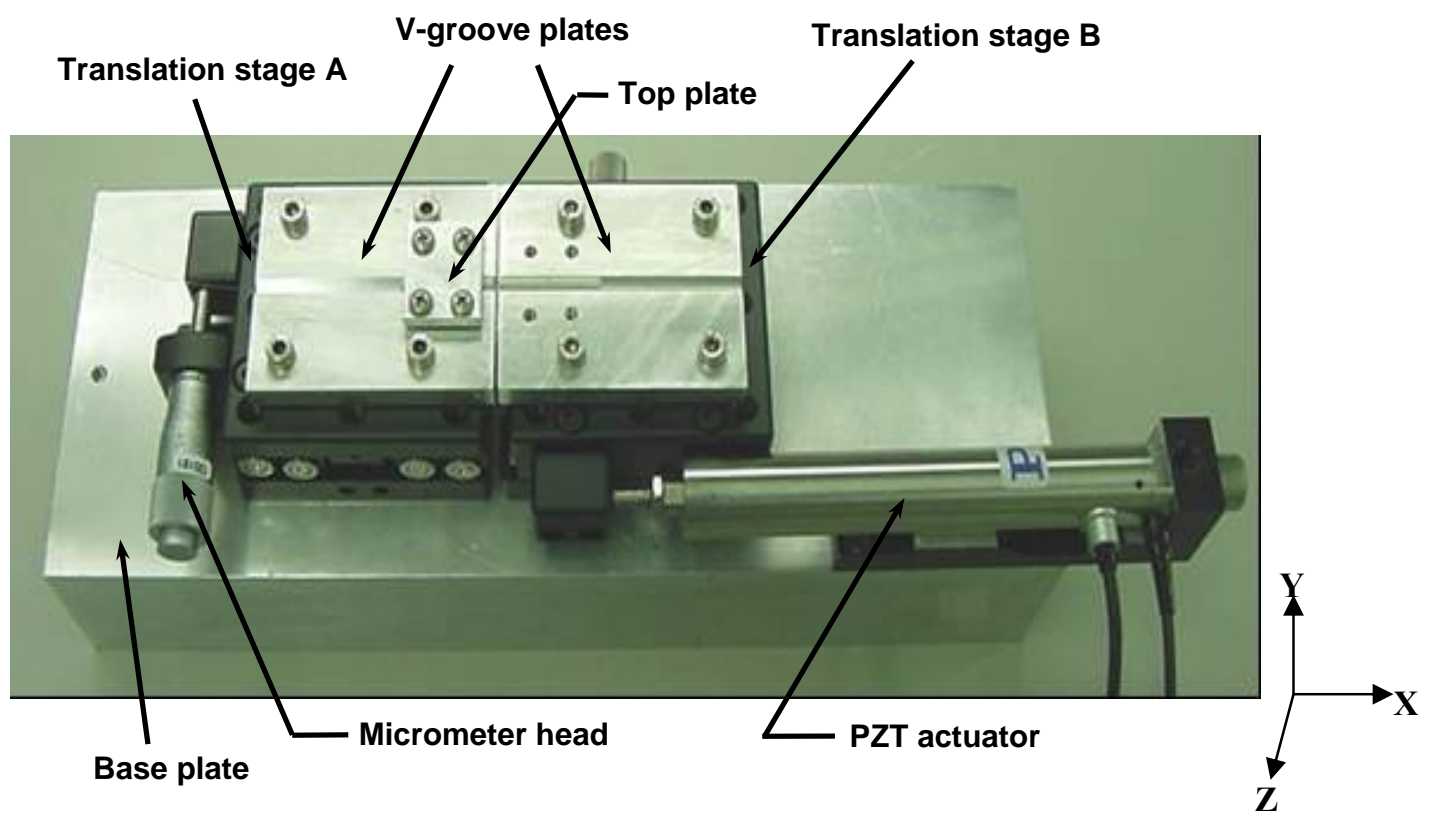

Figure 3.18: Mechanical Design for Compression of FBG Using PZT Actuator.

2. Some lock washers were provided between the translation stages and the Vgroove (the V-groove plate was attached on top of the translation stages) so that any misalignment in the Y-direction can be adjusted. Both translation stages 
were fixed to the base. The PZT was mounted in a similar way to that of mechanical stretching of the optical fiber to avoid any tilting and shear forces. The ferrule system in this case was the same as in the compression design except that two ferrules on each V-groove (there were two). This consideration was to ensure that the $\mathrm{V}$-groove plate would not overturn around the z-axis (see Figure $3.18)$.

\subsubsection{V-grooves System with Micrometer Head}

In this case the PZT actuator is replaced by a micrometer head so that a long travel and thus more compression of the FBG can be achieved (Figure 3.19). The micrometer head was attached to the fixed part of the translation stage and the tip of the micrometer head was in contact with the ball tip which was further attached to the moving part of the translation stage. The micrometer head used can provide a travel of $13 \mathrm{~mm}$. The least movement resolution of the micrometer head was $10 \mu \mathrm{m}$.

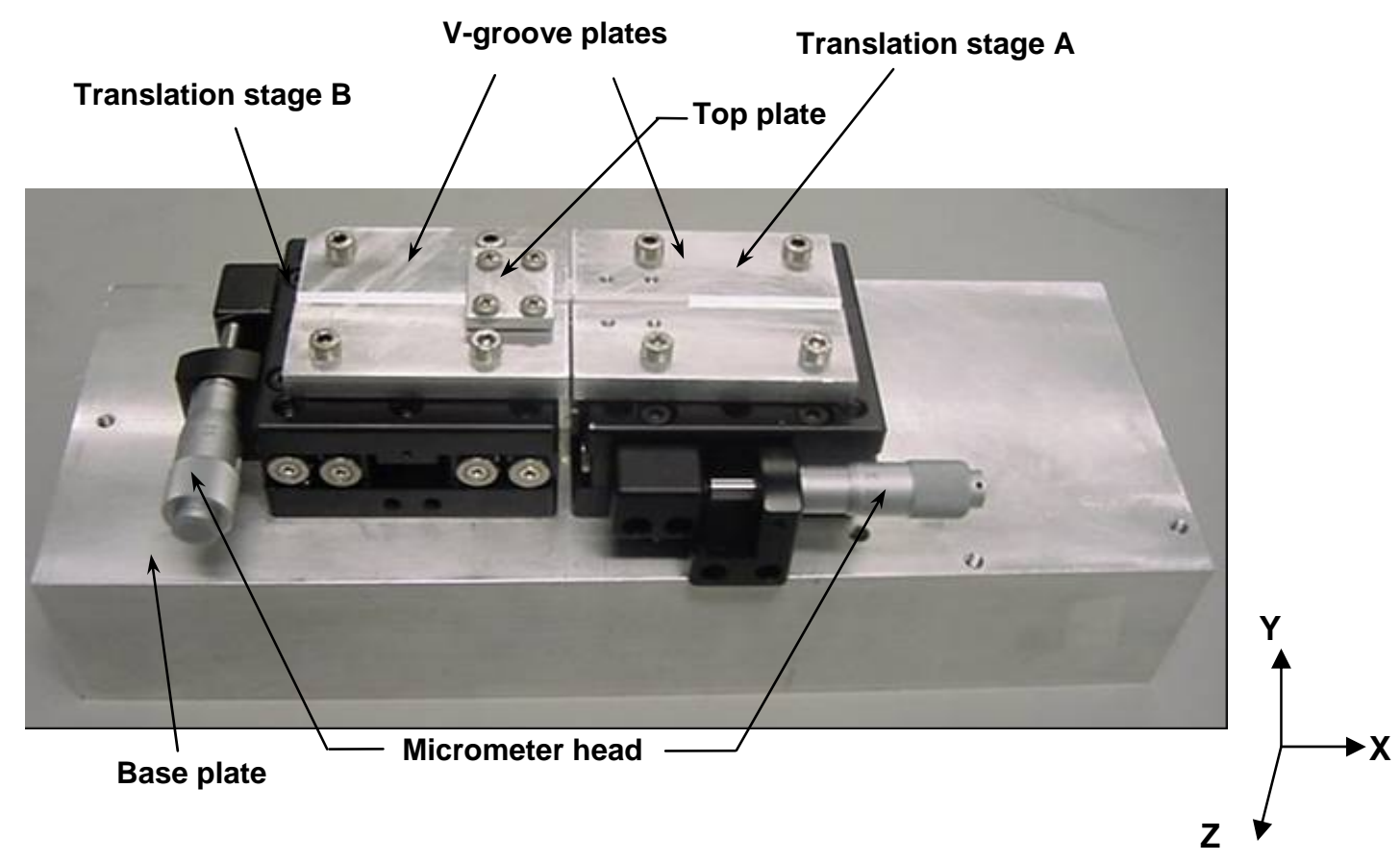

Figure 3.19: Mechanical Design for Compression of FBG Using Micrometer Head 
Before starting the compression test the $\mathrm{V}$-grooves were aligned by adjusting the location of translation stage B and also by adjusting the height of the V-groove plates since lock washers were provided between the $\mathrm{V}$-groove plates and the translation stage. The alignment of the V-grooves was tested by mounting two ferrules (not glued to the fiber) on each of the translation stages and then the optical fiber was passed through hole of the ferrules. The error was only $2 \mu \mathrm{m}$, which was the difference between the internal diameter of the ferrule and the diameter of the optical fiber. This is again the rationale for choice of the internal diameter (D) of ferrules (i.e., $\mathrm{D}=127 \mu \mathrm{m}$ ).

\subsection{Summary}

Based on theoretical and experimental analyses a device was designed for axial tension/compression of FBGs. Experimental analysis showed that the radius of curvature of more than $20 \mathrm{~mm}$ is required to keep the optical power loss to less than 0.5 dB. Ceramic ferrules of 127 um inside diameter were used to minimize the bending of FBGs which corresponds to a radius of curvature of $24 \mathrm{~mm}$ for $4 \%$ compression. The guiding system was mounted on V-grooves and the V-grooves were mounted on translation stages which can be adjusted in the horizontal and vertical axes to minimize misalignment. The PZT actuator was used for fast and accurate tuning of the FBG which had a limited displacement of 120 um ( $1 \%$ axial strain on FBG). To achieve $4 \%$ compression, a micrometer screw gauge was used. 


\section{EXPERIMENTAL STUDY}

\subsection{Introduction}

This chapter presents an experimental study of a tunable FBG device. The main purpose of the experimental study was to verify the design presented in Chapter 3. Both the stretching and compression of the FBG fiber were examined. Both the PZT actuator and the micrometer screw gauge were used in the experiment. The length of fiber Bragg gratings depends upon its application. The length of fiber Bragg gratings varies from 1 $\mathrm{mm}$ to $11 \mathrm{~cm}$ or more [6-9]. In telecommunication and sensing systems the standard length currently in use is from $8 \mathrm{~mm}$ to $12 \mathrm{~mm}$. Fiber Bragg gratings of $12 \mathrm{~mm}$ were used in the present experiment. Section 4.2 presents the experiment set-up. Section 4.3 presents the experimental results with discussion. Section 4.4 summarizes the conclusions.

\subsection{Experiment Setup}

\subsubsection{Measurement Setup}

Figure 4.1 shows schematically the characterization set up in the reflection configuration. The description of the setup is as follows:

1. A Broad band light source (BBS) [50] was used which had a bandwidth range of 1500 to $1600 \mathrm{~nm}$. The output power was almost constant from 1520 to $1590 \mathrm{~nm}$ but there was a drop in power outside this range [50]. 
2. An optical spectrum analyzer (AQ6317B, ANDO Electric Corporation, Japan) was used to obtain the reflection spectrum of the light reflected from the FBG and to measure the wavelength shift of the Bragg wavelength $\left(\lambda_{B}\right)$ when the FBG is axially tuned. The measurement wavelength range of OSA was from 600 to $1750 \mathrm{~nm}$ and the maximum resolution was better than $0.015 \mathrm{~nm}$. Wavelength accuracy was within $\pm 0.02 \mathrm{~nm}[51]$.

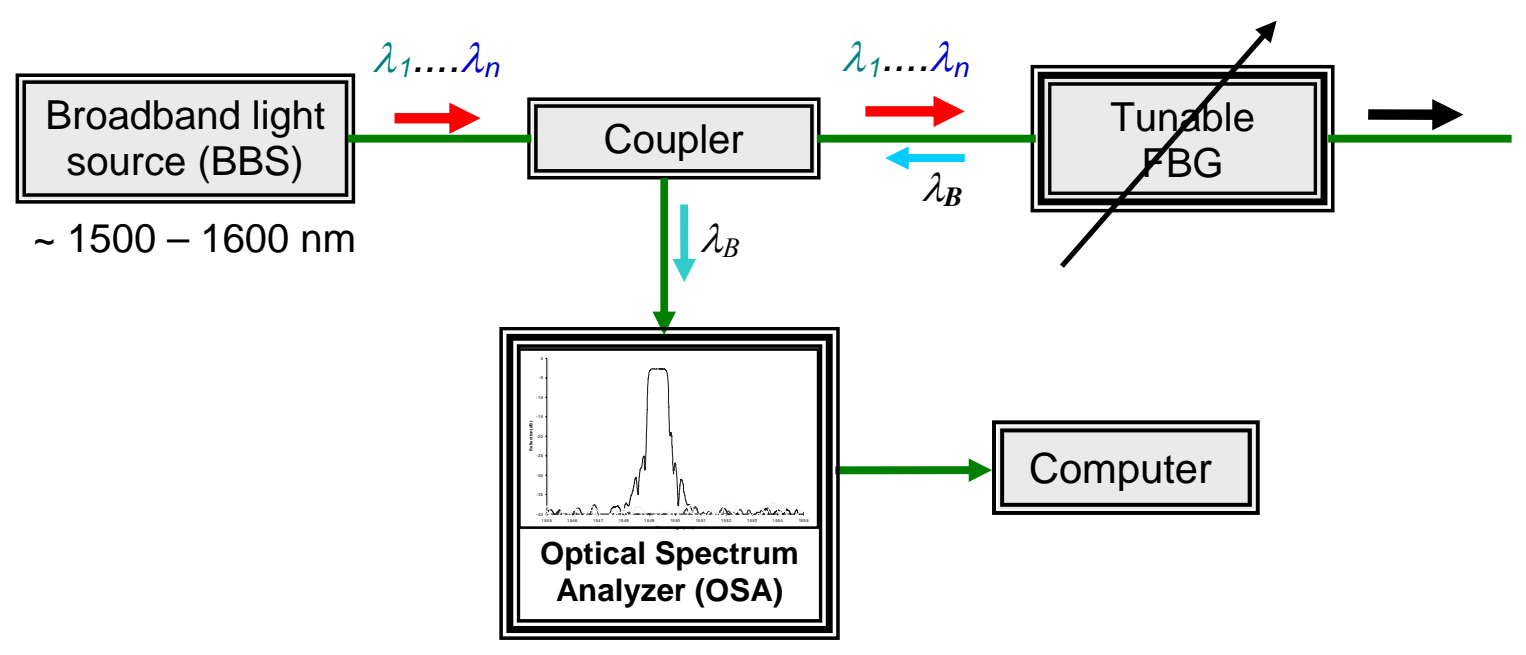

Figure 4.1: Schematic Diagram of Experimental Setup

3. A coupler was used to separate the light waves reflected from the FBG [1]. The coupler used was manufactured by MPB Communications Inc, Montreal,Canada.

4. The tunable FBG consists of the ferrule system, the mechanical system, and the PZT actuator as explained previously.

5. The BBS sends the light which passes through the coupler and reaches the FBG. The FBG reflects the Bragg wavelength $\left(\lambda_{B}\right)$ and lets the light waves on the other wavelengths to pass through uninterrupted. The reflected wavelength then goes back to the coupler, where it is separated from the other light waves, and is sent 
towards the OSA where the reflection spectrum can be seen. The OSA was connected to a computer (PentiumIII, $950 \mathrm{MHz}$ ) through a serial port so that the reflection spectrum data can be saved.

\subsubsection{FBG Tuning}

A tunable FBG consists of the ferrule system, the mechanical system, and a PZT actuator. The ferrule and mechanical systems for stretching and compression were explained previously. The PZT actuator was used for actuating the FBG tuning process as well as for achieving a high tuning speed and tuning accuracy.

Piezo-translators are electrically controllable actuators working on the basis of the piezo effect, from the Greek word for pressure "piesh". In 1880, Jacques and Pierre Curie discovered that a pressure on a quartz crystal creates an electrical charge. Later they also verified that an electrical field applied to the crystal leads to a material deformation, the inverse piezo effect [52].

Modern actuators, based on lead zirconate titanate ceramics ( $\mathrm{Pb}(\mathrm{Zr}, \mathrm{Ti}) \mathrm{O} 3)$ ( $\mathrm{PZTs}$ ), permit very precise and repeatable movements at high frequencies. On the other hand, they can also be designed to move heavy loads, up to several tons, from the nanometer to the millimetre range [54]. Piezoelectric actuators are also suitable for switching applications.

The PZT stack actuator (Physik Instrumente, PI-176412 [49]) used in the experiment could provide a travel of around $120 \mu \mathrm{m}$. Similar to electromagnetic devices, PZT actuators exhibit hysteresis. The actuator expansion depends not only on the driving tension, but also on the previous operating voltages due to the remaining polarization. This hysteresis is in the order of 10 to $15 \%$ of the imposed displacement [49]. To achieve a high resolution in the piezoelectric actuator positioning and to minimize the 
hysteresis, high voltage amplifier and PZT servo controller (Physik Instrumente, E471.00) were used $[55,56]$.

Figure 4.2 shows the schematic diagram of the data acquisition system. The amplifier output range was from 0 to $1000 \mathrm{~V}$. The servo controller was connected to a computer by using a DAQ board which was connected to a PCI board in the computer. Special routines have been developed using LabView software to drive the PZT actuator. A Computer (PentiumIII, $950 \mathrm{MHz}$ ) was used to control the amplifier/controller. The amplifier/controller was connected to a Data acquisition board (National Instruments Corporation, SCB-68) which was connected to the computer by using an interface card (National Instruments Corporation, 6052E).

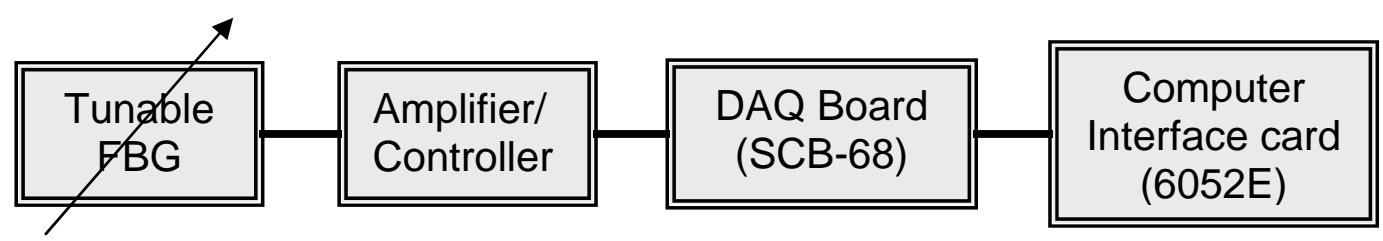

Figure 4.2: Schematic Diagram of Data Acquisition System.

The interface card can acquire data at a rate of up to 330 kilo samples/second. The input to the amplifier was from 0 to $10 \mathrm{~V}$, which was amplified from 0 to $1000 \mathrm{~V}$ to enable the PZT actuator to travel to its full extent $[55,56]$. The accuracy in the actuator positioning was better than $2 \%$ of the imposed displacement. Both stretching and compression tests were done by using the PZT actuator. The PZT actuator used had a maximum travel range of about $120 \mu \mathrm{m}$ which can give a Bragg wavelength shift of around $10 \mathrm{~nm}$ for a stretch/compress FBG length of $12 \mathrm{~mm}$. The time the PZT actuator required to travel its full range of $120 \mu \mathrm{m}$ was about 7 millisecond as shown in Figure 4.3. For a stretching/compression length of $13 \mathrm{~mm}$ of optical fiber, the tuning speed calculated was about $1.5 \mathrm{~nm} / \mathrm{ms}$. A tuning speed of $0.032 \mathrm{~nm} / \mathrm{ms}$ was reported in [24] for a compression length of $30 \mathrm{~mm}$ using a stepper motor. Also, a tuning speed of $19 \mathrm{~nm} / \mathrm{ms}$ was reported in [11] for a compression length of $1 \mathrm{~mm}$ using a PZT actuator. 


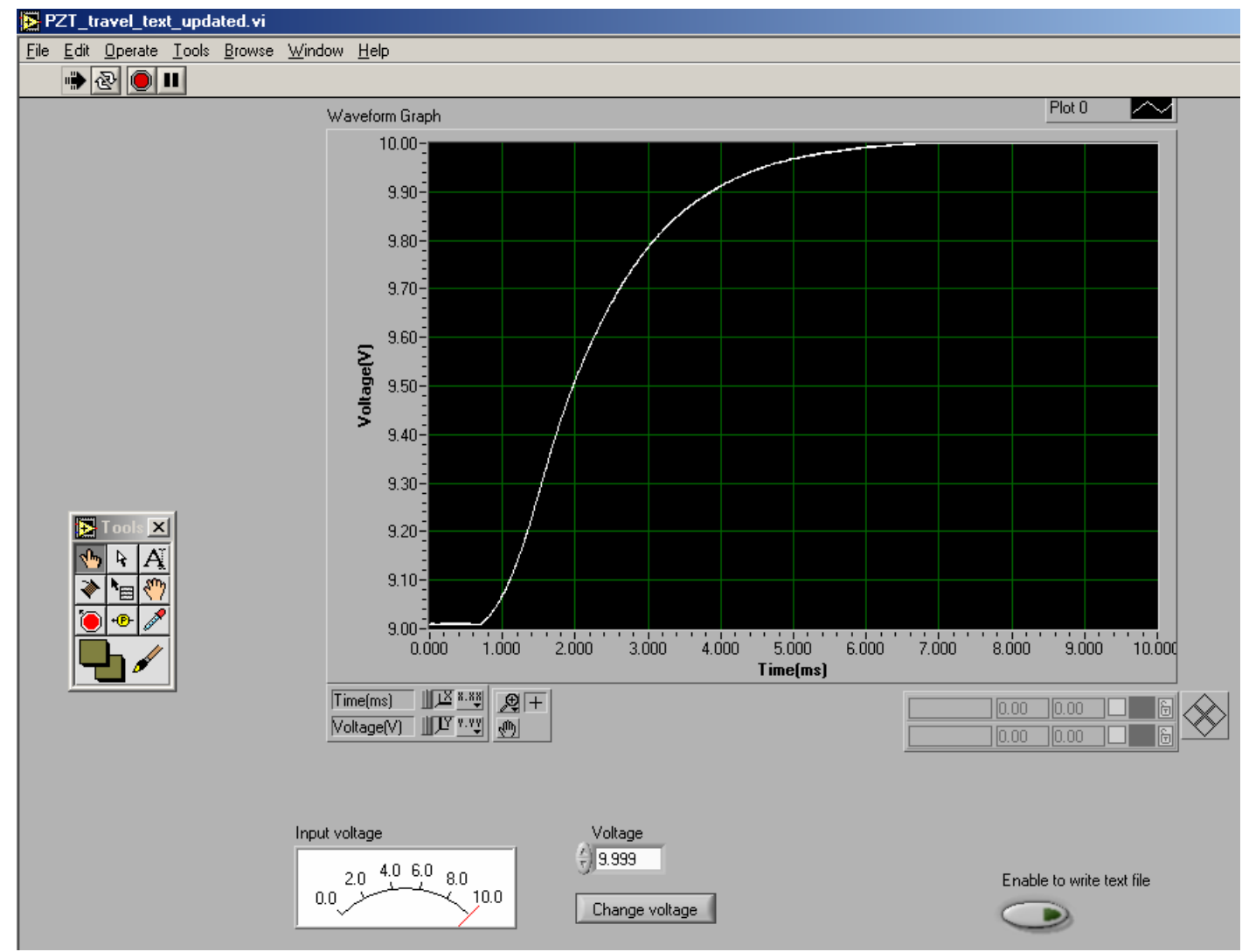

Figure 4.3: PZT Actuator Travel Using LabView Software.

A micrometer head (Melles Griot Inc.[48]) was also used as an actuator in order to achieve Bragg wavelength shift of more than $40 \mathrm{~nm}$ (actuator travel of more than 500 $\mu \mathrm{m})$. The micrometer head had a travel range of 0 to $13 \mathrm{~mm}$ with resolution better than $\pm 3 \mu \mathrm{m}[48]$. An overall view of the experimental setup can be seen in Figure 4.4. 


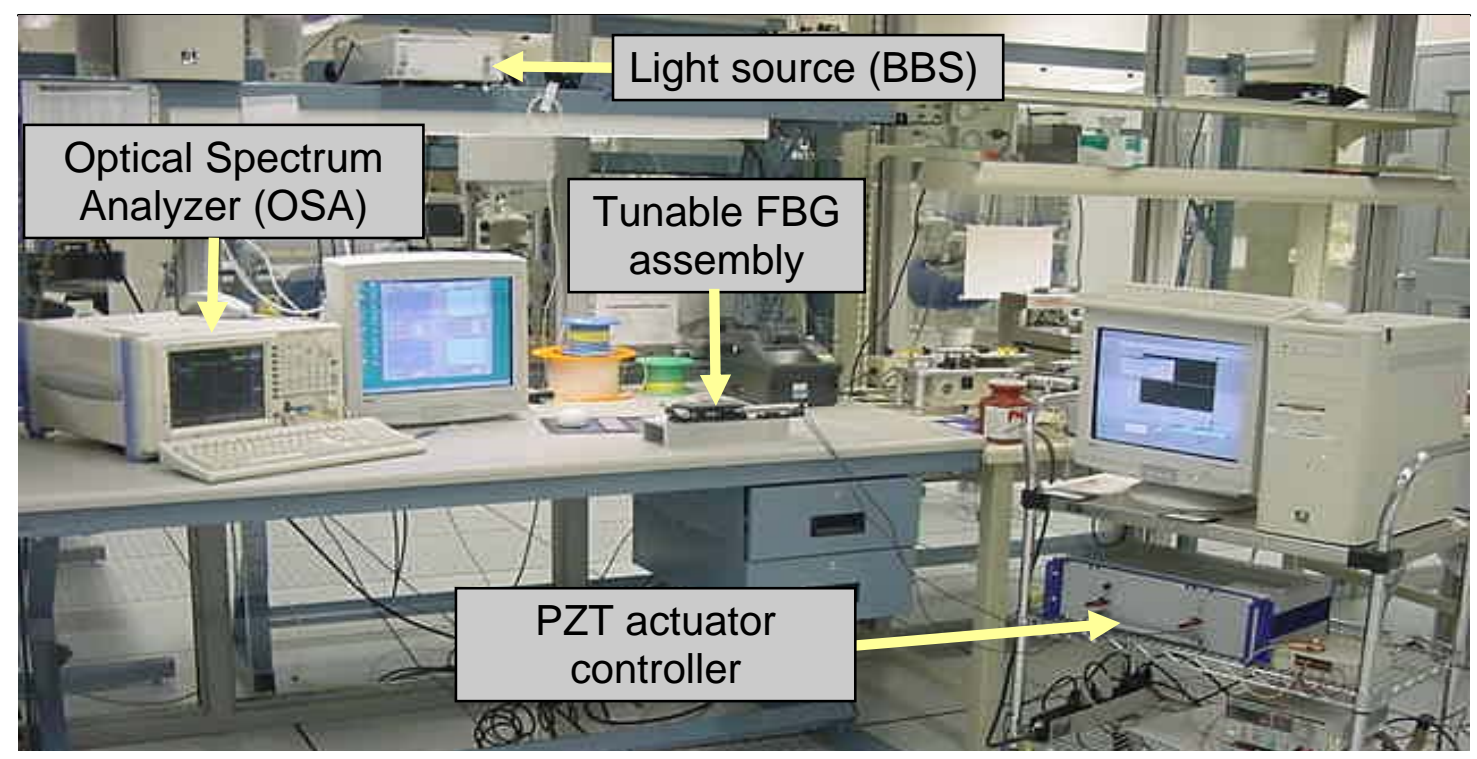

Figure 4.4: Experimental Setup for Tuning of FBG.

\subsubsection{FBG Fabrication}

A $12 \mathrm{~mm}$ long Bragg grating was fabricated in Boron/Germanium (B/Ge) co-doped optical fiber by exposing a standard telecommunication fiber (Corning, SMF28) to a 193 $\mathrm{nm}$ Argon-Fluorine (ArF) Excimer laser (ASX-750, MPB Communications Inc.,Montreal) through a uniform period phase mask [6, 7]. The period of the fiber Bragg grating $(\Lambda)$ is one-half of the phase mask period $\left(\Lambda_{\mathrm{pm}}\right)$. Therefore, the phase mask period selected depends upon the Bragg wavelength $\left(\lambda_{\text {Bragg }}\right)$ required on the optical fiber and can be calculated from equation (2.1).

Before writing the grating, the fiber was kept in a hydrogen loaded cylinder at a pressure of around 10.35 $\mathrm{MPa}$ for about 3 days at room temperature. This is to increase the sensitivity for writing the grating. After writing the grating, annealing was performed to stabilize the Bragg wavelength $\left(\lambda_{\text {Bragg }}\right)$ of FBG. In this case, the fiber was kept in an environmental chamber for 24 hours at $120^{\circ} \mathrm{C}$ [57]. 


\subsection{Results From the Testing of $12 \mathrm{~mm}$ FBG}

\subsubsection{Stretching of FBG}

The $12 \mathrm{~mm}$ grating used for the stretching test had a reflectivity of about $99.97 \%$ (the transmission depth of $-35 \mathrm{~dB}$ ), a Bragg wavelength of $1569 \mathrm{~nm}$, and a full wavelength half maximum (FWHM) bandwidth of $0.43 \mathrm{~nm}$ [57]. The stretched length in this case was $13 \mathrm{~mm}$ and the ferrule system was prepared as described in Chapter 3.

Figure 4.5 shows the reflection spectra of the FBG during stretching. The maximum wavelength shift achieved was $\Delta \lambda=10.5 \mathrm{~nm}$, corresponding to a PZT actuator displacement of $120 \mu \mathrm{m}\left(\varepsilon_{m} \approx 0.92 \%\right)$.

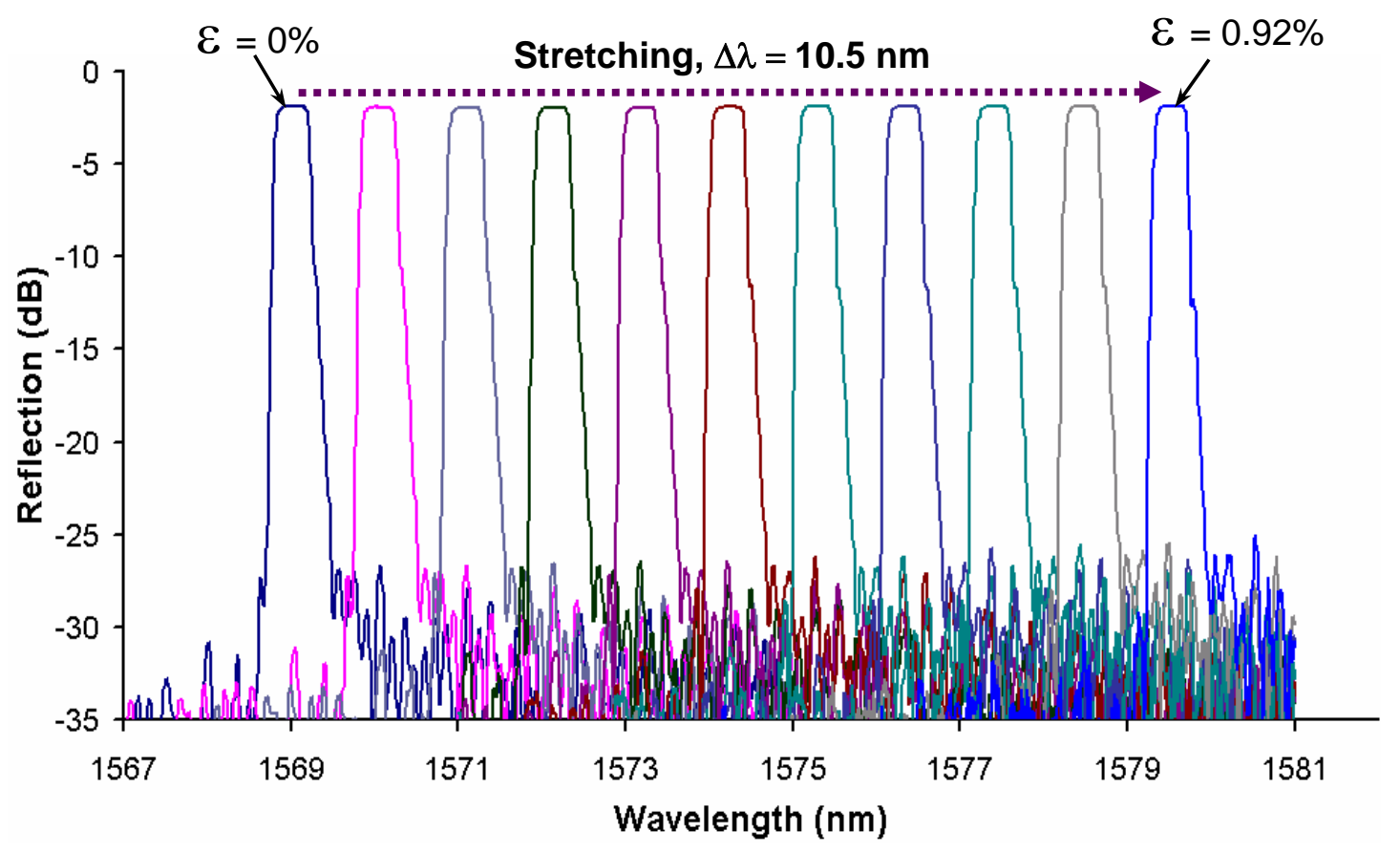

Figure 4.5: Reflection Spectra of a $12 \mathrm{~mm}$ FBG During Stretching.

Figure 4.6 shows the evolution of the peak reflectivity of the Bragg wavelength during stretching. The insertion losses observed were about $1.9 \mathrm{~dB}$. The variation in peak reflectivity was around $0.09 \mathrm{~dB}$. In Figure 4.7 the evolution of the FWHM $(-3 \mathrm{~dB})$ 
bandwidth during stretching is presented. The variation in bandwidth was around 0.02 $\mathrm{nm}$. Both variations are well below the Bellcore standards requirement of $\pm 0.5 \mathrm{~dB}$ for peak reflectivity variation and $\pm 0.1 \mathrm{~nm}$ for bandwidth variation [43].

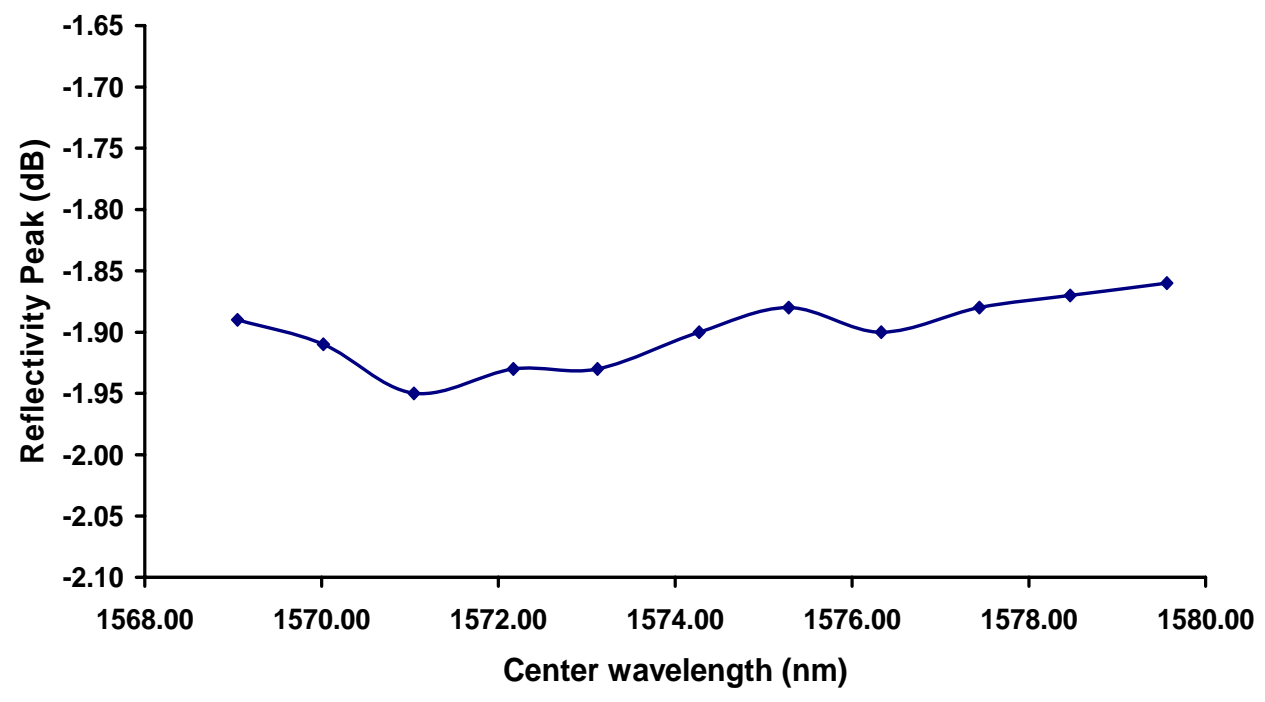

Figure 4.6: FBG peak reflectivity during stretching.

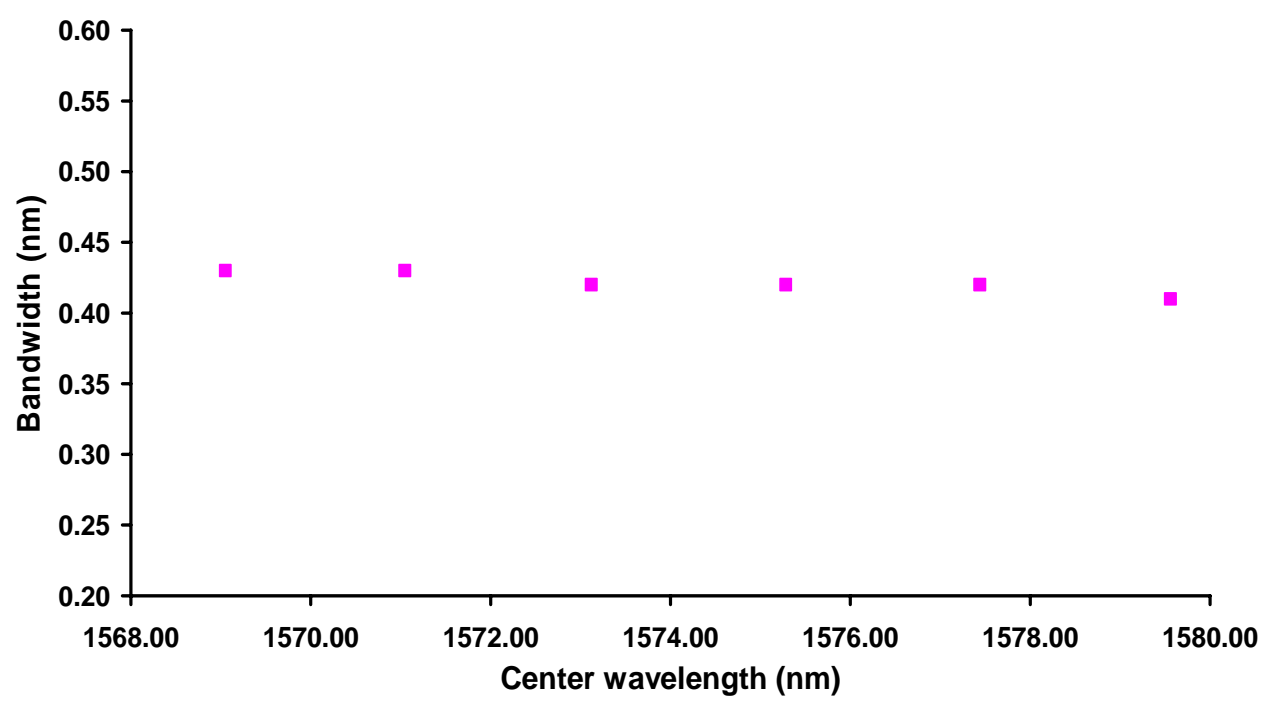

Figure 4.7: -3dB (FWHM) Bandwidth Variation 
Figure 4.8 compares the theoretical and experimental wavelength shifts. The plot can be used to determine the experimental value of the photoelastic constant $P_{e}{ }^{E x p}$, which was realized in this particular experiment. From the slope of the plot, a new value of $P_{e}{ }^{\operatorname{Exp}}$ 0.268 was obtained. Since there was no waving, it is assumed that the difference between $P_{e}$ and $P_{e}^{E x p}$ is due to the glue deformation. The process was repeated several times and the repeatability in the positioning was observed better than $0.02 \mathrm{~nm}$.

After several cycles of compression and release, a small hysteresis was observed as shown in Figure 4.9. The maximum hysteresis found in this case was $0.06 \mathrm{~nm}$.

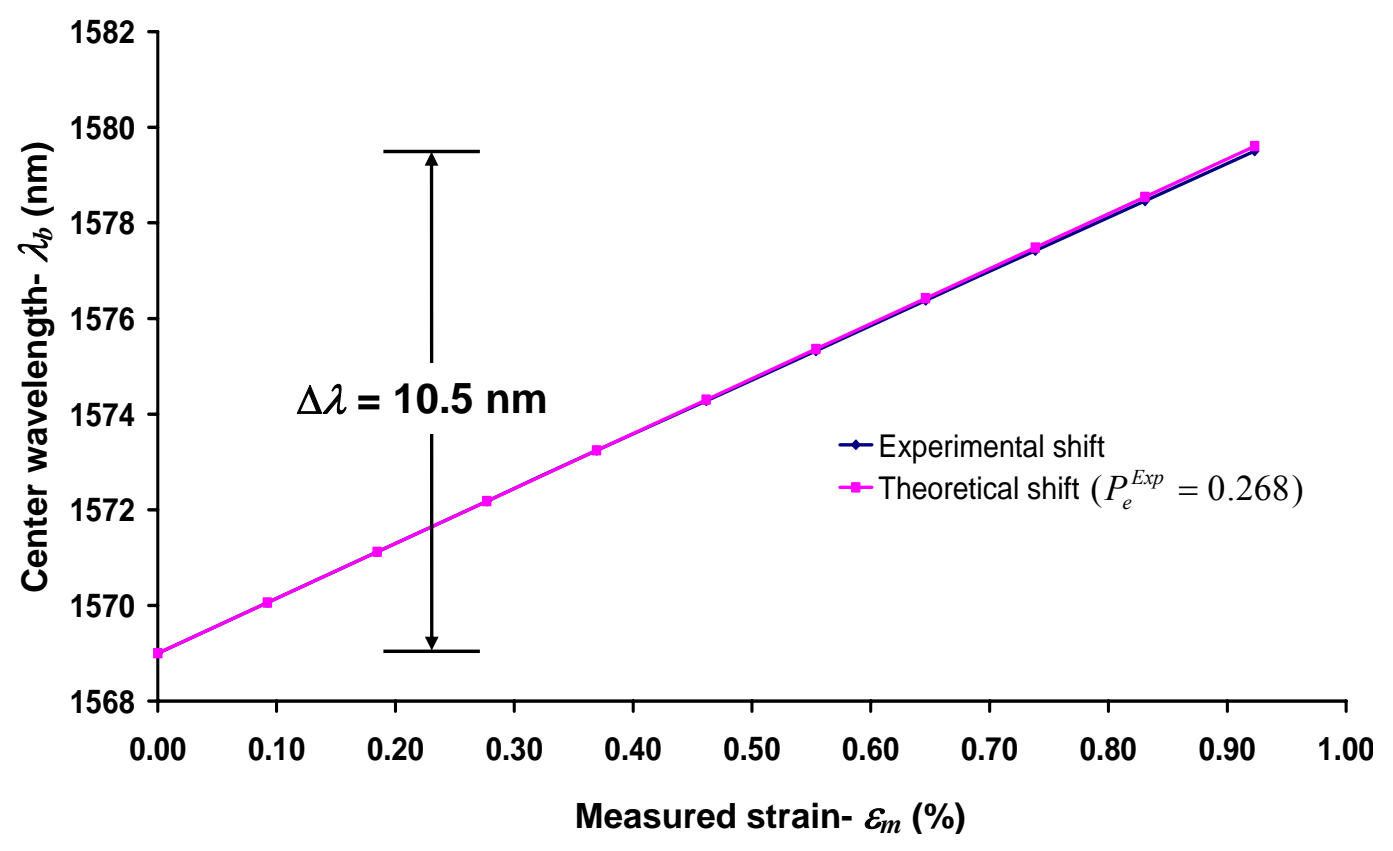

Figure 4.8: Comparison Between the Theoretical and Experimental Results During Tension. 


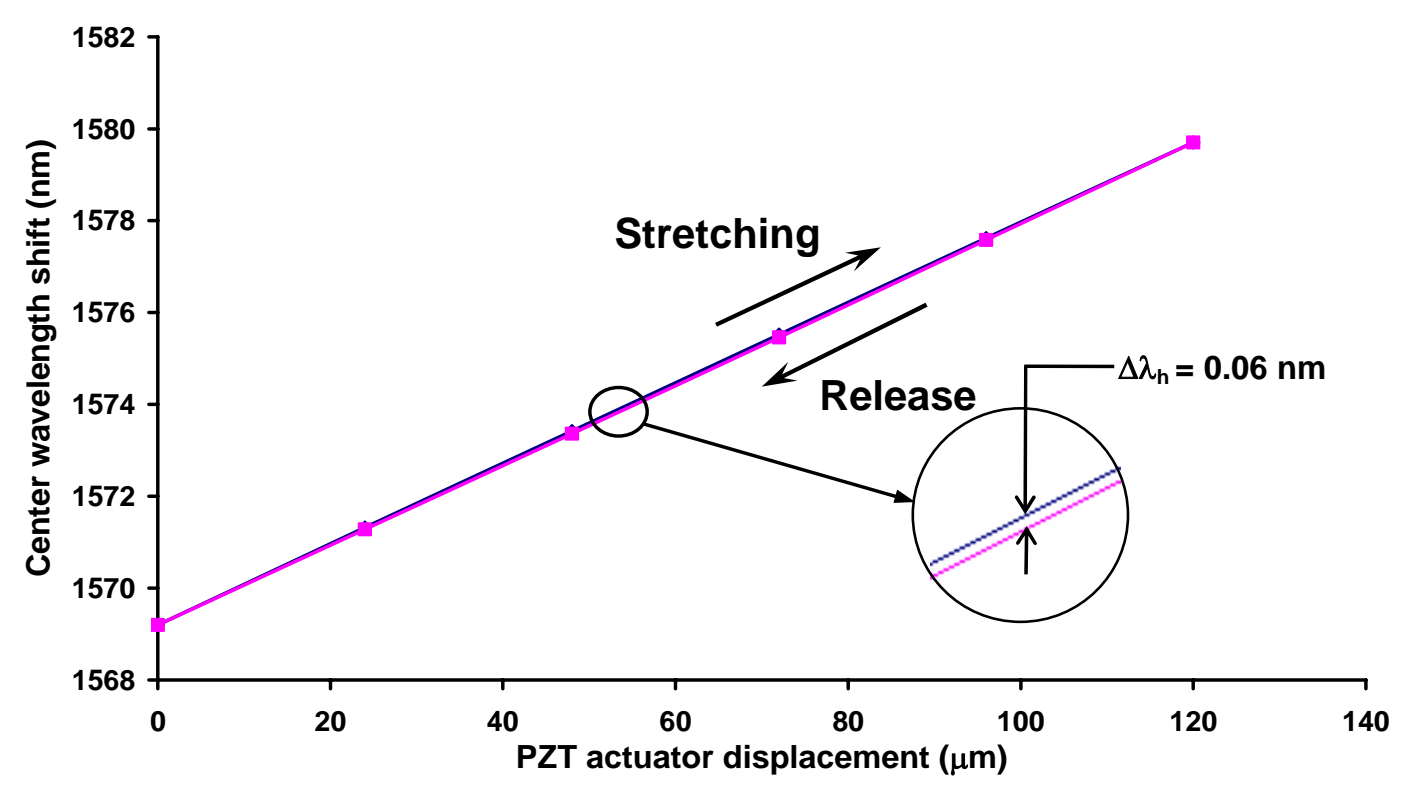

Figure 4.9: Device Hysteresis Obtained for 12mm FBG During Stretching

\subsubsection{Compression of FBG Using the PZT Actuator}

A $12 \mathrm{~mm}$ long Bragg grating was fabricated in a similar way as that described for stretching. The grating has a reflectivity of about $99.97 \%$ (transmission depth of -35 $\mathrm{dB}$ ), a Bragg wavelength of $1586 \mathrm{~nm}$, and a full wavelength half maximum (FWHM) bandwidth of $0.49 \mathrm{~nm}$ [57]. The compressed length in this case was $13 \mathrm{~mm}$ and the ferrule system was prepared in the same as described in Chapter 3.

Figure 4.10 shows the reflection spectra of FBG during compression. The maximum wavelength shift $(\Delta \lambda)$ achieved was $10.54 \mathrm{~nm}$ corresponding to a piezoelectric actuator displacement of $120 \mu \mathrm{m}$. Since the compressed length in this case was $13 \mathrm{~mm}$, the maximum measured strain on the fiber was therefore $0.92 \%$. 


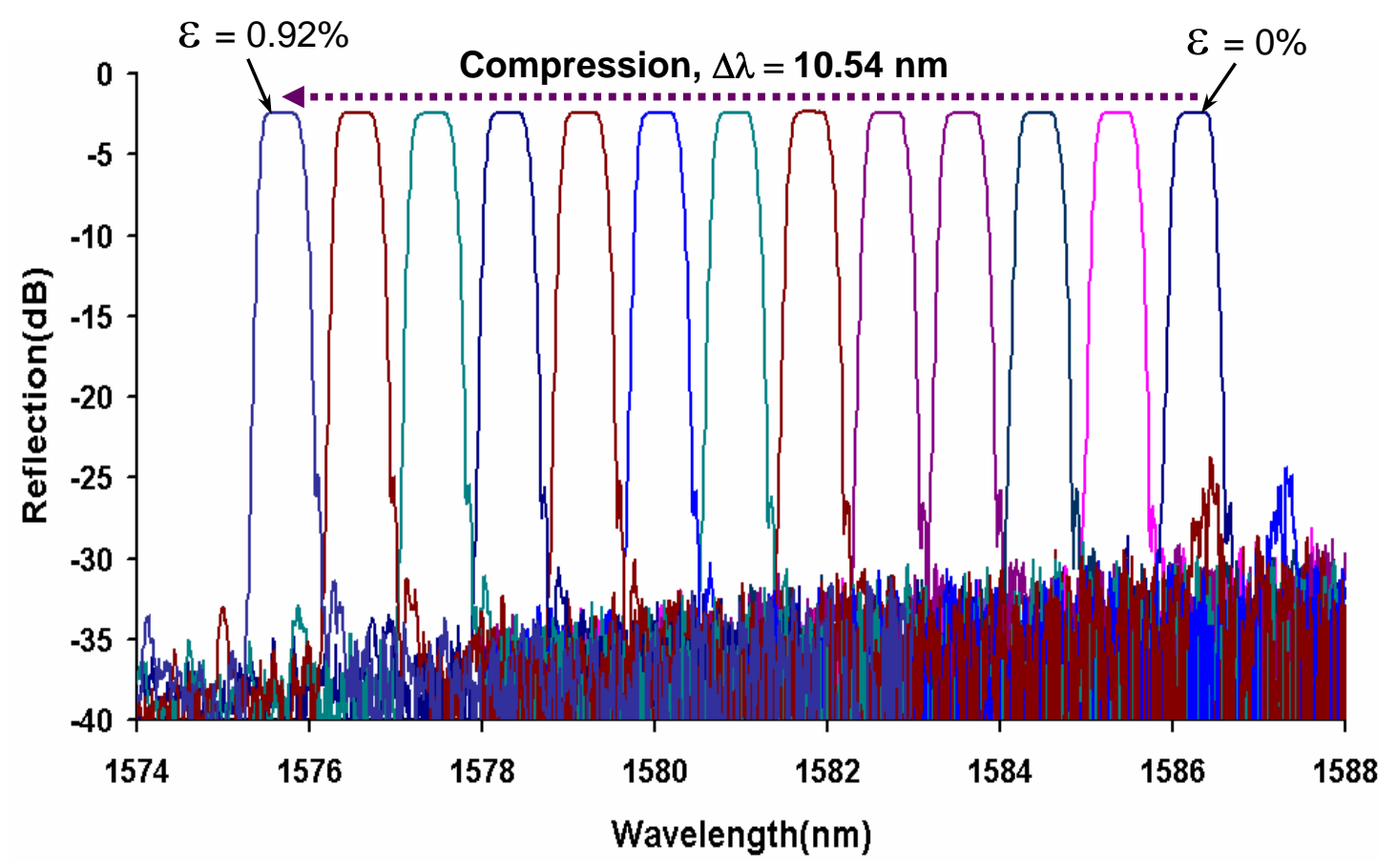

Figure 4.10: Reflection Spectra of a 12mm FBG During Compression

Figure 4.11 shows the evolution of the peak reflectivity of the Bragg wavelength during compression. The variation in reflectivity was around $0.06 \mathrm{~dB}$. In Figure 4.12 the evolution of FWHM (-3dB) bandwidth during compression is presented. The variation in bandwidth was around $0.02 \mathrm{~nm}$. Figure 4.13 shows a comparison of the theoretical and experimental wavelength shifts. The value of $P_{e}^{E x p}$ of 0.268 obtained in the stretching test is used in this case which fits well with the $\Delta \lambda\left(\varepsilon_{m}\right)$ curve plotted in Figure 4.13. It shows that for under $1 \%$ of measured compressive strain $\left(\varepsilon_{m}\right)$ the effect of fiber waving inside the ferrule is minimum. The process was repeated several times and the repeatability in the positioning was observed better than $0.02 \mathrm{~nm}$. 


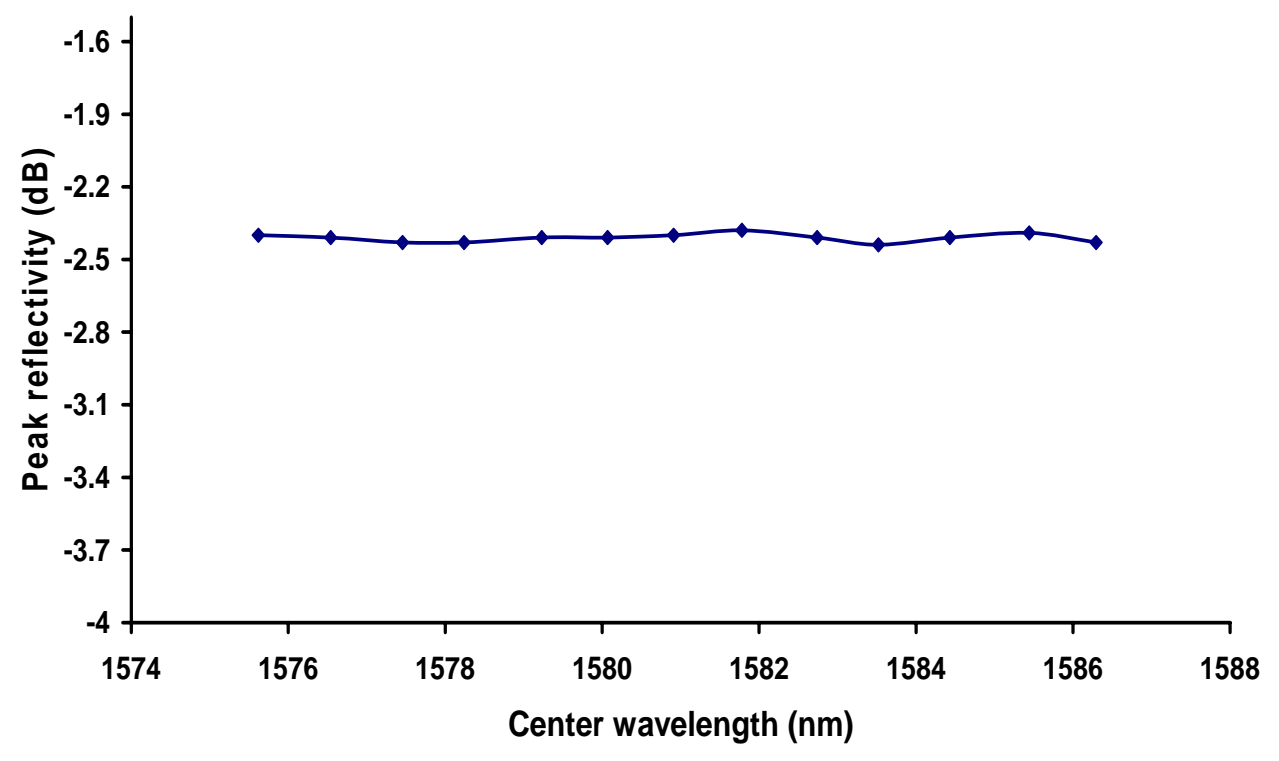

Figure 4.11: FBG Peak Reflectivity During Compression.

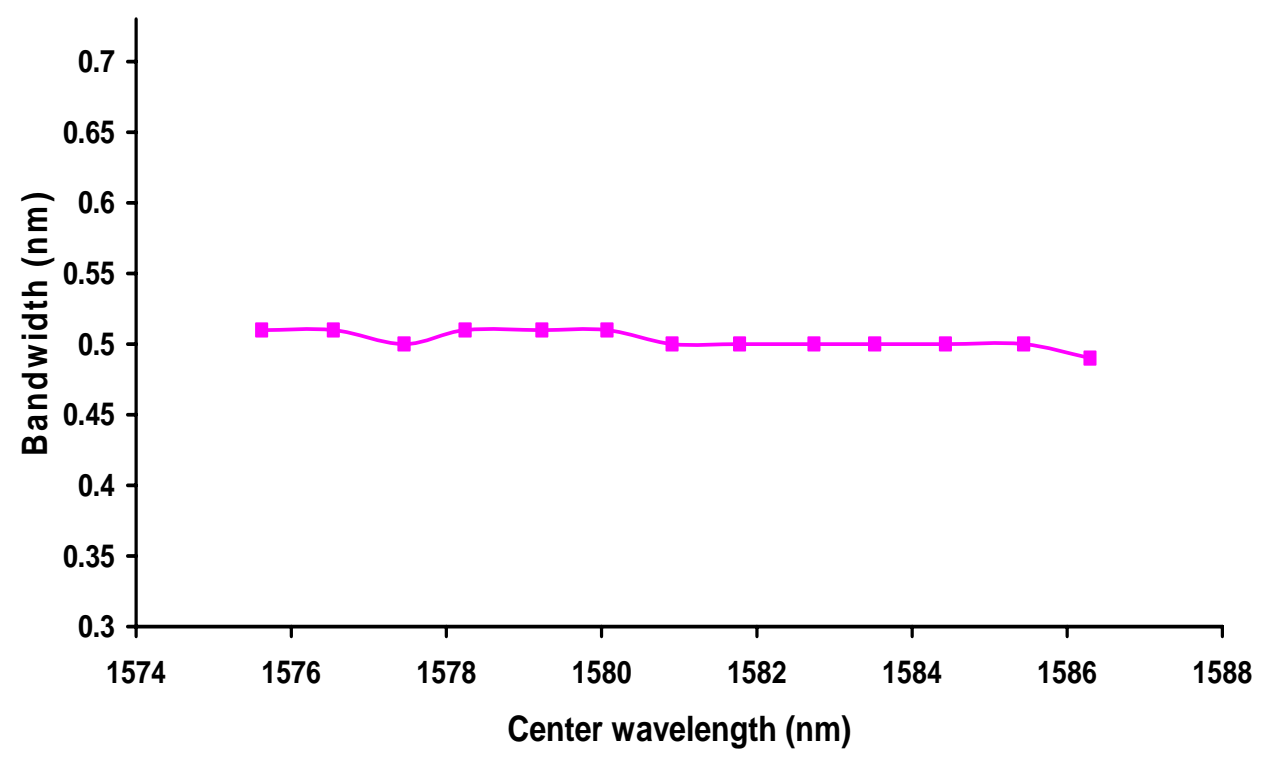

Figure 4.12: FWHM Bandwidth Variation During Compression. 


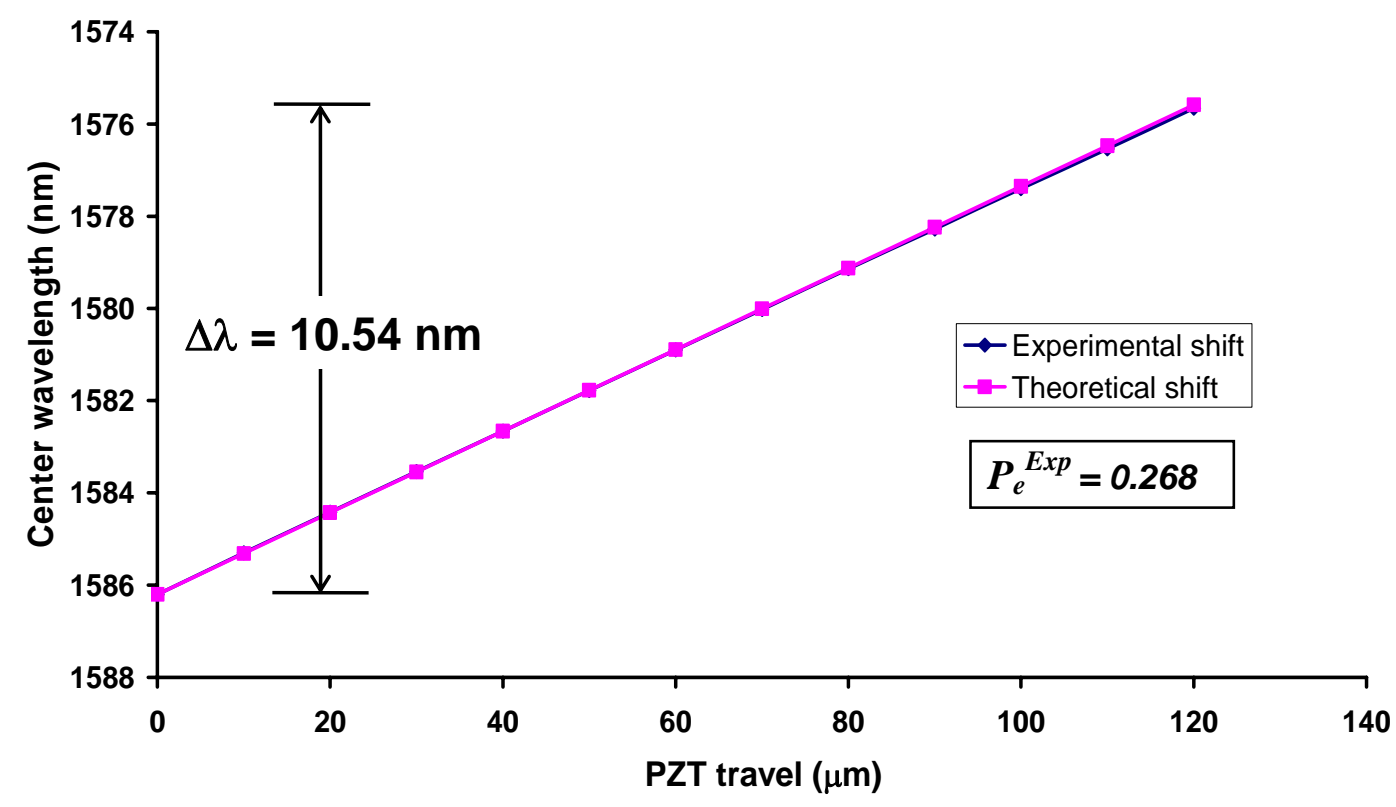

Figure 4.13: Comparison Between the Theoretical and Experimental Results During Compression.

After several cycles of compression and release a small hysteresis was observed as shown in Figure 4.14. The maximum hysteresis found in this case was $0.05 \mathrm{~nm}( \pm 0.025$ $\mathrm{nm})$, which is well below the accuracy requirement of $\pm 0.1 \mathrm{~nm}$ [43]. 


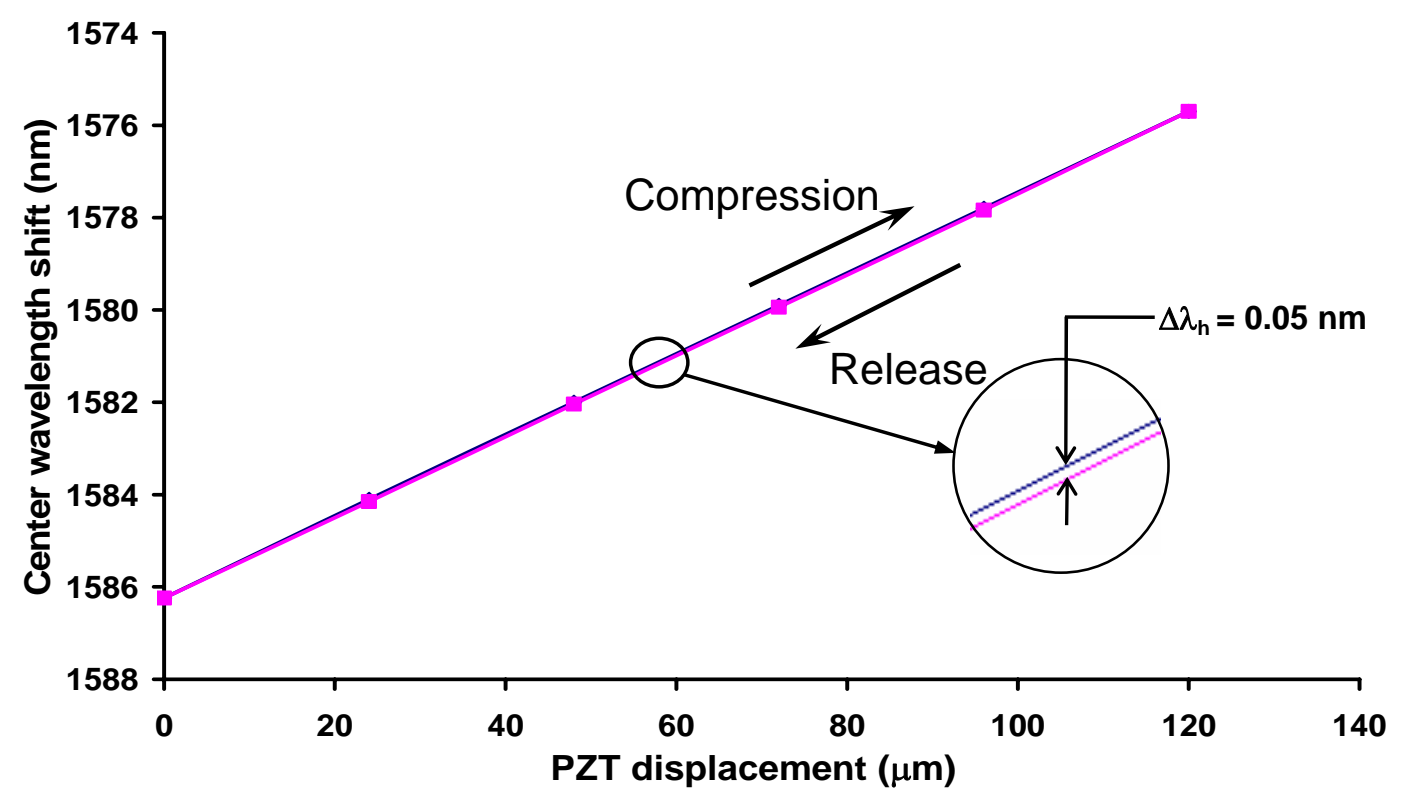

Figure 4.14: Device hysteresis obtained in compression.

\subsubsection{Compression of FBG Using Micrometer Head}

A $12 \mathrm{~mm}$ long Bragg grating was fabricated in similar way as described in stretching. The grating has a reflectivity of about $99.97 \%$ (transmission depth of $-35 \mathrm{~dB}$ ), a Bragg wavelength of $1586.5 \mathrm{~nm}$, and a full wavelength half maximum (FWHM) bandwidth of $0.5 \mathrm{~nm}$ [57]. The compressed length in this case was $13 \mathrm{~mm}$ and the ferrule system was prepared in the same way as described in Chapter 3.

The reflection spectra of FBG during compression are shown in Figure 4.15. The maximum wavelength shift $(\Delta \lambda)$ achieved was $46 \mathrm{~nm}$, which corresponded to a micrometer head displacement of $560 \mu \mathrm{m}$ and $4.3 \%$ of measured strain. 


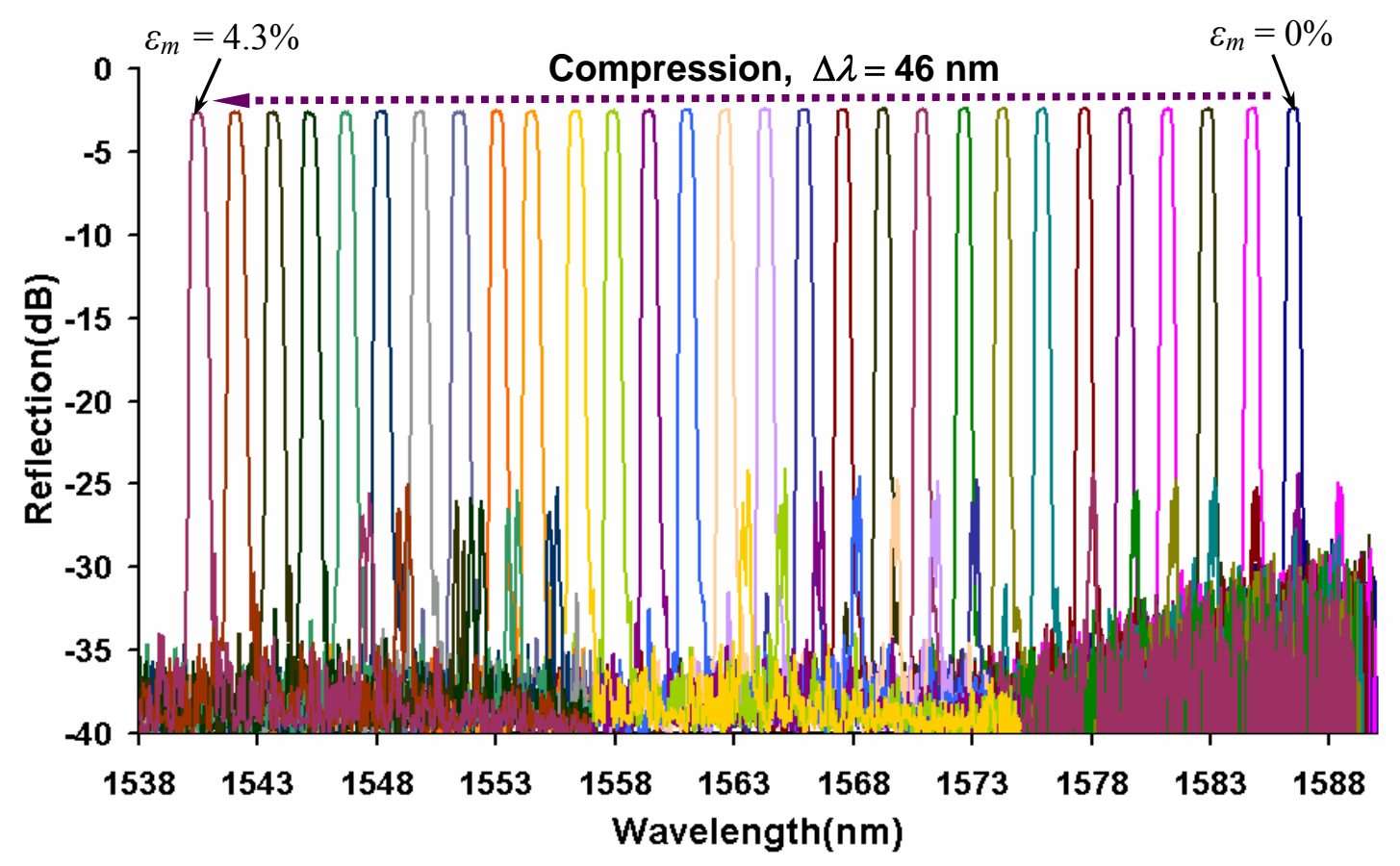

Figure 4.15: Reflection Spectra of a 12 mm FBG Under Compression

The process was repeated several times and the repeatability in positioning was around $0.12 \mathrm{~nm}$. The degraded repeatability is mostly attributed to using a micrometer screw gage in which there always was some error in reaching the desired position [48]. The repeatability can be improved by using a de servomotor or a PZT actuator with high resolution and travel range.

The wavelength shift in terms of $\varepsilon_{m}$ is plotted in Figure 4.16. The plot is, in fact, neither linear nor in agreement with equation (2.3) if the literature value of $P_{e}=0.22$ is used. As discussed previously the discrepancies are most probably due to deformations of glue and waving of the fiber inside the ferrule. These two effects are now analyzed in detail.

In order to quantify the glue effects let us write equation (3.4) in the form:

$$
\Delta L_{a x}=\Delta L_{m}-\Delta L_{g}
$$


Substituting $\Delta L_{a x}$ from equation (4.1) into equation (2.3) yields

$$
\frac{\Delta \lambda_{s t r}}{\lambda_{B}}=\left(1-P_{e}\right) \frac{\Delta L_{m}}{L_{o}}\left(1-\frac{\Delta L_{g}}{\Delta L_{m}}\right)=\left(1-P_{e}^{E x p}\right) \varepsilon_{m}
$$

where $1-P_{e}^{E x p}=\left(1-P_{e}\right)\left(1-\frac{\Delta L_{g}}{\Delta L_{m}}\right)$

After rearranging the above equation we get

$$
\frac{\Delta L_{g}}{\Delta L_{m}}=\frac{\varepsilon_{g}}{\varepsilon_{m}}=\frac{P_{e}^{E x p}-P_{e}}{1-P_{e}}=\alpha
$$

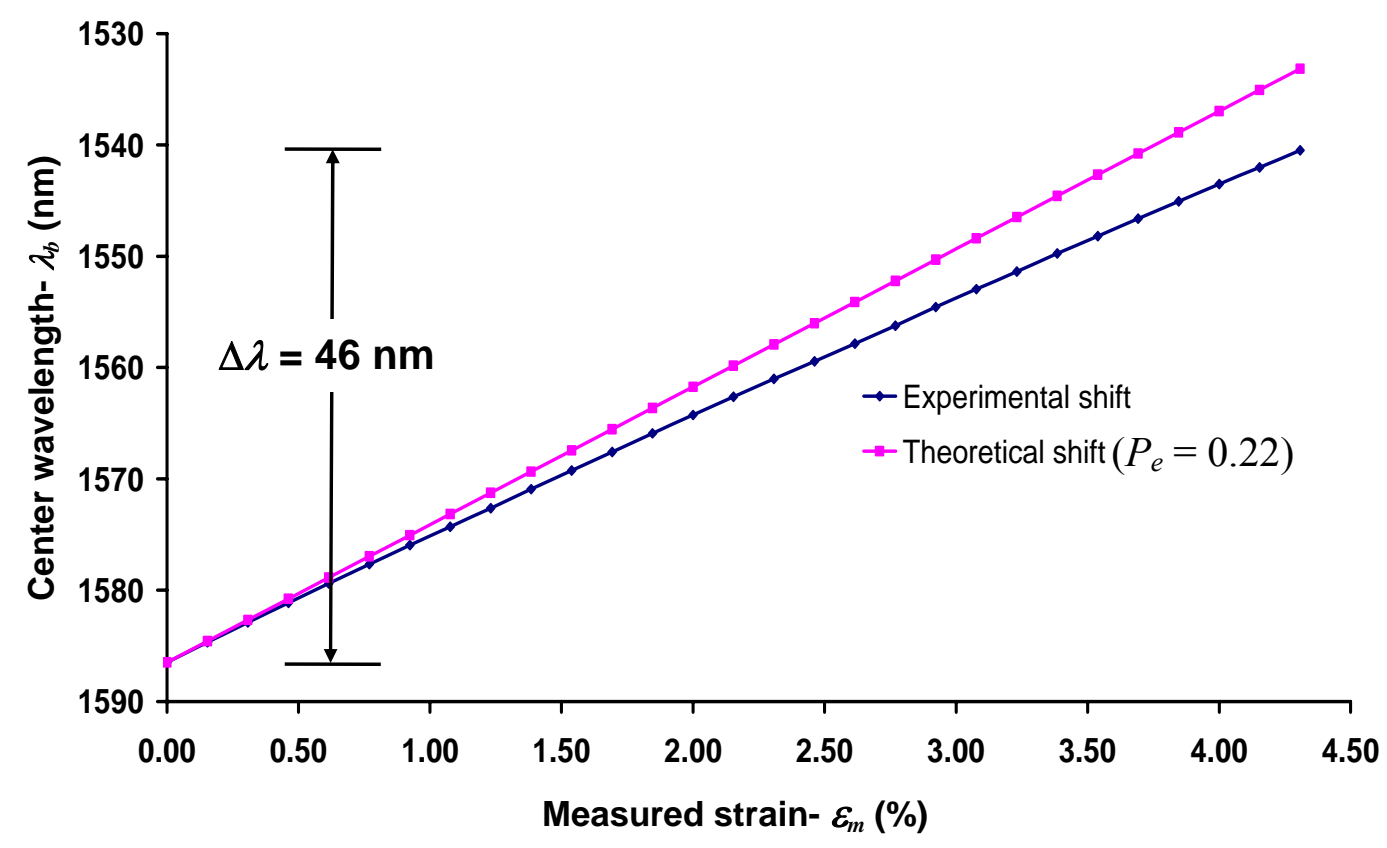

Figure 4.16: Comparison Between Theoretical and Experimental Results from Compression of FBG

The results shown in Figure 4.8 were linear almost up to the maximum strain measured, only for higher strain value was the experimental shift was slightly lower than that 
predicted by equation (4.2). This might have been due to some non-linearity in glue deformation at high strain value. Substituting the value of $P_{e}^{E x p}=0.268$ and $P_{e}=0.22$ in equation (4.4), the value of $\alpha$ is found to be 0.0615 . Thus the glue deformation adds about $6 \%$ to the measured strain, which has to be accounted for in the calibration of the wavelength shift measurement.

The compression test results from Figure 4.16, as well as equation (4.2) for $P_{e}^{\operatorname{Exp}}=0.268$ are plotted in Figure 4.17. The results match very well up to about $\varepsilon_{m} \approx 1 \%$, which verifies that the glue effects in tension and compression are very similar. For higher compression the experimental shift in Figure 4.17 is consistently lower than that predicted by equation (4.2). For example, for $\varepsilon_{m}=4.3 \%$ the experimental wavelength shift was $4 \mathrm{~nm}$ less than the theoretical shift. Note that equation (4.2) already includes elasticity of glue. The other reasons for the above difference seem to be waving of the FBG inside the ferrule and in the gap between the ferrules and, possibly, some inelastic behavior of the glue.

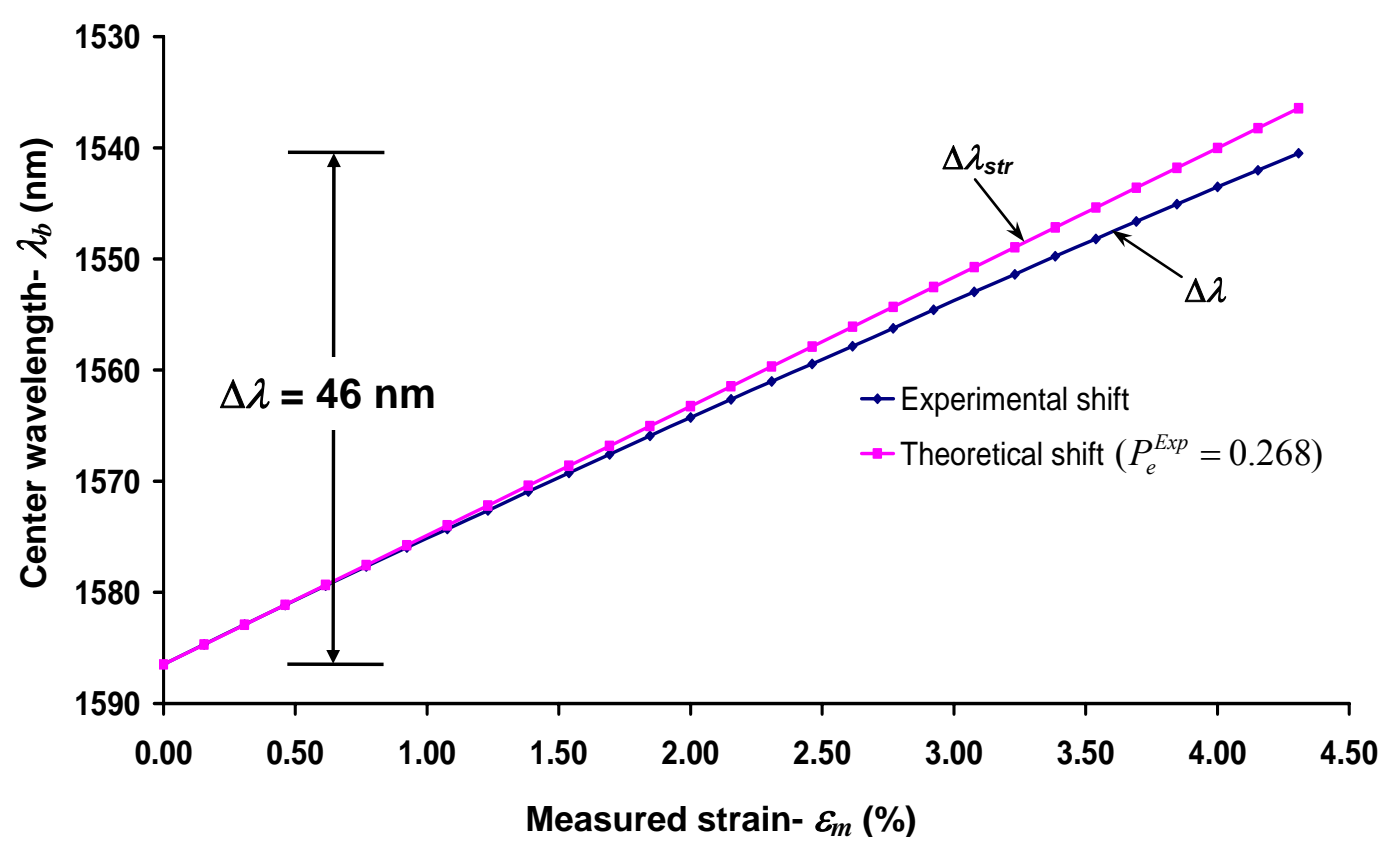

Figure 4.17: Comparison Between Theoretical and Experimental Results During Compression 
If one assumes that the glue remains elastic, then the compression test allows for quantification of the waving effects. Substituting the value of $\Delta L_{a x}$ from equation (3.4) into equation (2.3) and rearranging, we have

$$
\frac{\Delta \lambda}{\lambda_{B}}=\left(1-P_{e}\right)\left(1-\frac{\Delta L_{g}}{\Delta L_{m}}\right)\left(1-\frac{\frac{\Delta L_{w}}{\Delta L_{m}}}{1-\frac{\Delta L_{g}}{\Delta L_{m}}}\right) \varepsilon_{m}
$$

Substituting from equation (4.3) in to the above equation gives:

$$
\frac{\Delta \lambda}{\lambda_{B}}=\left(1-P_{e}^{E x p}\right)\left(1-\frac{\frac{\Delta L_{w}}{\Delta L_{m}}}{1-\frac{\Delta L_{g}}{\Delta L_{m}}}\right) \varepsilon_{m}=\frac{\Delta \lambda_{S t r}}{\lambda_{B}}\left(1-\frac{\frac{\Delta L_{w}}{\Delta L_{m}}}{1-\frac{\Delta L_{g}}{\Delta L_{m}}}\right)
$$

Substituting $\Delta L_{g} / \Delta L_{m}$ from equation (4.4) one obtains from equation (4.5):

$$
\frac{\Delta L_{w}}{\Delta L_{m}}=\frac{\varepsilon_{w}}{\varepsilon_{m}}=\left(1-\frac{\Delta \lambda}{\Delta \lambda_{S t r}}\right)\left(1-\frac{\Delta L_{g}}{\Delta L_{m}}\right)=(1-\alpha)\left(1-\frac{\Delta \lambda}{\Delta \lambda_{S t r}}\right)
$$

For a given $\varepsilon_{m}$ the value of $\Delta \lambda$ was measured and the value of $\Delta \lambda_{s t r}$ was calculated from equation (4.2). Also, $\alpha=0.0615$ was used. This way, using equation (4.6), the experimental variation of $\varepsilon_{w}$ with $\varepsilon_{m}$ was determined and is plotted in Figure 4.18. The relation between $\varepsilon_{w}$ and $\varepsilon_{m}$ in Figure 4.18 can be approximated by using curve fitting:

$$
\varepsilon_{w}=0.00026 \varepsilon_{m}+1.1 \varepsilon_{m}^{1.85}
$$

The linear term of equation (4.5) is identical to that predicted theoretically from equation (3.13d) for a fixed $D / d$ ratio. This term seems to be valid for small strains (less than $1 \%)$. For high strains, the quadratic term prevails. 


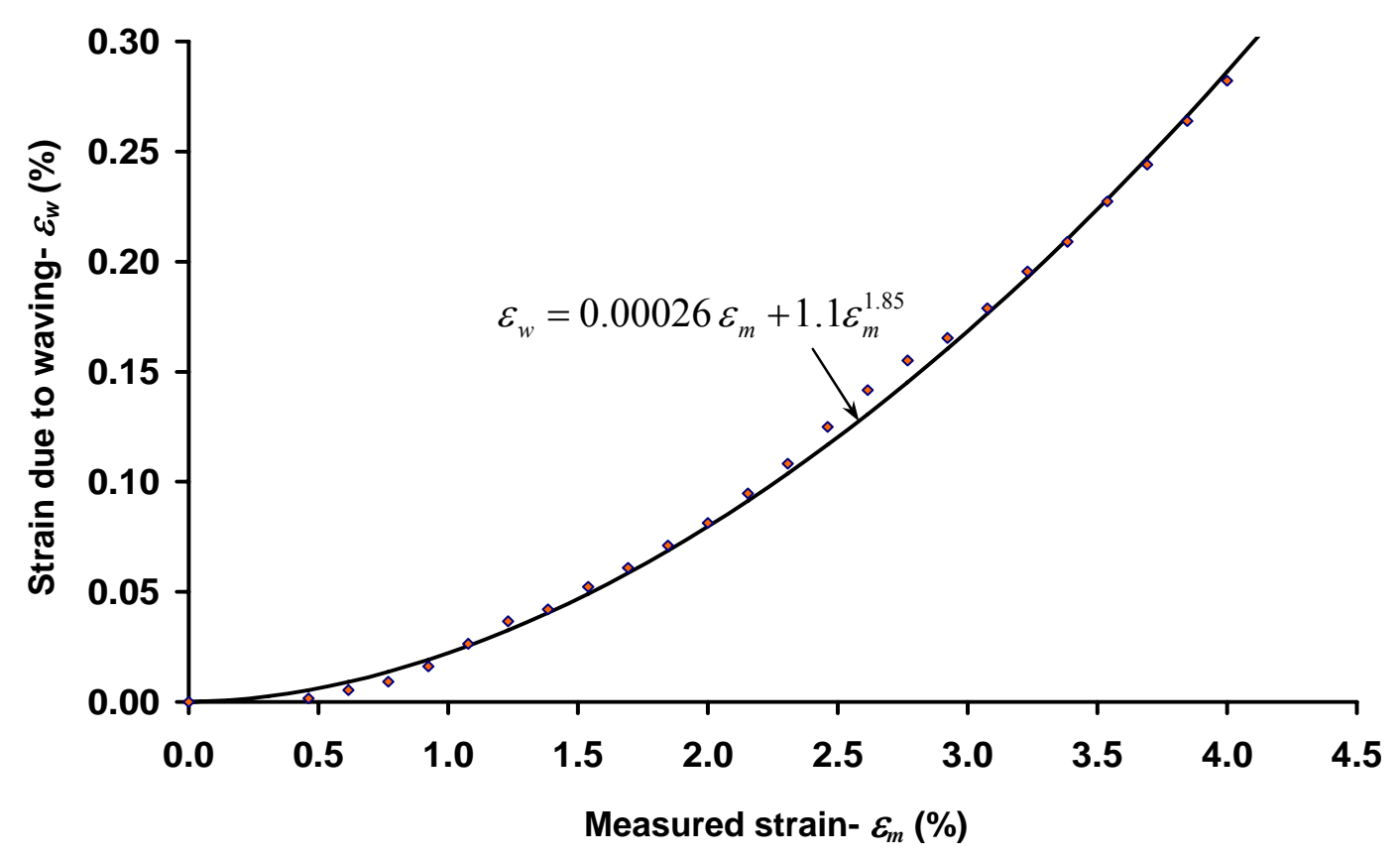

Figure 4.18: Variation of $\varepsilon_{w}$ with $\varepsilon_{m}$.

One of the possible explanations for the results in Figure 4.18 may be that equation (3.13d) assumes in-plane buckling while, in reality the buckling is three-dimensional, with the FBG taking a spiral shape inside the ferrule during compression. Again, the above formula can be used to precisely calibrate the wavelength shift measurement. Also, as mentioned before, at a high strain value the glue deformation may be nonlinear.

\subsubsection{Some Other Effects}

The variation in the peak reflectivity of the Bragg wavelength during compression was approximately $0.22 \mathrm{~dB}$ as shown in Figure 4.19. Also, the variation of the FWHM ($3 \mathrm{~dB}$ ) bandwidth, presented in Figure 4.19, was roughly $0.1 \mathrm{~nm}$ for a wavelength shift of about $46 \mathrm{~nm}$. After several cycles of compression and release, a small hysteresis was observed as shown in Figure 4.20. The maximum hysteresis for a wavelength shift of 40 $\mathrm{nm}$ was about $0.62 \mathrm{~nm}$. A significant portion of it may be caused by using the micrometer head instead of the PZT actuator. 


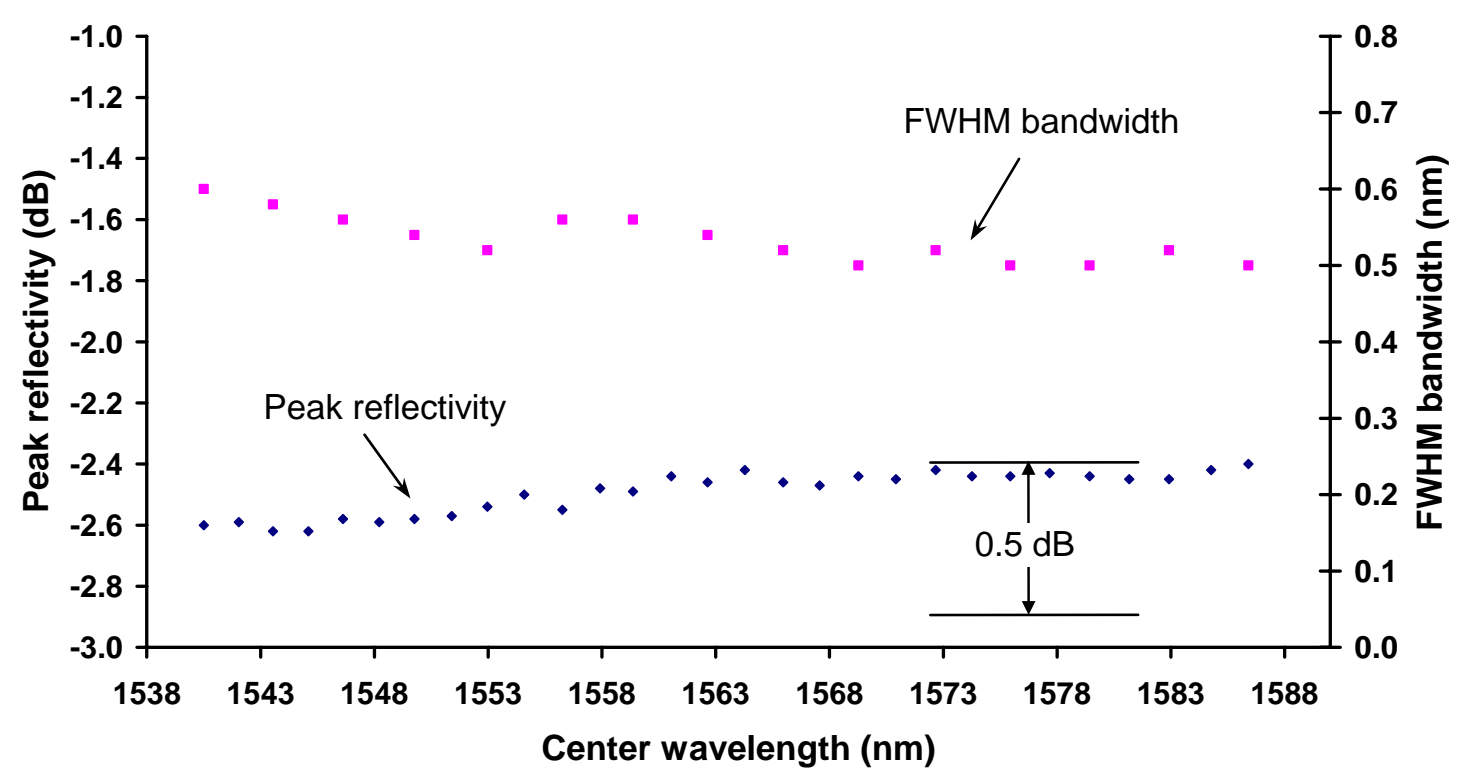

Figure 4.19: Variation in FBG Peak Reflectivity and FWHM Bandwidth During Compression.

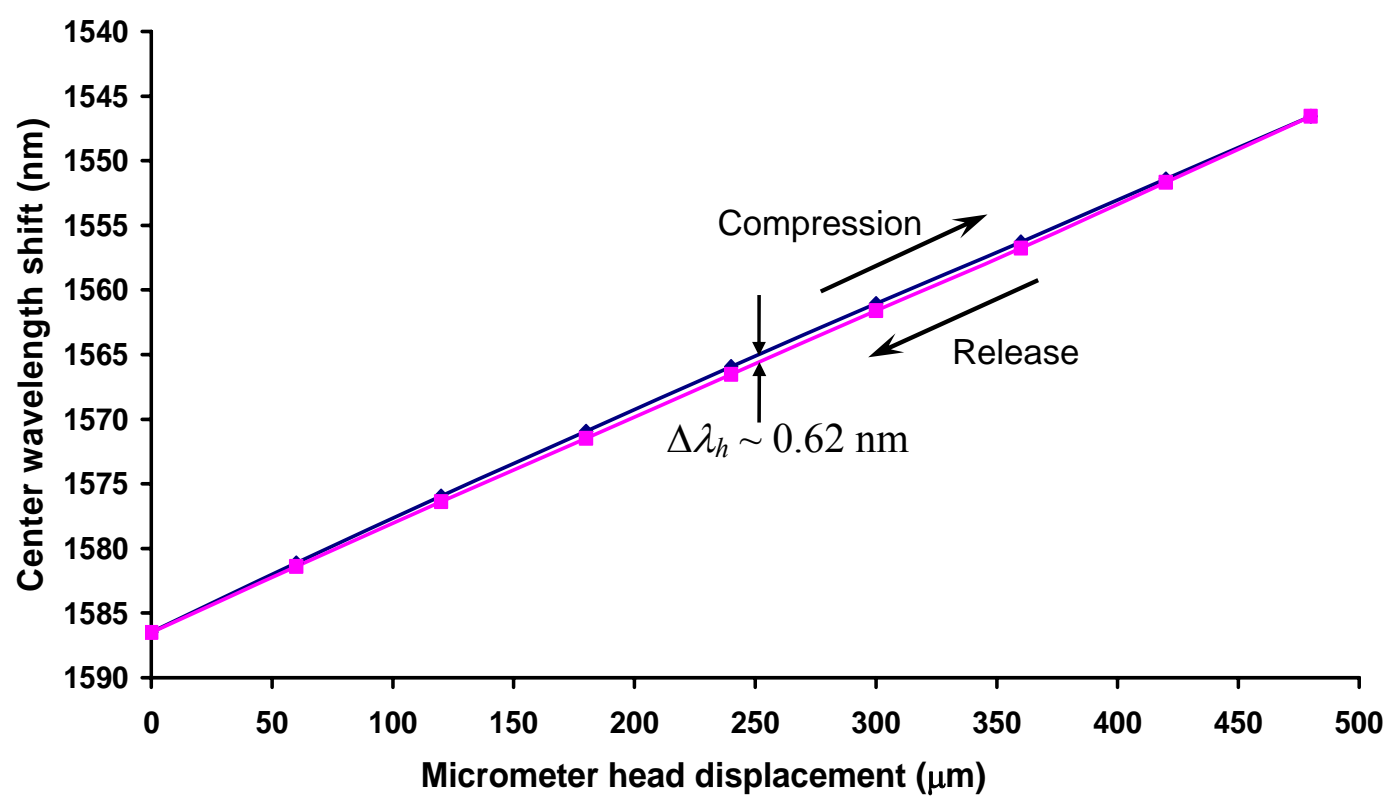

Figure 4.20: Device Hysteresis Obtained for $12 \mathrm{~mm}$ FBG 


\subsection{Summary}

An experimental value of $P_{e}$ of 0.268 was found which assumed to have glue deformation effects. Some non-linearity was found for axial strains higher than $1 \%$. Some of the possible reasons for the non-linearity are the waving of the FBG inside the

ferrule, the inelastic behavior of epoxy, the micrometer screw guage and three dimensional buckling of the FBG. A relation was also developed between the measured axial strain and the axial strain due to waving, which is useful in predicting the effect of waving during axial compression of FBGs. 


\section{CONCLUSIONS AND SUGGESTIONS FOR FUTURE WORK}

\subsection{Overview}

The FBG device is an important system for the telecommunication and sensor industry. To achieve as long wavelength tuning range as possible, compression of the FBG is an effective method. However, during compression the FBG may be subject to bucking especially when the amount of compression is large. The challenge for the FBG device is therefore to design and fabricate a guiding system for the FBG in order to prevent the bucking. This thesis presented the development of a novel guiding system which was based on rational design instead of ad-hoc methods reported in the literature. The common feature of these ad-hoc methods is a lack of thorough analysis from mechanics. This thesis set up the following specific objectives:

Objective 1: Develop some analytical equations with which the device to strain the fiber can be designed and constructed in a rational way.

Objective 2: Design and construct a device and experiment test bed to improve the central wavelength shift up to the $45 \mathrm{~nm}$.

These two objectives have been found achievable through the study presented in this thesis. The study included (1) the development of a theory based on the mechanics analysis to account for the reflection power loss due to the bending of the FBG and due to the glue fatigue, and (2) the development of the experiment test bed. 
In order to achieve $45 \mathrm{~nm}$ of wavelength shift an axial compression of about $4 \%$ is required. The compression is accompanied by bending due to instability. Minimizing bending is experimentally very challenging. Analytical relations are needed in order to minimize the bending effects. Optical power loss can be minimized by minimizing the radial gap and carefully adjusting misalignments.

\subsection{Contributions of the Thesis}

The following are the main contributions of this thesis:

1. Developed a theory for rationally designing a guiding system for axial compression of FBGs. This theory establishes the relationship between the reflection power loss and various design parameters such as the bending of a fiber and glue fatigue. The fiber bending is further associated with the design parameters of the device. This theory can be used for similar problems.

2. Achieved a tuning range of $46 \mathrm{~nm}$ in compression and $10.5 \mathrm{~nm}$ in tension with a reflection power loss of less than $0.25 \mathrm{~dB}$ and FWHM bandwidth variation of roughly $0.1 \mathrm{~nm}$ [58]. Both the variations meet the Bellcore standards requirement of $0.5 \mathrm{~dB}$ for peak reflectivity variation and $0.1 \mathrm{~nm}$ for bandwidth variation [43].

\subsection{Future Work}

For an axial strain of more than $1 \%$ in compression of FBG, some non-linearity has been found. This non-linearity is most likely due to glue fatigue and the hysteresis presented in the whole device system. A future work should be interesting which develops a model to describe the glue behaviour such as curing and rheology. The study reported in this thesis has not gone to that level of details about the glue fatigue; the study is largely based on the experimental observation. Such a model is then used to compensate the FBG tuning behaviour. 
The study presented in this thesis is largely static especially in the case of compression (notice that in the compression for a large strain the manual micrometer was used). The dynamic tuning behaviour (e.g., the settling time of the tuning) using the PZT actuator with an amplification mechanism is worth further study. Also, a feedback control system is worth studying to realize a dynamic tuning with high tuning accuracy and fast tuning speed.

In order to maximize the wavelength shifts for long wave bands (1520 to 1610), a tension-compression based system can be developed. Also, the compression range can be extended. 


\section{References}

1. Harry J. R. Dutton, "Understanding optical communications", Prentice hall, New Jersey, 1998.

2. Joseph C. Palais, "Fiber optic communications", Fourth edition, Prentice hall, New Jersey, 1998.

3. John Powers, “An introduction to fiber optic systems", McGraw Hill, Boston, 1997

4. Pierre Halley, "Fibre optic systems", John Willey \& Sons, New York, 1987.

5. Govind P. Agrawal, "Fiber optic communication systems", John Willey \& Sons, New York, 1997.

6. Andreas Othonos and K. Kalli, "Fiber Bragg gratings - Fundamentals and applications in telecommunications and sensing", Artech House, Norwood, 1999

7. R. Kashyap, “Fiber Bragg gratings”, Academic Press, San Diego, 1999.

8. K.O. Hill, G. Meltz, "Fiber Bragg grating technology fundamentals and overview", Journal of Lightwave Technology, vol. 15, no. 8, pp. 1263-1276, 1997.

9. Andreas Othonos, "Fiber Bragg gratings", Review of Scientific Instruments, vol. 68, no. 12, pp. 4309-4341, 1997.

10. R. Giles, "Lightwave applications of fiber Bragg gratings", Journal of Lightwave Technology, vol. 15, no. 8, pp. 1391-1404, 1997.

11. Alessandro Iocco, "Tunable fiber Bragg grating filters" PhD Thesis, Swiss Federal Institute of Technology Lausanne, Switzerland, 1999.

12. Yariv, P. Yeh, “Optical waves in crystals”, John Wiley \& Sons, New York, 1984, (ch. 9).

13. W. Primak, D. Post, "Photoelastic constants of vitreous silica and its elastic coefficient of refractive index", Journal of Applied Physics, vol. 30, no. 5, pp. 779$788,1959$. 
14. Bertholds, R. Dändliker, "Determination of the individual strain-optic coefficients in single-mode optical fibers", Journal of Lightwave Technology, vol. 6, no. 1, pp. 17-20, 1988.

15. N.F. Borrelli, R.A. Miller, "Determination of the individual strain-optic coefficients of glass by an ultrasonic technique", Applied Optics, vol. 7, no. 5, pp 745-750, 1968.

16. G.B. Hocker, "Fiber-optic sensing of pressure and temperature", vol. 18, no. 9, pp. 1445-1448, 1979.

17. M.G. Xu, L. Reekie, Y.T. Chow, J.P. Dakin, "Optical in-fibre grating high pressure sensor", Electronics Letters, vol. 29, no. 4, pp. 398-399, 1993.

18. W.W. Morey, G. Meltz, W.H. Glenn, "Bragg grating temperature and strain sensors", Springer proceeedings of OFS'89, vol. 44, pp. 526-531, 1989.

19. G.A. Ball, W.W. Morey, "Tunable Bragg grating fiber filters and their applications", Procedings of CLEO'97, Baltimore, USA, pp. 108-109, 1997.

20. H.G. Limberger, Nguyen Hong Ky, D.M. Costantini, R.P. Salathé, C.A.P. Muller, G.R. Fox, "Efficient active Bragg grating tunable filters", Proceedings of OSA Topical meeting, paper number BTuA5, Williamsburg, USA, October 26-28, pp. 265- 267, 1997.

21. A.D. Kersey, M.A. Davis, H.J. Patrick, M. LeBlanc, K.P. Koo, C.G. Askins, M.A. Putnam, E.J. Friebele, "Fiber grating sensors", Journal of Lightwave Technology, vol. 15, no. 8, pp. 1442-1463, 1997.

22. A.A. Abramov, A. Hale, R.S. Windeler, T.A. Strasser, "Temperature-sensitive long-period fiber gratings for wideband tunable filters", Proceedings of OFC, paper number ThJ2, pp. 144-146, San Diego, USA, February 21-26, 1999.

23. W.W. Morey, G. Meltz, J.M. Weiss, "Recent advances in fiber grating sensors for utility industry applications", Proceedings of SPIE, vol. 2594, pp. 90-98, 1995.

24. G.A. Ball, W.W. Morey, "Compression-tuned single-frequency Bragg grating fiber laser", Optics Letters, vol. 19, pp. 1979-1981, 1994.

25. Iocco, H.G. Limberger, R.P. Salathé, L.A. Everall, K.E. Chisholm, J.A.R. Williams, I. Bennion, "Bragg grating fast tunable filter for Wavelength Division 
Multiplexing", Journal of Lightwave Technology, vol. 17, no. 7, pp. 1217-1221, 1999.

26. T. Erdogan, V. Mizrahi, P.J. Lemaire, D. Monroe, "Decay of ultraviolet-induced fiber Bragg gratings", Journal of Applied Physics, vol. 76, no. 1, pp. 73-80, 1994.

27. G. Meltz, "Overview of fiber grating-based sensors", Proceedings of SPIE, Distributed and Multiplexed Fiber Optic Sensors VI, Denver, Colorado, vol. 2838, pp. 1-21, 1996.

28. S. Jin, H. Mavoori, R.P. Espindola, L.E. Adams, T.A. Strasser, "Magnetically tunable fiber Bragg gratings", Proceedings of OFC, paper number ThJ2, pp. 135137, San Diego, USA, February 21-26, 1999.

29. Y. Yu, H. Tam, S. Geng, M. S. Demokan, Z. Liu, W. Chung, "Chirp-free tuning of fiber Bragg grating using a cantilever beam”, Jpn. Journal of Applied Physics, Vol. 38, Part 2, No. 9A/B, pp. 1032-1034, 1999.

30. Z. Qin, Q. Zeng, X. Yag, "Bidirectional grating wavelength shifter with a broadrange tunibility by using a beam of Uniform strength", IEEE Photonics Technology Letters, vol. 13, no. 4, pp. 1041 - 1135, 2001.

31. Jian Jim Wang, "Electrically tunable free-space sub-wavelength grating filter with $30 \mathrm{~nm}$ tuning range", Optical fiber Communications Meeting, MF28, March 23-38, 2003, Atlanta US Georgia.

32. W. H. Chung, H.Y. Tam, M. S. Demokan, "Improved tuning accuracy of fiber grating lasers using a linear variable differential transformer", Microwave and Optical Technology Letters, vol. 32, no. 1, pp. 37 - 40, 2002.

33. S. Goh, M. R. Mokhtar, S. A. Butler, "Wavelength tuning of fiber Bragg gratings over $90 \mathrm{~nm}$ using a simple tuning package", IEEE Photonics Technology Letters, vol. 15, no. 4, pp. 557-559, 2003.

34. S.M. Melle, K. Liu, R.M. Measures, "Practical fiber optic Bragg grating strain gauge system", Applied Optics, vol. 32, no. 19, pp. 3601-3609, 1993.

35. C.D. Butter, G.B. Hocker, "Fiber optics strain gauge", Applied Optics, vol. 17, no. 18, pp. 2867-2869, 1978. 
36. J.D. Prohaska, E. Snitzer, B. Chen, M.H. Maher, E.G. Nawy, W.W. Morey, "Fiber optic Bragg grating sensor in large scale concrete structures”, Proceedings of SPIE, vol. 1798, pp. 286-294, 1992.

37. F.P. Mallinder, B.A. Proctor, "Elastic constants of fused silica as a function of large tensile strain", Physics and Chemistry of Glasses, vol. 5, no. 4, pp. 91-103, 1964.

38. D.A. Pinnow, "Elastooptical materials" in Handbook of lasers with selected data on optical technology, CRC Press, Boca Raton, 1971.

39. Jaroslav Mencik, "Strength and fracture of glass and ceramics", Elsevier, New York, 1992.

40. G. P. Carman, G. P. Sendeckyj, "Review of the mechanics of embedded optical sensors", Journal of composites technology and research, Vol. 17, No. 3, pp. 183193, 1995.

41. S. Starodubov, V. Grubsky and J. Feinberg, "Ultrastrong fiber gratings and their applications," in Optical Fiber Reliability and Testing, Proc. SPIE 3848, pp. 178$185,1999$.

42. J.M. Gere, S.P. Timoshenko, "Mechanics of materials", PWS Publishing Company, Boston, 1997.

43. "Generic reliability assurance requirements for passive optical components, GR1221-CORE”, Bellcore, Issue 2, January 1999.

44. Corning MetroCor optical fiber, "Product information for SMF-28 optical fiber", 2001.

45. S.P. Timoshenko, J.N. Goodier, "Theory of elasticity", McGraw-Hill, Auckland, 1970.

46. Nikon Corporation, "Catalog and product documentation for SMZ-1 stereoscopic Microscopes", 2000.

47. Fiber optic center Inc., "Product guide for EPO-TEK 353ND, AngstromBond", 2001.

48. Single Axis Translation Stages, Melles Griot Catalog Book, Barloworld Scientific, 1997-1998.

49. Physik Instrumente, "Catalog of products for micro positioning", 2001. 
50. MPB Communications Inc., "Catalog and product documentation for Erbium broadband sources EBS-7210”, 2001.

51. ANDO Electric Co., Ltd., "Instruction manual for Optical spectrum AnalyzerAQ6317B”, 2000.

52. A.J. Moulson, J.M. Herbert, "Electroceramic”, Chapman and Hall, London, 1997.

53. W.G. Cady, "Piezoelectricity", McGraw-Hill (1946), reprinted by Dover Press, New York, 1964.

54. Bernard Jaffe, “Piezoelectric ceramics”, Academic press, London, 1971

55. Physik Instrumente, “Operating manual PZ 78E, E-420- Amplifiers for high voltage PZTs", 1997.

56. Physik Instrumente, "Operating manual PZ 77E, E-509- Position servo control module", 1997.

57. "Sensor grating data sheet for 8 and $12 \mathrm{~mm}$ FBG", MPB communications Inc., 2002.

58. N. Mohammad, W. Szyszkowski, W. J. Zhang, W. Jamroz, R. Kruzelecky, E. Haddad and J. Zou "Analysis and Development of a Tunable Fiber Bragg Grating Filter Based on Axial Tension/Compression", IEEE Journal of Lightwave Technology, Vol. 22, No. 8, pp. 2001 - 2013, 2004. 